\title{
ASIA-PACIFIC SUSTAINABLE DEVELOPMENT GOALS OUTLOOK
}




The Economic and Social Commission for Asia and the Pacific is the regional development arm of the United Nations and serves as the main economic and social development centre for the United Nations in the region. Its mandate is to foster cooperation between its 53 members and 9 associate members. ESCAP provides the strategic link between the global and country-level programmes and issues. It supports governments in consolidating regional positions and advocates regional approaches to meeting the unique socioeconomic challenges in a globalizing world. The ESCAP office is located in Bangkok.

The Asian Development Bank's vision is an Asia and Pacific region free of poverty. Its mission is to help its developing member countries reduce poverty and improve the quality of life of their people. Despite the region's many successes, it remains home to a large share of the world's poor. ADB is committed to reducing poverty through inclusive economic growth, environmentally sustainable growth and regional integration. Based in Manila, ADB is owned by 67 members, including 48 from the region. Its main instruments for helping its developing member countries are policy dialogue, loans, equity investments, guarantees, grants and technical assistance.

The United Nations Development Programme partners with people at all levels of society to help build nations that can withstand crisis and drive and sustain the kind of growth that improves the quality of life for everyone. On the ground in nearly 170 countries and territories, we offer global perspectives and local insight to help empower lives and build resilient nations. 


\section{ASIA-PACIFIC SUSTAINABLE DEVELOPMENT GOALS OUTLOOK}




\section{Asia-Pacific Sustainable Development Goals Outlook}

๑) 2017 United Nations, Asian Development Bank, United Nations Development Programme

Published in March 2017.

Printed in Thailand.

This is a copublication of the United Nations (ESCAP), the Asian Development Bank (ADB) and the United Nations Development Programme (UNDP). This work is available open access by complying with the Creative Commons license created for intergovernmental organizations, available at: http://creativecommons.org/licenses/by/3.0/igo/. The CC license does not apply to non-UN (ESCAP and UNDP) or non-ADB copyright materials in this publication. Publishers who wish to produce their own version of this publication must delete the original emblems from their edition and create a new cover design. Translations must bear the following disclaimer: "The present work is an unofficial translation for which the publisher accepts full responsibility."

Photocopies and reproductions of excerpts are allowed with proper credits. For queries related to the open access license or queries and/or requests not covered by the open access license, please contact the United Nations at permissions@un.org

ISBN 978-92-9257-775-9 (Print), 978-92-9257-776-6 (e-ISBN)

DOI: http://dx.doi.org/10.22617/TCS178699-2

\section{Cataloging-In-Publication Data}

United Nations, Asian Development Bank, and United Nations Development Programme.

Asia-Pacific Sustainable Development Goals Outlook

Bangkok, Thailand: United Nations, 2017

1. Poverty 2. Asia-Pacific $\quad 3$. United Nations, Asian Development Bank, and United Nations Development Programme

The views expressed in this publication are those of the authors and do not necessarily reflect the views and policies of the Asian Development Bank or its Board of Governors or the Secretariat of the United Nations (ESCAP and UNDP) or the governments they represent. The United Nations (ESCAP and UNDP) and ADB do not guarantee the accuracy of the data included in this publication and accept no responsibility for any consequence of their use. Any reference to a commercial entity or product in this publication does not imply endorsement.

The designation of or reference to a particular territory or geographic area, or the use of the term "country" in this document do not imply the expression of any opinion whatsoever on the part of the Secretariat of the United Nations, ADB or its Board of Governors, or the governments they represent concerning the legal or other status of any country, territory, city or area, or of its authorities, or concerning the delimitation of its frontiers or boundaries. This publication follows the United Nations practice in references to countries. Where there are space constraints, some country names have been abbreviated. In the ADB, China is referred to as the People's Republic of China and Kyrgyzstan is referred to as the Kyrgyz Republic.

All queries other than requests for translations and other uses not covered by the CC BY 3.0 IGO license can be addressed to any of the co-publishing organizations as follows:

\section{Director}

Environment and Development

Division United Nations Economic and Social Commission for Asia and the Pacific

5th Floor United Nations Building Rajadamnern Nok Avenue Bangkok 10200, Thailand escap-esdd-evs@un.org
Director

Result Management and Aid Effectiveness Division Strategy, Policy and Review Department Asian Development Bank

6 ADB Avenue Mandaluyong City, Metro Manila 1550, Philippines sdgs@adb.org
Practice Team Leader Inclusive Growth and Poverty Reduction Asia-Pacific Regional Centre United Nations Development Programme

3rd Floor United Nations Building Rajadamnern Nok Avenue Bangkok 10200, Thailand aprc.msu@undp.org

\section{Also available online at:}




\section{Acknowledgements}

The diversity of the issues covered by this report required the collaboration of a large community of experts and practitioners based in the region and beyond. The Economic and Social Commission for Asia and the Pacific (ESCAP), the Asian Development Bank (ADB) and the United Nations Development Programme (UNDP) acknowledge the contributions made by more than 100 experts towards the preparation and production of the Asia-Pacific Sustainable Development Goals Outlook report.

\section{Steering committee}

Shamshad Akhtar, Under-Secretary-General of the United Nations and Executive Secretary of ESCAP; Bambang Susantono, Vice-President for Knowledge Management and Sustainable Development, ADB; Haoliang Xu, Assistant Administrator and Director, Regional Bureau for Asia and the Pacific, UNDP

\section{Technical team}

Arman Bidar Bakhtnia, Caridad Canales, Stefanos Fotiou, Margarita Guerrero, Eric Hermouet, Kareff Rafisura, Hitomi Rankine, Katinka Weinberger (ESCAP); Vivian Francisco, Marinella Gamboa, Smita Nakhooda, Bernard Woods (ADB); Joseph D'Cruz, Hannie Meesters, Bishwa Nath Tiwari, Caitlin WiesenAntin (UNDP)

\section{Supervision}

Katinka Weinberger (ESCAP)

\section{Coordinating team}

Caridad Canales, Eric Hermouet, Kareff Rafisura, Hitomi Rankine, Panpaka Supakalin (ESCAP)

\section{Lead authors, reviewers and contributors}

\section{Regional outlook}

Lead author: Hitomi Rankine (ESCAP)

Reviewers and contributors: Vivian Francisco, Smita Nakhooda (ADB); Hannie Meesters, Michaela Prokop, Bishwa Nath Tiwari (UNDP)

\section{SDG 1}

Lead authors: Sudip Ranjan Basu, Steve Loris Gui-Diby, Vatcharin Sirimaneetham (ESCAP) Reviewers and contributors: Sung-Eun Kim, Marisa Limawongpranee, Syed Nuruzzaman, Christopher Ryan, Panpaka Supakalin (ESCAP); Arturo Martinez Jr. (ADB); Bishwa Nath Tiwari (UNDP)

\section{SDG 2}

Lead authors: Katinka Weinberger, Caridad Canales, Masakazu Ichimura (ESCAP)

Reviewers and contributors: Eric Hermouet, Nongnuch Hiranyapaisansakul, Syed Nuruzzaman (ESCAP); Arturo Martinez Jr. (ADB); Bishwa Nath Tiwari (UNDP)

\section{SDG 3}

Lead authors: Nadia Rasheed, Kazuyuki Uji (UNDP), Tristram Price, Grace Puliyel, Chol O Han (ESCAP) Reviewers and contributors: Taoufik Bakkali, Brianna Harrison, Khin Cho Winthin, Anthony Lisle (UNAIDS); Arman Bidarbakht Nia, Syed Nuruzzaman, Panpaka Supakalin (ESCAP); Arturo Martinez Jr. (ADB); Bishwa Nath Tiwari (UNDP) 


\section{SDG 4}

Lead author: Chol O Han

Reviewers and contributors: Marco Eugenio Roncarati, Grace Puliyel, Nongnuch Hiranyapaisansakul, Marisa Limawongpranee, Syed Nuruzzaman, Yanhong Zhang (ESCAP); Arturo Martinez Jr., Tania Rajadel (ADB); Bishwa Nath Tiwari (UNDP)

\section{SDG 5}

Lead authors: Diana Rodriguez, Grace Puliyel (ESCAP)

Reviewers and contributors: Cai, Cai, Nongnuch Hiranyapaisansakul, Syed Nuruzzaman, Teerapong Praphotjanaporn (ESCAP); Arturo Martinez Jr., Vivian S. Francisco (ADB), Hannie Meesters, Koh Miyaoi (UNDP)

\section{SDG 6}

Lead authors: Aida Karazhanova, Caridad Canales (ESCAP)

Reviewers and contributors: Jayakumar Ramasamy (UNESCO), Michael Russell Biddington, Nongnuch Hiranyapaisansakul, Syed Nuruzzaman, Panpaka Supakalin (ESCAP); Arturo Martinez Jr., Xiaoyun Xu (ADB); Gordon Johnson (UNDP)

\section{SDG 7}

Lead authors: Sergey Tulinov, Igor Litvinyuk (ESCAP)

Reviewers and contributors: Rikke Munk Hansen, Nixie Mabanag, Syed Nuruzzaman (ESCAP), Arturo Martinez Jr, (ADB); Gordon Johnson (UNDP)

\section{SDG 8}

Lead authors: Oliver Paddison, Yusuke Tateno (ESCAP)

Reviewers and contributors: Nongnuch Hiranyapaisansakul, Mia Mikic, Syed Nuruzzaman, Zeynep Orhun (ESCAP); Arturo Martinez Jr. (ADB); Bishwa Nath Tiwari (UNDP)

\section{SDG 9}

Lead authors: Giuseppe de Simone, Maria M. Sophia Freynhofer, Nobuya Harabuchi, Sooksiri Chamsuk (UNIDO)

Reviewers and contributors: Marisa Limawongpranee, Nixie Mabanag, Alick Nyasulu, Syed Nuruzzaman (ESCAP); Arturo Martinez Jr., Smita Nakhooda (ADB); Bishwa Nath Tiwari (UNDP)

\section{SDG 10}

Lead authors: Grace Puliyel, Ermina Sokou (ESCAP)

Reviewers and contributors: Nongnuch Hiranyapaisansakul, Christopher Sean Lovell, Riccardo Mesiano, Syed Nuruzzaman (ESCAP); Arturo Martinez Jr. (ADB); Michaela Prokop, Bishwa Nath Tiwari (UNDP)

\section{SDG 11}

Lead author: Bishwa Nath Tiwari (UNDP)

Reviewers and contributors: Hong Pum Chung, Sung-Eun Kim, Syed Nuruzzaman, Lorenzo Santucci Panpaka Supakalin (ESCAP); Sameer Kamal, Arturo Martinez Jr., Smita Nakhooda (ADB)

\section{SDG 12}

Lead authors: Aneta Nikolova, Nina Schneider (ESCAP)

Reviewers and contributors: Michale Bordt, Nixie Mabanag, Borja Fernandez Martinez, Syed Nuruzzaman, Joao Lopes Resende (ESCAP); Vivian Francisco (ADB); Christine Wellington Moore, Bishwa Nath Tiwari (UNDP) 
SDG 13

Lead author: Kareff Rafisura (ESCAP)

Reviewers and contributors: Daniel Clarke, Sung-Eun Kim, Marisa Limawongpranee, Syed Nuruzzaman, Laura Zahar (ESCAP); Arturo Martinez Jr., Esmyra Javier, Smita Nakhooda (ADB); Srilata Kammila, Taimur Khilji, Rohini Kohli, Pradeep Kurukulasuriya (UNDP)

\section{SDG 14}

Lead author: Tim Westbury (ESCAP)

Reviewers and contributors: Nongnuch Hiranyapaisansakul, Syed Nuruzzaman, Farzana Sharmin (ESCAP), Arturo Martinez Jr., Smita Nakhooda, Patrick Safran (ADB); Jose Padilla (UNDP)

\section{SDG 15}

Lead authors: Caridad Canales, Hitomi Rankine (ESCAP)

Reviewers and contributors: Daniel Clarke, Nongnuch Hiranyapaisansakul, Syed Nuruzzaman (ESCAP); Arturo Martinez Jr. (ADB); Christine Wellington Moore, Bishwa Nath Tiwari, Doley Tshering (UNDP)

\section{SDG 16}

Lead authors: Paavani Reddy, Sebastian Boll, Kaori Kawarabayashi (UNDP); Tristram Price (ESCAP) Reviewers and contributors: Nixie Mabanag, Syed Nuruzzaman, Tanja Sejersen, Panpaka Supakalin (ESCAP); Arturo Martinez Jr. (ADB); Nicholas Booth, Nadia Rasheed, Phil Matsheza (UNDP)

\section{- SDG 17-Finance}

Lead authors: Smita Nakhooda, Marinella Gamboa (ADB); Zheng Jian (ESCAP)

Reviewers and contributors: Nongnuch Hiranyapaisansakul, Syed Nuruzzaman (ESCAP); Arup Chatterjee, Shigehiro Shinozaki (ADB); Ashley Palmer, Bishwa Nath Tiwari (UNDP)

\section{SDG 17-Technology}

Lead authors: Jonathan Tsuen Yip Wong, Susan F. Stone, Siope Vakataki Ofa (ESCAP)

Reviewers and contributors: Marisa Limawongpranee, Alick Nyasulu, Syed Nuruzzaman (ESCAP); Vivian Francisco, Smita Nakhooda (ADB); Bishwa Nath Tiwari (UNDP)

SDG 17-Trade

Lead authors: Arun Jacob, Mia Mikic (ESCAP)

Reviewers and contributors: Krisana Boonpriroje, Syed Nuruzzaman (ESCAP); Arturo Martinez Jr. (ADB); Bishwa Nath Tiwari (UNDP)

\section{Administrative support}

Aqira Bhatchayutmaytri, Wipavee Kasemsawasdi, Rujira Khrueachotikul (ESCAP)

\section{Editor}

Karen Emmons

\section{Design and layout}

Jeff Williams 


\section{Contents}

Acknowledgements _ 5

Explanatory notes _.. 9

Introduction _......... 11

Regional Outlook on the Sustainable Development Goals in Asia and the Pacific ............. 12

SDG1 18

SDG2 24

SDG $3 \ldots 30$

SDG 4 - 36

SDG5 42

SDG6 48

SDG7 $\quad 54$

SDG $8 \quad 60$

SDG $9 \quad 66$

SDG $10 \ldots 72$

SDG11 78

SDG $12 \ldots 84$

SDG13 90

SDG14

SDG $15 \ldots 102$

SDG 16

SDG 17-Finance _........... 114

SDG 17-Technology _............

SDG 17-Trade 126

Conclusions _- 132

Endnotes 133 


\section{Explanatory notes}

The Asia-Pacific region, unless otherwise specified, refers to the group of ESCAP members and associate members that are within the Asia and the Pacific geographic region (ADB and UNDP, partners in this publication, have differing regional compositions).

Geographic subregions in this report are defined (unless otherwise specified), as follows: East and North-East Asia: China, Democratic People's Republic of Korea (DPR Korea), Japan, Mongolia, Republic of Korea; South-East Asia: Brunei Darussalam, Cambodia, Indonesia, Lao People's Democratic Republic, Malaysia, Myanmar, Philippines, Singapore, Thailand, Timor-Leste, Viet Nam; South and South-West Asia: Afghanistan, Bangladesh, Bhutan, India, Islamic Republic of Iran, Maldives, Nepal, Pakistan, Sri Lanka, Turkey; North and Central Asia: Armenia, Azerbaijan, Georgia, Kazakhstan, Kyrgyzstan, Russian Federation, Tajikistan, Turkmenistan, Uzbekistan; Pacific: American Samoa, Australia, Cook Islands, Fiji, French Polynesia, Guam, Kiribati, Marshall Islands, Federated States of Micronesia, Nauru, New Caledonia, New Zealand, Niue, Northern Mariana Islands, Palau, Papua New Guinea, Samoa, Solomon Islands, Tonga, Tuvalu, Vanuatu.

\section{Developing countries:}

ESCAP members and associate members, excluding Australia, Japan and New Zealand.

Developed or industrialized countries:

Australia, Japan and New Zealand.

\section{Countries with special needs}

Least developed countries: Afghanistan, Bangladesh, Bhutan, Cambodia, Kiribati, Lao People's Democratic Republic, Myanmar, Nepal, Solomon Islands, Timor-Leste, Tuvalu and Vanuatu. Samoa was part of the group of least developed countries prior to its graduation in 2014.

\section{Landlocked developing countries:}

Afghanistan, Armenia, Azerbaijan, Bhutan, Kazakhstan, Kyrgyzstan, Lao People's Democratic Republic, Mongolia, Nepal, Tajikistan, Turkmenistan and Uzbekistan.

Small island developing States:

Cook Islands, Fiji, Kiribati, Maldives, Marshall Islands, Federated States of Micronesia, Nauru, Niue, Palau, Papua New Guinea, Samoa, Solomon Islands, Timor-Leste, Tonga, Tuvalu and Vanuatu.

\section{Economic classifications and groupings}

The classification of countries into income groups is from the World Bank. The World Bank divides countries according to their 2015 gross national income per capita, calculated using the World Bank Atlas method. Group classifications are: low income $(\$ 1,025$ or less), lower-middle income $(\$ 1,026-$ $\$ 4,035)$, upper-middle income $(\$ 4,036-\$ 12,475)$ and high income $(\$ 12,476$ or more). 
Low-income economies:

Afghanistan, Democratic People's Republic of Korea, Nepal.

Lower middle-income economies: Armenia, Bangladesh, Bhutan, Cambodia, India, Indonesia, Kiribati, Kyrgyzstan, Lao People's Democratic Republic, Federated States of Micronesia, Mongolia, Myanmar, Pakistan, Papua New Guinea, Philippines, Samoa, Solomon Islands, Sri Lanka, Tajikistan, Timor-Leste, Tonga, Uzbekistan, Vanuatu, Viet Nam.

Upper-middle-income economies:

American Samoa, Azerbaijan, China, Fiji, Georgia, Islamic Republic of Iran, Kazakhstan, Malaysia, Maldives, Marshall Islands, Palau, Russian Federation, Thailand, Turkey, Turkmenistan, Tuvalu.

High-income economies:

Australia, Brunei Darussalam, French Polynesia, Guam, Hong Kong, China, Japan, Macau, China, Nauru, New Caledonia, New Zealand, Northern Mariana Islands, Republic of Korea, Singapore.

\section{Other groupings}

Association of Southeast Asian Nations (ASEAN):

Brunei Darussalam, Cambodia, Indonesia, Lao People's Democratic Republic, Malaysia, Myanmar, Philippines, Singapore, Thailand, Viet Nam.

\section{Economic Cooperation Organization (ECO):}

Afghanistan, Azerbaijan, Islamic Republic of Iran, Kazakhstan, Kyrgyzstan, Pakistan, Tajikistan, Turkey, Turkmenistan, Uzbekistan.

South Asian Association for Regional Cooperation (SAARC):

Afghanistan, Bangladesh, Bhutan, India, Maldives, Nepal, Pakistan, Sri Lanka.

\section{A note about SDG 17}

SDG 17 includes two other components, one on capacity building and the other on systemic issues, that are not included in this outlook report. Target 17.9 and targets $17.13-17.19$ also are not included.

\section{Symbols and units}

- References to dollars (\$) are to United States dollars, unless otherwise stated.

- The dash (-) between dates signifies the full period involved, including the beginning and end years.

- Percentages do not necessarily add to totals because of rounding.

- "Tonnes" refers to metric tons. 


\section{Introduction}

\section{A successful journey starts with understanding how far we need to go.}

The Asia-Pacific Sustainable Development Goals Outlook report aims to develop a shared understanding of the opportunities and challenges confronting the region. This report provides a goalby-goal snapshot of where we stand, including bright spots, hot spots and emerging issues for our region as we implement the 2030 Agenda for Sustainable Development.

Limitations of data and the sheer complexity of the issues addressed by the 2030 Agenda have constrained this effort. Nonetheless, a picture emerges of a region that has, on the aggregate level, achieved several of the Millennium Development Goals but in which too many of its people are still not benefiting from growth and progress and are increasingly vulnerable to economic, social and environmental risks. In 2013, 400 million people lived on less than $\$ 1.90$ per day (in 2011 PPP). With business-as-usual practices, we may not realize the brighter future that global leaders in 2015 committed to reach in 15 years' time.

This outlook report provides a starting point for dialogue and will support follow-up and review at the regional level. It can also help governments and other stakeholders to reach much-needed social and political consensus and focus on the gaps and priorities for moving forward. It also focuses attention on the opportunities for bringing the Asia-Pacific region together in action on cross-cutting issues and in support of the countries that face multiple challenges.

In conjunction with the Asia-Pacific SDG Data Portal, the Asia-Pacific Sustainable Development Goals Outlook is the first knowledge product under a renewed partnership between the Economic and Social Commission for Asia and the Pacific (ESCAP), the Asian Development Bank (ADB) and the United Nations Development Programme (UNDP). Having come together to track progress on the Millennium Development Goals, this partnership now builds on its experiences to achieve the 2030 Agenda.

The 2030 Agenda for Sustainable Development is ambitious and transformative, requiring a stronger push for coherent policies that create synergies and out-of-the-box thinking. It is an also an Agenda which, as intended by SDG 17, requires strengthened partnerships and regional action. The AsiaPacific SDG outlook report can foster new ideas by providing an informed overview of where we stand as a region in relation to the SDGs and by highlighting those issues that will require a concerted effort to fulfil the dream of a region without poverty. 
The 2030 Agenda for Sustainable Development, adopted by 193 United Nations Member States in September 2015, and its framework of 17 Sustainable Development Goals (SDGs) are the results of a three-year global dialogue. Through extensive stakeholder engagement processes, this dialogue connected people in remote villages with the United Nations General Assembly in New York. With that increased participation comes an increased stake in the outcomes.

Asian and Pacific governments have responded, moving from adoption of the 2030 Agenda and the SDGs to their implementation at the national level much faster than was the case with the Millennium Development Goals. Some countries have taken steps to integrate the SDGs into existing national development plans, policies and legislation, while many other governments are establishing or strengthening coordination bodies or mapping institutional responsibilities.

\section{There are reasons for optimism.}

The proactive response indicates that many governments are committed to change, and some have already proven that that they are capable of transforming. Poverty rates have fallen dramatically. Infrastructure investments are bearing fruit, and economic transformations are ripening.

Social protection investments are being strengthened in at least 20 countries in the region. There is growing investment in energy efficiency and renewable energy, which have become the most economical solutions for new energy capacity in an increasing number of countries.

High-level strategies and policy innovations indicate the readiness of governments to take the lead in transformation and innovation to achieve development goals. In Kyrgyzstan, Nepal and Singapore, for example, pioneering governments are bringing more balanced gender representation to parliament. In Indonesia, universal health care legislation has been passed, and in Thailand, universal health care is a national priority.

Elsewhere, governments are actively supporting domestic industries attractive to investment. Investors are invited to Make In India, and there are new industrial policies in Bangladesh and Indonesia. China, Japan, New Zealand and the Republic of Korea are already global leaders in additive manufacturing, in which 3D printing technologies are applied.

\section{By examining the SDGs goal by goal, this report shows that governments will confront many common and fundamental challenges as they work to advance sustainable development.}

Increasing inequality in most countries points to systemic issues that entrench marginalization and exclusion and hamper the achievement of shared prosperity. Widening gaps between the rich and the poor and low wages threaten to reduce the sustainability of economic growth and are also associated with negative social and environmental outcomes. Shortcomings in the recognition and protection of human rights are a systemic issue that impacts the conditions under which many people work. The Asia and Pacific region has the largest number of victims of forced labour in the world, amounting to around 11.7 million people in 2012. Approximately one billion persons in the region are in vulnerable employment, with women significantly more likely than men to be affected. Simply by not having had their births registered, large numbers of people are excluded from education or social services - as many as 70 per cent of the population is affected this way in one country alone. 
Corruption is a systemic barrier to sustainable development that impacts the neediest of households. An estimated 40 per cent of investments in electricity, water and sanitation, for example, are lost due to corruption. The slow progress on these issues is often rooted in social, cultural, geographic and other factors and will continue to undermine poverty eradication and inclusive growth efforts, even if global economic prospects and foreign direct investment flows to the region improve.

\section{Gender inequality is one of the most fundamental challenges confronting the region. Tackling} the shortcomings in gender equality and women's empowerment is urgent and long overdue. Education advances are not yet translating to more equal and just societies for half of the region's population. There are unacceptable levels of domestic violence with uneven judicial and other protection, disproportionately large numbers of women in vulnerable work, persistent harmful practices and institutionally entrenched injustices (for example, in relation to inheritance). The effect on the progress of countries to date is evident-discriminatory practices coincide with lingering poverty and childhood vulnerability. In some countries, the proportion of stunted children was greater than 35 per cent in 2014. Almost every SDG has a gendered perspective-because action on the gender-based inequities is the key to boosting the collective progress across the goals.

Marginalization and exclusion are related to another fundamental and even more complex challenge: the capacity of regional economies to generate high-quality employment for all workers, particularly youth. Growth in real wages has not kept pace with increases in productivity, and employment creation is slowing. Some of the issues are structural while others are market related and institutional. And others are demographic, with increasing numbers among the populations who are of working age. At the same time, the region is growing old before it grows rich. Youth unemployment, marginalization and exclusion that, together, promote civil conflict are increasing the risks, especially as migration pressures intensify and other factors, such as climate change, increase the vulnerabilities.

Education provides a foundation for progress. Although the region has achieved near-universal primary school enrolment, this success is poorly distributed within countries and communities, and its quality does not yet match the needs of this generation. Twenty-one million children in the region are not enrolled in primary school, and pre-primary enrolment rates are as low as 10 per cent. The most glaring deficits in education investment are in the least developed countries, where human capital formation will continue to undermine the prospects for slashing chronic poverty. A different quality of education is required for innovation, for entrepreneurship and for all learners to acquire knowledge on the complex challenges of sustainable development. In 2014, 44 countries received development assistance for education from the donor community; but the total amount of such assistance received by the region decreased by almost 8 per cent in only a few years' time (between 2011 and 2014).

Although demand for a diversified range of food is growing, the agriculture sector and food security are underinvested. In some countries, the proportion of people who are undernourished has increased rather than decreased. Good health and well-being cannot be assured without food security, enhanced agricultural productivity and diversification. Climate change, land tenure, land-use policy, know-how and technology, access to production inputs as well as cross-border investments and trade policies are among the factors influencing the scale of the challenge in the agriculture sector, to varying degrees. Effective management of the natural resources, including fish stocks, is an important component of the regional food security challenge. Arable land per capita is decreasing, and about 85 per cent of the global fish stocks are fully fished, overfished or have collapsed. Coral reefs in the region, which are important for maintaining fish stocks, particularly for near-shore fishing, are already impacted by climate change. Around 40 per cent of the world's oceans are heavily affected by human activities and land-ocean interactions. 
Terrestrial ecosystem protection shortcomings are impacting rural livelihoods, food security and biodiversity in some of the most vulnerable areas of the region: rural areas, coastal communities and small island developing States. Water is perhaps the most fundamental resource and is under pressure across the region. Per capita water resources are declining, and some 80-90 per cent of wastewater is discharged without treatment in the region's developing countries. Between 1990 and 2010 , per capita water availability dropped by more than one third in some countries, including some of the poorest. Groundwater contamination and depletion are growing concerns, although it remains difficult to assess to what degree. Failure to safeguard water resources will be an increasing challenge to overcoming the considerable level of unmet basic needs and to achieving the wider goals of agricultural diversification and food security-and perhaps in the long term, social stability.

The region is facing increasingly complex health challenges that, in many places, governments are not fully equipped to cope with. The outlook on SDG 2 on health and well-being is dimmed by the growing risks and challenges related to both communicable and non-communicable diseases, population ageing, cross-border epidemics, antimicrobial resilience, pollution and mental health. As a result, the outlook for other goals, such as in relation to poverty and economic growth, are also threatened. Investments in health care are inadequate in most countries; but when compared with the World Health Organization's estimate of a minimum of $\$ 44$ per person per year, they are extremely low in the most impoverished of situations, with per capita spending as low as $\$ 4$ per person. In some areas of health access (such as access to preventive medication for mother-to-child transmission of HIV), per capita spending is far below the global standards for some groups. Four non-communicable diseases are now the major causes of death and disability in Asia and the Pacific and are responsible for economic losses in the range of billions of dollars in India alone. According to the World Health Organization, of the most polluted 100 cities in the world, nearly 70 per cent are in Asia. High levels of chemical inputs for food production, pollution from plastics and textile industry waste, mercury and dioxin emissions are threats that require better chemical management. Lifecycle analysis and demand-side management are an integral part of the response to the increasingly complex health threats.

This outlook report recognizes that change is a difficult process. Many of the issues discussed are long standing and persistent, and they may become future crises if not resolved. The capacity to catalyse societal transformation is an important element of governance for sustainable development. This involves setting a clear direction for transformations, creating the conditions to enable systemic changes and managing politically complex processes, including confronting issues of power and vested interests while recognizing the values and interests of all stakeholders.

The strength of the relationships between governments and citizens and between and among all stakeholders will define the societal consensus on the ideals of the 2030 Agenda. A "healthy" social contract will be reflected in political and economic systems that equitably fulfil the needs of all stakeholders, including future generations and in both developing and industrialized countries. 


\section{Many transboundary issues will require a regional response, and there are many opportunities for joint action.}

Issues highlighted in this report with important transboundary dimensions include migration, trade and environmental protection, particularly in relation to water resources and cross-border investment. As well, regional economic integration, cooperation and dialogue will provide endless opportunities for strengthening the response to these shared concerns.

Many of the SDGs deal with global and regional public goods, such as climate change, mitigation, digital connectivity, trade and investment agreements. Therefore, regional cooperation and partnerships for investing more in public goods are needed.

\section{This outlook report focuses attention on the need to strengthen policy coherence and recognize the links between the goals.}

Transformations for sustainable development require that the foundations described previously are built well and that links between the goals are better recognized and, in response, that more coherent policy frameworks are developed. Strengthened policy coherence is targeted within SDG 17 as a hallmark of an effective response to the integrated and interlinked 2030 Agenda.

A review of policy frameworks as part of the implementation process for the 2030 Agenda can help to strengthen the policy response, ensuring that policies do not work against each other or against the people they are intended to support and that resources are efficiently allocated and used.

Policy coherence also sends a distinctive signal, fostering initiatives and new partnerships to take on the complex issues, such as financial inclusion, food security, education access and quality and providing services that meet the needs of people at "the bottom of the pyramid". In particular, policy coherence is necessary to achieve SDG 1 on poverty, SDG 2 on hunger and sustainable agriculture, SDG 8 on inclusive and sustainable economic growth, SDG 9 on industrialization, innovation and infrastructure and SDG 12 on sustainable consumption and production.

The regional outlook for achievement of the SDGs will be brightened by greater policy coherence in the following areas:

- Economic growth, investment strategies and inequality. The labour share of GDP, comprising wages and social protection transfers, has increased in a few countries, including Australia, Georgia and New Zealand. However, the share is decreasing in East Asia and North-East Asia and in high-income economies. Decent work and economic diversification are foundations for SDG achievement and are needed to reduce inequality and poverty. The impact of capital and energy-intensive investments on poverty outcomes needs to be assessed, while the cultural, social, economic, geographic and other factors that underpin marginalization and exclusion should be dismantled in the context of inclusive growth strategies.

- Youth unemployment, human capital formation and infrastructure development, in particular for information and communication technology connectivity. Access should be closely aligned with human capital formation strategies to enable countries to capitalize on the opportunities presented for innovation and entrepreneurship. Twenty countries have low broadband penetration rates, and there is the growing digital divide, while youth unemployment is a concern in both developed and industrialized countries. 
- Trade and investment. Trade and investment policies should be better aligned with the fundamental requirements for sustainable development. For example, multilateral and bilateral free trade and investment agreement provisions can further mainstream public policy objectives related to health and food security. The continuing proliferation of preferential trade agreements, as opposed to strengthening of the multilateral trade system under the World Trade Organization, is complicating the global trade system in a way that places a greater burden on poorer, developing countries, and small and medium-sized enterprises within them. Furthermore, to harness the full potential of trade as a means of implementation, there is a need to contain the rising threat of protectionism, both in terms of tariffs and non-tariff measures.

- Inclusive growth and climate change. Policies that are driving land-use change trends can undermine goals to support poverty eradication by creating increased vulnerability in rural areas to climate change. Strengthened policy coherence in relation to inclusive growth and investment and the protection of terrestrial ecosystems are needed to secure livelihoods, strengthen food security and ensure the continued flow of ecosystem services on which the achievement of the SDGs rests. Natural forest losses continue across the region, although plantations are expanding.

- Greenhouse gas emissions. Although carbon intensities are decreasing, total emissions are still on the rise. Climate change and its impacts must be urgently tackled across the entire 2030 Agenda, given the vulnerabilities in the region. Levels of political commitment are high, and as of December 2016, 30 countries in the region had ratified the Paris Agreement and submitted their Nationally Determined Contributions.

- Energy, technology and infrastructure. Action on climate change and growth policies must be integrated within poverty-reduction strategies. At the most basic level, bridging the access gaps in relation to energy and other forms of infrastructure should also respond to climate action. In East Asia and North-East Asia, only 61 per cent of people use modern forms of energy; in South-East Asia, it is only about half the population, while in South Asia and South-West Asia, it is only 35 per cent. The health impacts of using traditional fuels in the home and the gendered dimensions are well documented.

\section{Finally, implementing the SDGs in a transformative agenda requires new government capacities.}

The challenges of an interlinked and integrated agenda require governments and all stakeholders to develop a more concrete understanding of the interactions between the goals. This is fundamental to ensure that institutional structures for monitoring and implementation are representative of the relationships between the goals and the cross-cutting nature of many of them. Localized indicators, data collection and monitoring systems should also reflect these interlinks.

Strengthened capacity to coordinate investments and strategies, to engage stakeholders and support effective and inclusive social dialogue will better equip governments to balance the interests of all stakeholders in society, including those of future generations. This will be the basis for ensuring that efforts to achieve the sustainable development goals are approached with a holistic understanding of their interactions and aligned with positive outcomes for everyone. 


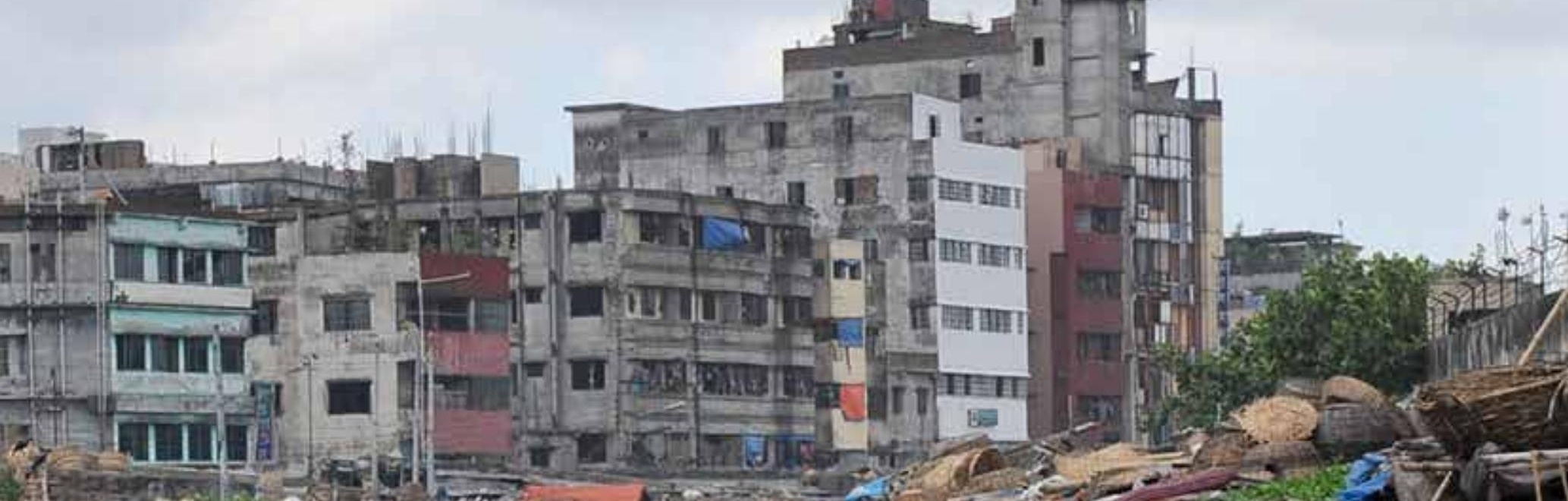

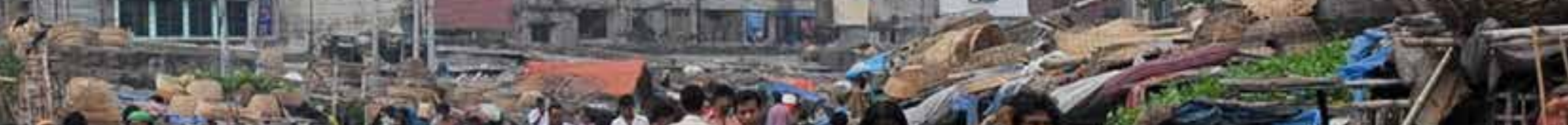

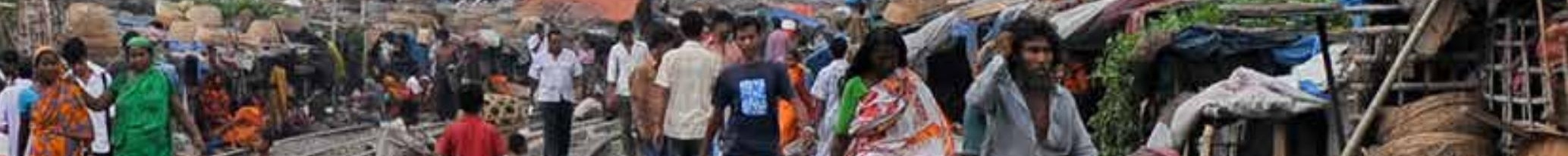
i 1 -

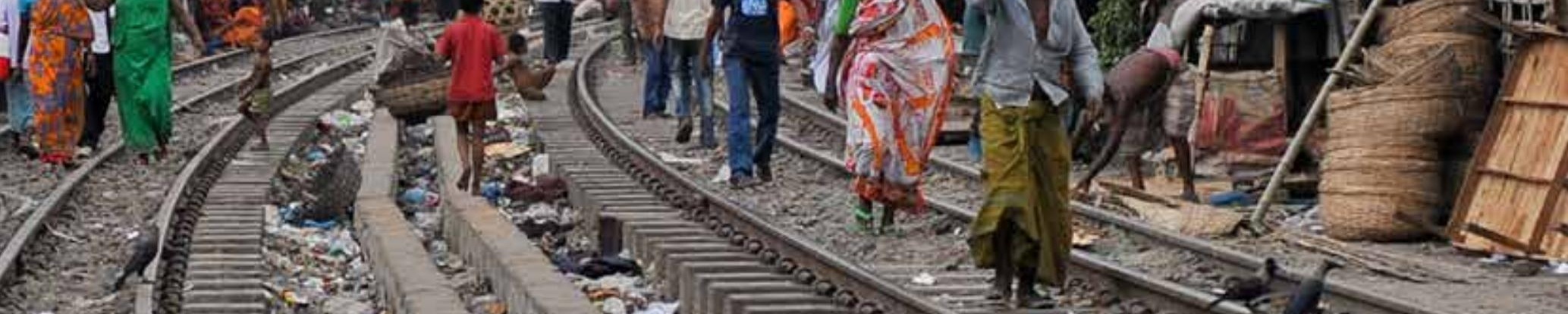

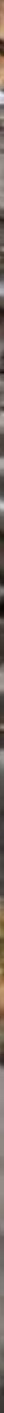




\section{End poverty in all its forms everywhere}

\section{OUTLOOK}

Countries in Asia and the Pacific have made important progress in reducing income poverty, and eradicating it is within reach. The primary challenge is to end poverty in all its forms ${ }^{1}$ everywhere while ensuring equitable and secure economic opportunities for all people and strengthening resilience, particularly in the face of new threats and risks, including as a result of climate change. Success will be highly dependent on several critical factors, including the effective targeting of social protection policies and job creation that increases support for the most vulnerable groups and marginalized communities of people.

\section{THEPHOTO}




\section{End poverty in all its forms everywhere}

\section{INSIGHTS}

- Between 2010 and 2013, the poverty rate or the proportion of people living on less than $\$ 1.90$ per day (in $2011 \mathrm{PPP}^{2}$ ) in the Asia-Pacific region fell to 10.3 per cent of the total population, down from 29.7 per cent for the period 2000-2004. For the same period (2010-2013), the total number of people who are poor fell to 400 million. ${ }^{3}$

- When considering multidimensional poverty, at least 931 million people are impoverished across the region. Deprivations in health and living standards are the most striking. ${ }^{4}$

- Sticking to business-as-usual practices will not make any significant impact on poverty reduction. A more innovative and comprehensive approach is needed, with increased focus on reducing the economic, social and environmental risks confronting people who are poor and who are particularly vulnerable to economic shocks and/or living in marginalized communities.

- Although there has been progress in the use of social protection programmes as a tool to address inequalities of opportunity (in health care and education, for instance) in the region, ${ }^{5}$ limited data disaggregation prevents the effective targeting of social protection and other policies to those who need it most.

- People living on less than $\$ 1.90$ per day (in 2011 PPP) are concentrated in rural areas, among the young ages and in agriculture sector employment. Having only a primary school education and large-sized households are common features of poor people in South and South-West Asia. ${ }^{6}$

- People in poverty are particularly more vulnerable to climate-related extreme events. They tend to live in hazard-prone areas, such as slums, steep slopes, seismic zones, floodplains, river banks and remote areas. Impoverished people lack the resources to invest in preventive measures, and they lack adequate savings to draw upon should disaster strike. Disasters are thus likely to push people who are poor into extreme poverty or push near-poor households into poverty.

- Women are more vulnerable to various forms of poverty due to the challenges they encounter when seeking decent jobs, credit, health care and education. In particular, women are more likely to end up with informal employment and to receive lower wages than men for an equal amount of work because of the limited protection of their workers' rights, lack of wagebargaining mechanisms and unsafe working conditions, typically while juggling the extra burden of unpaid care or household work. 


\section{BRIGHTSPOTS}

\section{Poverty reduction and eradication}

- Poverty rates ( $\$ 1.90$ per day) are below 1 per cent in countries like Azerbaijan, the Islamic Republic of Iran, Kazakhstan, Malaysia, Mongolia, the Russian Federation, Samoa, Thailand and Turkey. ${ }^{7}$

- Poverty rates have fallen dramatically in Cambodia, China, Indonesia, Kyrgyzstan, Nepal, Pakistan, Tajikistan and Viet Nam-they are now about 40-50 percentage points lower than the rates in the 1990 s. $^{8}$

\section{HOTSPOTS}

\section{Poverty reduction and eradication}

- In South and South-West Asia, nearly one in five persons (more than 338 million people) were living in poverty in 2012. Although poverty rates for this subregion have reduced by half (in Bangladesh and India, the rate even decreased by almost 30 percentage points) over the past two decades, poverty rates are still among the highest in the Asia-Pacific region. ${ }^{9}$

- In smaller countries, such as Georgia and Papua New Guinea, poverty rates have fallen slowly or have been stagnant. ${ }^{10}$

- In some countries, such as Timor-Leste, the poverty rate has increased.

- People living in poverty often live in rural areas. In China, the share of the rural population living in poverty in 2012 was 13 per cent, much higher than the 0.4 per cent in urban areas. In India, the poverty figures showed 24.8 per cent in rural areas and 13.4 per cent in urban areas in $2011 .^{11}$

\section{Fulfilment of economic, social, financial and environmental rights}

- In many countries, such as Afghanistan, Bangladesh, India, Pakistan and Papua New Guinea, fewer than one in five persons are covered by social assistance programmes. In other countries, like Bhutan, Kyrgyzstan and Tajikistan, fewer than one in ten persons are covered. ${ }^{12}$ Similar trends are also apparent when looking at the proportion of the population covered by labour market programmes or the proportion of unemployed workers receiving unemployment benefits. 


\section{Resilience and vulnerability to climate-related extreme events}

- Poverty eradication will be challenging with the occurrence of climate-related events because the region is particularly exposed to the impacts of climate change, with nine Asia-Pacific countries on the list of the 15 countries that are the most exposed and vulnerable to natural hazards. ${ }^{13}$ Over the past decade (2006-2015), disasters caused by natural hazards affected a total of 1.3 billion people in the region ${ }^{14}$-roughly the same size as India's entire populationand resulted in economic losses of roughly $\$ 379,000$ billion. $^{15}$

\section{EMERGINGISSUES}

- Rapid population ageing combined with the lack of social security or pension benefits and the lack of targeted social programmes will likely further increase poverty among older persons.

- Social exclusion, economic uncertainty and environmental risks are increasing, including those related to natural disasters and extreme climate-related events.

- Although migration contributes to economic development, climate change-related migration will increase the vulnerability of women and communities in coastal areas, which in turn will lead to near-poor households falling into poverty.

\section{TARGETS}

1.1 By 2030, eradicate extreme poverty for all people everywhere, currently measured as people living on less than $\$ 1.25$ a day

1.2 By 2030, reduce at least by half the proportion of men, women and children of all ages living in poverty in all its dimensions according to national definitions

1.3 Implement nationally appropriate social protection systems and measures for all, including floors, and by 2030 achieve substantial coverage of the poor and the vulnerable

1.4 By 2030, ensure that all men and women, in particular the poor and the vulnerable, have equal rights to economic resources, as well as access to basic services, ownership and control over land and other forms of property, inheritance, natural resources, appropriate new technology and financial services, including microfinance

1.5 By 2030, build the resilience of the poor and those in vulnerable situations and reduce their exposure and vulnerability to climate-related extreme events and other economic, social and environmental shocks and disasters

1.a Ensure significant mobilization of resources from a variety of sources, including through enhanced development cooperation, in order to provide adequate and predictable means for developing countries, in particular least developed countries, to implement programmes and policies to end poverty in all its dimensions

1.b Create sound policy frameworks at the national, regional and international levels, based on pro-poor and gendersensitive development strategies, to support accelerated investment in poverty eradication actions 


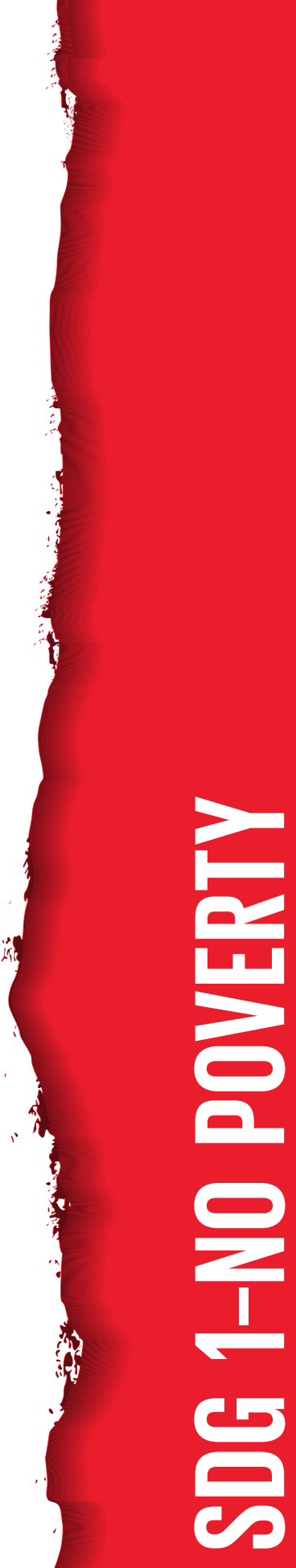




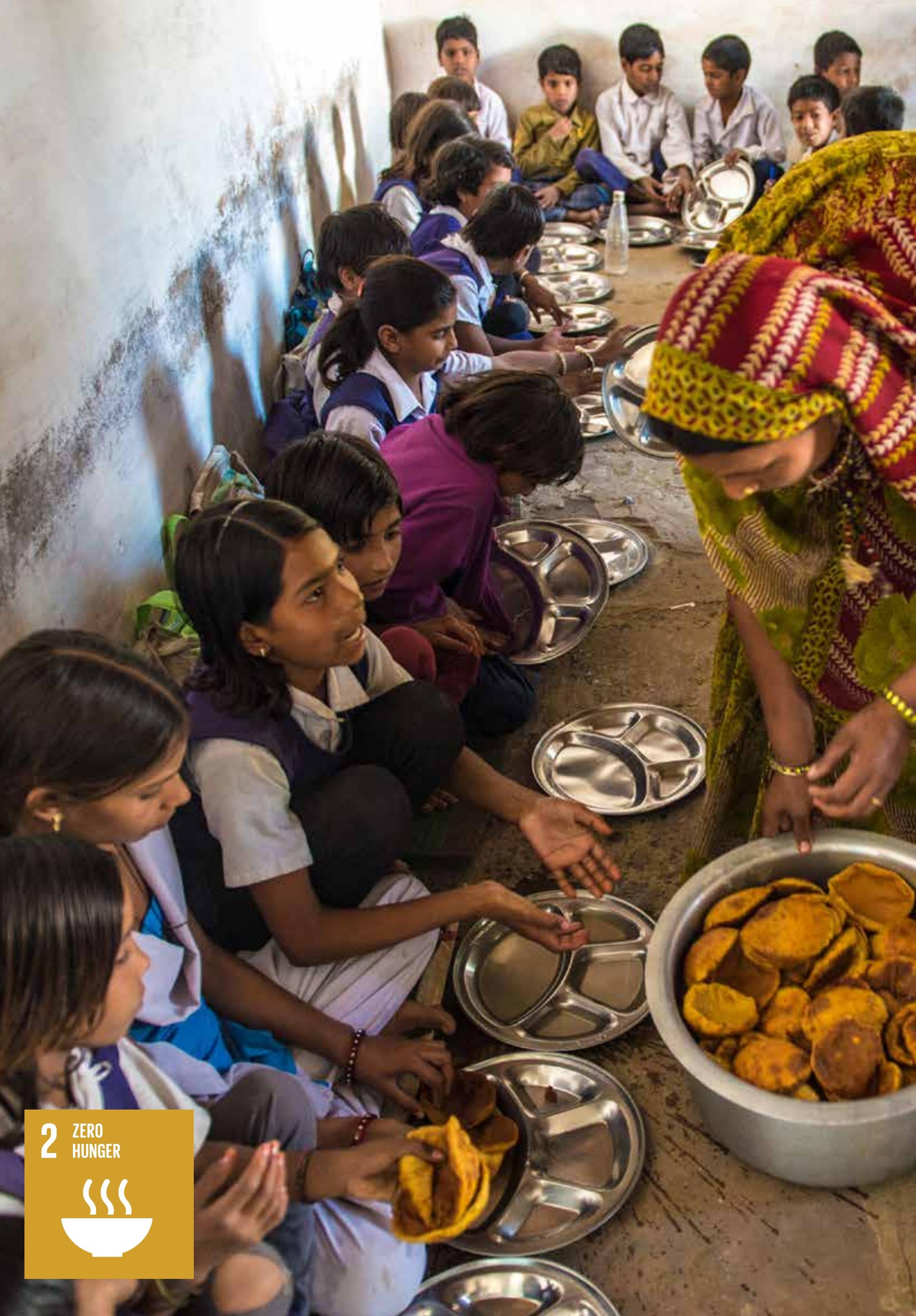




\section{(1)}

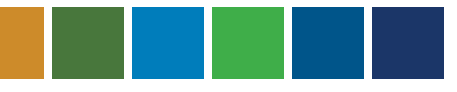

\section{End hunger, achieve food} security and improved nutrition and promote sustainable agriculture

\section{OUTLOOK}

There is a challenging road ahead to achieve this goal. Despite significant progress in the reduction of hunger and malnutrition, improvements vary across subregions and countries and disproportionally affect the nutritional status, food security and livelihoods of vulnerable groups. In many places, undernourishment and obesity co-exist; and agriculture continues to pose an unsustainable burden on the planet's carrying capacity. Climate change will have a significant impact on crop yields and harvests, disproportionally affecting the nutritional status and livelihoods of impoverished households.

\section{THEPHOTO}




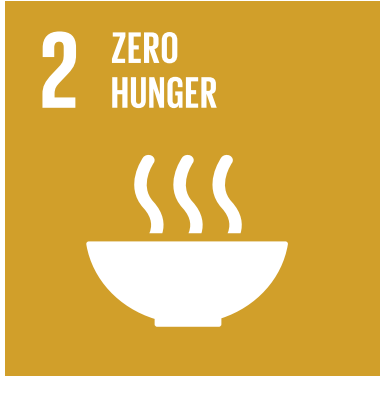

\section{End hunger, achieve food security and improved nutrition and promote sustainable agriculture}

\section{INSIGHTS}

- The prevalence of undernourishment is an important indicator of hunger. Nonetheless, many other phenomena affecting the short-term food situation of a country or of specific population groups also need to be measured. Seasonal variations, food price volatility, impact of natural disasters or irregular weather conditions on food production are just some of the phenomena that are not captured by the prevalence of undernourishment and for which additional measures can be used. ${ }^{1}$

- Many countries in the region need to pay more attention to growth in their agriculture sector and to supporting diverse food systems. Evidence consistently shows that growth originating in agriculture has a stronger impact on poverty and hunger reduction than growth originating in other sectors. $^{2}$

- Achieving SDG 2 will be challenging due to the convergence of expanding populations, climate change, fertilizer overuse, competing use of land for food, energy and industries, changing consumption patterns, the ageing population of working farmers and the degradation of agricultural land.

\section{BRIGHT SPOTS}

\section{Eradicating hunger and malnutrition (getting enough of the right food)}

- The region as a whole has halved the prevalence of undernourishment or the proportion of the population below the minimum level of dietary energy consumption, from 23 per cent in 1991 to 12 per cent in $2015 .^{3}$

- Food and agricultural resources have been an important base for pro-poor growth and have facilitated the rapid emergence from hunger and poverty for most households in the region.

\section{Agricultural productivity and sustainable food production systems}

- The region is the world's largest producer of cereals, vegetables, fruits, meat and fish, with strong growth in all areas. Agricultural production has been increasing steadily since 1990. Measured in terms of constant prices, the value of food produced in the region increased from $\$ 736$ billion in 1990 to $\$ 1,351$ billion in $2013 .{ }^{4}$

- Agricultural productivity in the region, as measured by value added per worker, has generally been rising, especially in East Asia. Although in South Asia, it has been a slow rise. With the exception of a few countries, it remains a fraction of what has been achieved in industrialized countries. $^{5}$ 
- Farm mechanization is increasingly used in crop production and harvest and post-harvest operations: While more than 90 per cent of farm power originated from animal sources in the 1960s, many countries of the region now have mechanization rates higher than 60 per cent. ${ }^{6}$

\section{HOTSPOTS}

\section{Eradicating hunger and malnutrition (getting enough of the right food)}

- There has been a slowdown in the rate of reducing undernourishment over the past five years (2010-2015) for many countries in the region, when compared with the rates for the previous two decades.

- Hunger reduction in South and South-West Asia is taking place more slowly than in other subregions and is not keeping pace with population growth. Nearly 300 million people were affected by hunger in 2016, reflecting the slow pace in reduction. ${ }^{7}$

- The rate of reducing undernourishment has reversed ${ }^{8}$ and it has even deteriorated for some countries. For example, the proportion of people affected by hunger in 2014-2016 increased from the level that existed in 1990-1992 in the Democratic People's Republic of Korea (from 23.3 per cent to 41.6 per cent) and Tajikistan (from 28.1 per cent to 33.2 per cent). Only limited improvements (a decline in the percentage of people affected by hunger) have been made in some other countries in that same time period: Afghanistan (from 29.5 per cent to 26.8 per cent); Mongolia (from 29.9 per cent to 20.5 per cent); India (from 23.7 per cent to 15.2 per cent); Pakistan (from 25.1 per cent to 22 per cent); and Sri Lanka (from 30.6 per cent to 22 per cent). ${ }^{9}$

- Stunting due to malnutrition affected more than 96 million children in 2014. ${ }^{10}$ In Bangladesh, India and Nepal, the proportion of stunted children was greater than 35 per cent in 2014. ${ }^{11}$ MDGs related to nutrition and stunting remain unmet in the region as a whole.

- Almost half of all overweight children younger than 5 years in the world live in Asia. The overweight concerns combined with the approximately 27 per cent of children younger than 5 years who are stunted (in 2014) has created a double burden of malnutrition for the region.

- The prevalence of overweight within the region has grown by 2.1 per cent and obesity by 4.3 per cent annually. The prevalence of obesity is especially high in the Pacific, ranging from 28 per cent in the Solomon Islands and Papua New Guinea to 43 per cent in Tonga and more than 40 per cent for Kiribati, Samoa and Tuvalu. Between 1990 and 2008, the prevalence of overweight and obesity increased most rapidly in South-East Asia. ${ }^{12}$ 


\section{Agricultural productivity and sustainable food production systems}

- Agriculture depends on the sustainable management of the genetic diversity of crops, breeds, trees and aquatic resources. But biodiversity is threatened throughout the region due to extensive agriculture, aquaculture and oil palm and rubber plantations. The proportion of threatened native mammal and plant species increased by more than 10 per cent and 18 per cent, respectively, in the past decade. Degradation of biota and ecosystems affects the livelihoods of $50-80$ per cent of rural people. ${ }^{13}$

- A total of 90 million hectares of agricultural land was lost in the region between 2000 and 2013. Between 1993 and 2013, the region lost 5.3 per cent, or 35 million hectares, of its arable land due to land degradation and conversion to other uses, such as industrial parks and urban centres. $^{14}$

- The region has the world's highest rates of mineral fertilizer use. By subregion, North-East Asia, followed by South Asia, are the heaviest users of fertilizers, at 445 kilograms and 150.4 kilograms per hectare, respectively. ${ }^{15}$

\section{EMERGINGISSUES}

- Climate change threatens all dimensions of food security. Projections show that increasing temperatures will result in decreased yields, especially in South and South-East Asia, and increased incidence of pest and disease outbreaks. The widespread melting of glaciers and snow cover in the major mountain ranges of Asia will affect the volume and timing of water flows and ultimately reduce the availability of irrigation water downstream. The effects of climate change on agricultural production and livelihoods are expected to intensify over time. ${ }^{16}$

- The availability of water is also a challenging issue, especially with agriculture a major user of water-the proportion of water withdrawn for agriculture is more than 90 per cent for 13 countries in the region, ${ }^{17}$ in particular in Central Asia. Nearly all countries in the region are experiencing increasing pressure on water resources due to their growing populations and economic development. Between 1990 and 2010, per capita water availability dropped by 42 per cent in the Solomon Islands, by 36 per cent in Malaysia, Nepal and Pakistan, by 29 per cent in India and Bangladesh and by 23 per cent in Viet Nam. ${ }^{18}$

- About half of the global food loss and waste occurs in China, Japan and the Republic of Korea (at 28 per cent) and in South and South-East Asia (at 23 per cent), although on a per capita basis, loss is lowest in South and South-East Asia. ${ }^{19}$

- Changing food consumption patterns across the region are increasing the demand for meat and thus compounding the land and water availability challenges. Between 1990 and 2011, animal sources contributed 200 calories per person per day, while fruits, vegetables and pulses contributed 125 calories more per day, and the contribution of cereals and starchy roots declined by more than 50 calories per person per day. ${ }^{20}$ 


\section{TARGETS}

2.1 By 2030, end hunger and ensure access by all people, in particular the poor and people in vulnerable situations, including infants, to safe, nutritious and sufficient food all year round

2.2 By 2030, end all forms of malnutrition, including achieving, by 2025, the internationally agreed targets on stunting and wasting in children under 5 years of age, and address the nutritional needs of adolescent girls, pregnant and lactating women and older persons

2.3 By 2030, double the agricultural productivity and incomes of small-scale food producers, in particular women, indigenous peoples, family farmers, pastoralists and fishers, including through secure and equal access to land, other productive resources and inputs, knowledge, financial services, markets and opportunities for value addition and non-farm employment

2.4 By 2030, ensure sustainable food production systems and implement resilient agricultural practices that increase productivity and production, that help maintain ecosystems, that strengthen capacity for adaptation to climate change, extreme weather, drought, flooding and other disasters and that progressively improve land and soil quality

2.5 By 2020, maintain the genetic diversity of seeds, cultivated plants and farmed and domesticated animals and their related wild species, including through soundly managed and diversified seed and plant banks at the national, regional and international levels, and promote access to and fair and equitable sharing of benefits arising from the utilization of genetic resources and associated traditional knowledge, as internationally agreed

2.a Increase investment, including through enhanced international cooperation, in rural infrastructure, agricultural research and extension services, technology development and plant and livestock gene banks in order to enhance agricultural productive capacity in developing countries, in particular least developed countries

2.b Correct and prevent trade restrictions and distortions in world agricultural markets, including through the parallel elimination of all forms of agricultural export subsidies and all export measures with equivalent effect, in accordance with the mandate of the Doha Development Round

2.c Adopt measures to ensure the proper functioning of food commodity markets and their derivatives and facilitate timely access to market information, including on food reserves, in order to help limit extreme food price volatility 


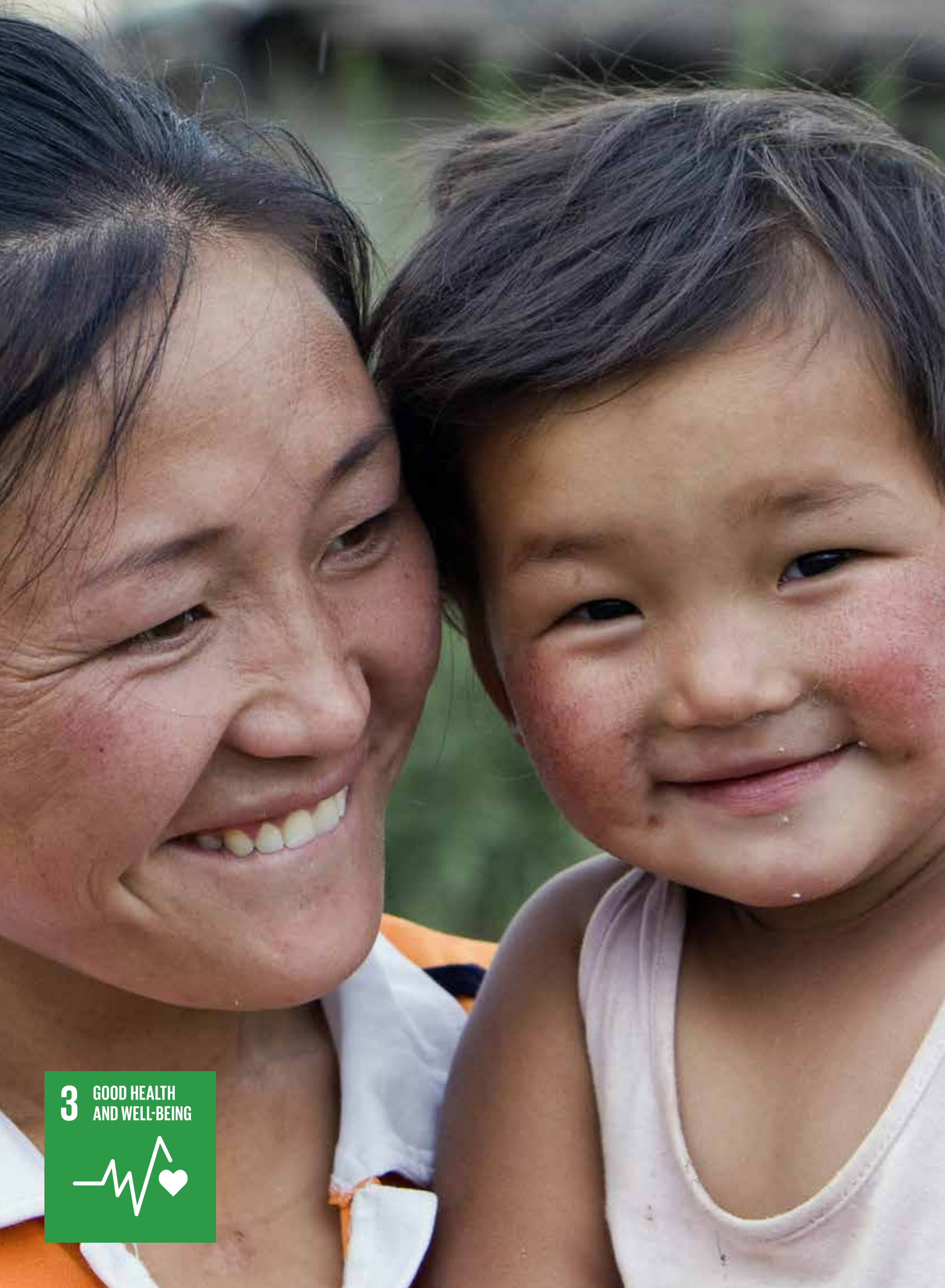




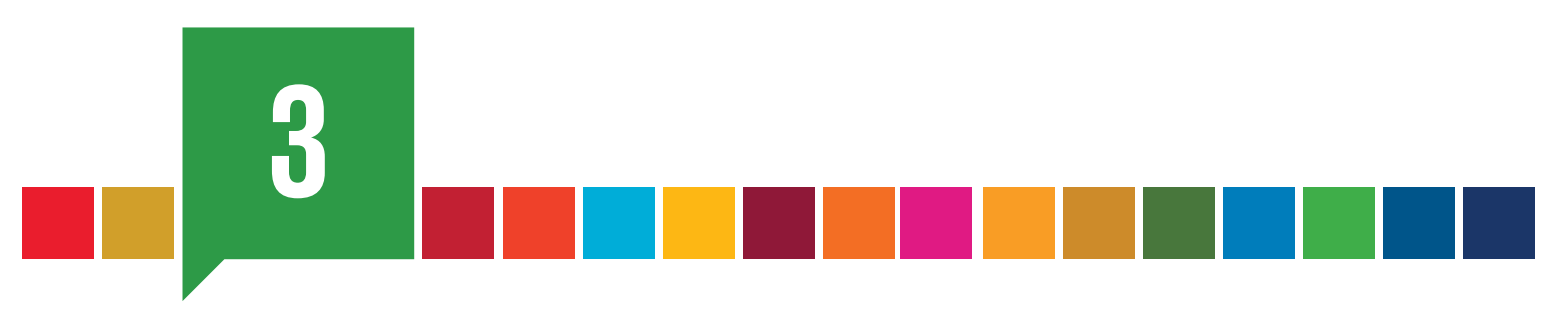

\section{Ensure healthy lives and promote well-being for all at all ages}

\section{OUTLOOK}

The Asia-Pacific region has made significant strides in expanding access to health services and universal health care coverage. In some countries, rates of maternal and child mortality are persistently high, and such diseases as HIV and tuberculosis (TB) continue to disproportionately impact marginalized groups of people. Access to affordable quality health care and medicines is constrained and unequal in many countries. The region also faces increasing incidence of non-communicable diseases, accompanied by population ageing, cross-border epidemics, antimicrobial resistance, natural disasters and environmental pollution. These emerging trends are likely to place considerable financial and capacity constraints on health care systems.

A Mongolian family in Tarialan Soum, Uvs Aimag, where UNDP supports community centres that focus on activities for Mongolian herding families 


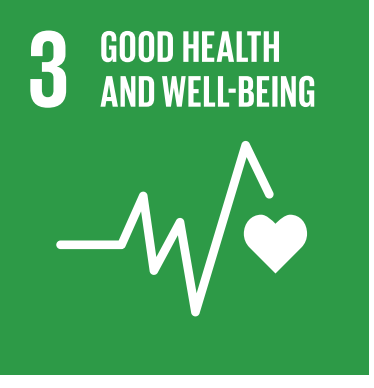

\section{Ensure healthy lives and promote well-being for all at all ages}

\section{INSIGHTS}

- A large proportion of the region's population is not protected by comprehensive health coverage and suffers from medical impoverishment (less than 10 per cent of the population is covered by health insurance in Cambodia, India and the Solomon Islands). ${ }^{1}$ Despite some progress, the level of government spending on health care is too low in many countries in the region to achieve universal health care coverage (the average for member countries of the Association of Southeast Asian Nations was 1.9 per cent of GDP in 2014, ${ }^{2}$ while the World Health Organization (WHO) recommends a GDP spending level of at least 5 per cent).

- Out-of-pocket spending as a share of total health care expenditure is still high in many countries (at 63.3 per cent in Bangladesh and 71.3 per cent in Myanmar in 2012, for example). Expanding publicly financed universal health coverage would reduce out-of-pocket expenses.

- There is critical need for an overall framework of social protection strengthening. Opportunities to raise capital for investment in health care institutions need to be pursued. Policies are needed that expand social protection for disability, critical illnesses and funeral expenses for people who are poor or extremely vulnerable to the financial impact of morbidity and mortality risks.

- Achieving universal health coverage and health equity requires dedicated attention and investments to address the unique barriers and needs of the most vulnerable and excluded people, including persons affected by HIV, persons with disabilities, slum dwellers, indigenous people and migrants.

- Promoting gender equality and the human rights of vulnerable groups can lead to markedly better disease prevention, treatment and care.

- With Asia moving towards an aged society, it is important to accelerate the development and expansion of pension, health care and other essential social protection schemes to support healthy ageing.

- Evidence shows that improving skilled birth attendance can significantly reduce maternal and child deaths when reinforced with training for health workers and by educating mothers. Non-health interventions that improve the health environment, such as access to clean water and sanitation, energy and formal education for girls and increased female representation in governance, also contribute towards reducing child and maternal health complications. ${ }^{3}$ 


\section{BRIGHT SPOTS}

\section{Declining malaria incidence}

- The estimated 14.4 million malaria cases in South-East Asia in 2015 represented a 54 per cent decline in the estimated incidence between 2010 and 2015. The estimated 1.2 million malaria cases in the Western Pacific in 2015 represented a 30 per cent decline in the estimated incidence between 2010 and $2015 .{ }^{4}$

\section{HOTSPOTS}

\section{Maternal mortality and maternal health care services}

- In 2015 , the number of maternal deaths per 100,000 live births was 117 , a decrease of 64 per cent from 323 in 1990. Increases have been observed in the percentage of live births attended by a skilled health professional in Asia and the Pacific, from 57 per cent in 1990 to 75 per cent in 2014. ${ }^{6}$

\section{Child mortality}

- The number of children estimated to die before reaching 5 years of age was 35 per 1,000 live births in 2015-a decrease of 60 per cent, from 88 per 1,000 live births in 1990.

\section{Health care}

- In 2011, per capita spending on health by governments was as low as $\$ 4$ (PPP) per person in low-income economies in the region. ${ }^{8}$ The WHO recommends a minimum of $\$ 44$ per person per year to provide basic life-saving health care.

\section{Communicable diseases}

- Although there has been much progress in the region in slowing down the prevalence of HIV, TB and malaria and achieving the MDG targets, current efforts must accelerate to achieve the SDG targets of ending these diseases by 2030 .

- TB: Globally in 2015, there were an estimated 10.4 million cases of TB, most of them occurring in the Asia-Pacific region ${ }^{9}$ (at 61 per cent). China, India and Indonesia alone accounted for 45 per cent of the global cases. ${ }^{10}$ The emergence of multidrug-resistant TB is a serious concern in the region.

- HIV: There was an estimated 300,000 new HIV infections in the region in 2015 , with young people accounting for 37 per cent of them. ${ }^{11}$ Although this is a decline of 36 per cent since 2000 , the rate of progress has slowed, with only a 5 per cent reduction in new infections between 2010 and $2015 .^{12}$ Less than half of the people living with HIV are accessing life-saving treatment in Asia and the Pacific. HIV infection is increasing among men who have sex with men in urban areas. Coverage to prevent mother-to-child transmission (at 30 per cent) in 2014 was far below the global average (at 67 per cent). ${ }^{13}$ 


\section{Non-communicable diseases and environmental health}

- Cardiovascular diseases, cancer, diabetes and chronic obstructive pulmonary diseases: These four diseases are now the major causes of death and disability in Asia and the Pacific. Noncommunicable diseases also create tremendous economic burden. China and India, for example, were projected to experience economic losses of $\$ 558$ billion and $\$ 237$ billion (PPP), respectively, due to non-communicable diseases between 2005 and 2015. ${ }^{14}$ Risk factors include a diet high in fat, sugar and salt as well as tobacco use, the harmful use of alcohol and physical inactivity.

- Tobacco use: In 2013, there were an estimated 728 million tobacco users-40.3 per cent of males and 3.9 per cent of females aged 15 years or older. ${ }^{15}$ Tobacco use is the leading noncommunicable disease risk factor and is higher among lower socioeconomic groups. Exposure to second-hand smoke exacerbates household air pollution, particularly jeopardizing the health of women and children.

- Alcohol consumption: The per-person intake of alcohol in the region increased from 4.5 litres in 2005 to 5.6 litres in 2015. This is still below the global average, which increased from 6 litres to 6.3 litres per person per year over the same period. ${ }^{16}$

- Air pollution: Unhealthy environments are causing significant health problems in the region, including more than 7 million deaths annually, ${ }^{17}$ mostly attributable to both outdoor and indoor air pollution, including second-hand smoke.

- Road traffic accidents: Of the ten countries in 2013 with the largest number of fatalities per 100,000 people, two were in Asia and the Pacific: Thailand, at 36.2 per 100,000 population, and the Islamic Republic of Iran, at 32.1 fatalities per 100,000 population.

\section{EMERGINGISSUES}

- Health systems are facing critical capacity and financial gaps to meet the challenges of ageing populations, non-communicable diseases, cross-border epidemics, antimicrobial resistance, environmental pollution, climate change impacts and natural disasters.

- Rapid urbanization, trade liberalization and the increasing cross-border movement of people in the region are changing the risk and disease profiles. While these trends are often associated with negative health consequences, they also offer new opportunities to promote better care and to protect health through multisector partnerships.

- Multilateral and bilateral free trade and investment treaty negotiations are increasingly containing provisions that can restrict countries from implementing health-promoting measures, such as tobacco control and access to affordable medicines. Careful health impact assessments of these trade agreements are needed for policymakers and the public to make informed decisions.

- Key populations at higher risk of HIV infection, including men who have sex with men, transgender people, people who use drugs and sex workers, continue to be left behind in access to appropriate health information and services, such as comprehensive prevention programmes. Countries need to invest more in creating enabling environments (including removing legal and policy barriers) for access to services. The expansion of highly discriminatory and punitive approaches to drug use, sexual orientation, gender identity and other marginalized populations, coupled with shrinking civil society space, threaten to undermine or reverse the progress of recent years. 


\section{- Coherent intercountry linked early warning and mobilization systems will be essential to address emerging and potential pandemics.}

\section{TARGETS}

3.1 By 2030, reduce the global maternal mortality ratio to less than 70 per 100,000 live births

3.2 By 2030, end preventable deaths of newborns and children under 5 years of age, with all countries aiming to reduce neonatal mortality to at least as low as 12 per 1,000 live births and under-5 mortality to at least as low as 25 per 1,000 live births

3.3 By 2030, end the epidemics of AIDS, tuberculosis, malaria and neglected tropical diseases and combat hepatitis, water-borne diseases and other communicable diseases

3.4 By 2030, reduce by one third premature mortality from non-communicable diseases through prevention and treatment and promote mental health and well-being

3.5 Strengthen the prevention and treatment of substance abuse, including narcotic drug abuse and harmful use of alcohol

\subsection{By 2020, halve the number of global deaths and injuries from road traffic accidents}

3.7 By 2030, ensure universal access to sexual and reproductive health-care services, including for family planning, information and education, and the integration of reproductive health into national strategies and programmes

3.8 Achieve universal health coverage, including financial risk protection, access to quality essential health-care services and access to safe, effective, quality and affordable essential medicines and vaccines for all

3.9 By 2030, substantially reduce the number of deaths and illnesses from hazardous chemicals and air, water and soil pollution and contamination

3.a Strengthen the implementation of the World Health Organization Framework Convention on Tobacco Control in all countries, as appropriate

3.b Support the research and development of vaccines and medicines for the communicable and non-communicable diseases that primarily affect developing countries, provide access to affordable essential medicines and vaccines, in accordance with the Doha Declaration on the TRIPS Agreement and Public Health, which affirms the right of developing countries to use to the full the provisions in the Agreement on Trade-Related Aspects of Intellectual Property Rights regarding flexibilities to protect public health, and, in particular, provide access to medicines for all

3.c Substantially increase health financing and the recruitment, development, training and retention of the health workforce in developing countries, especially in least developed countries and small island developing States

3.d Strengthen the capacity of all countries, in particular developing countries, for early warning, risk reduction and management of national and global health risks 


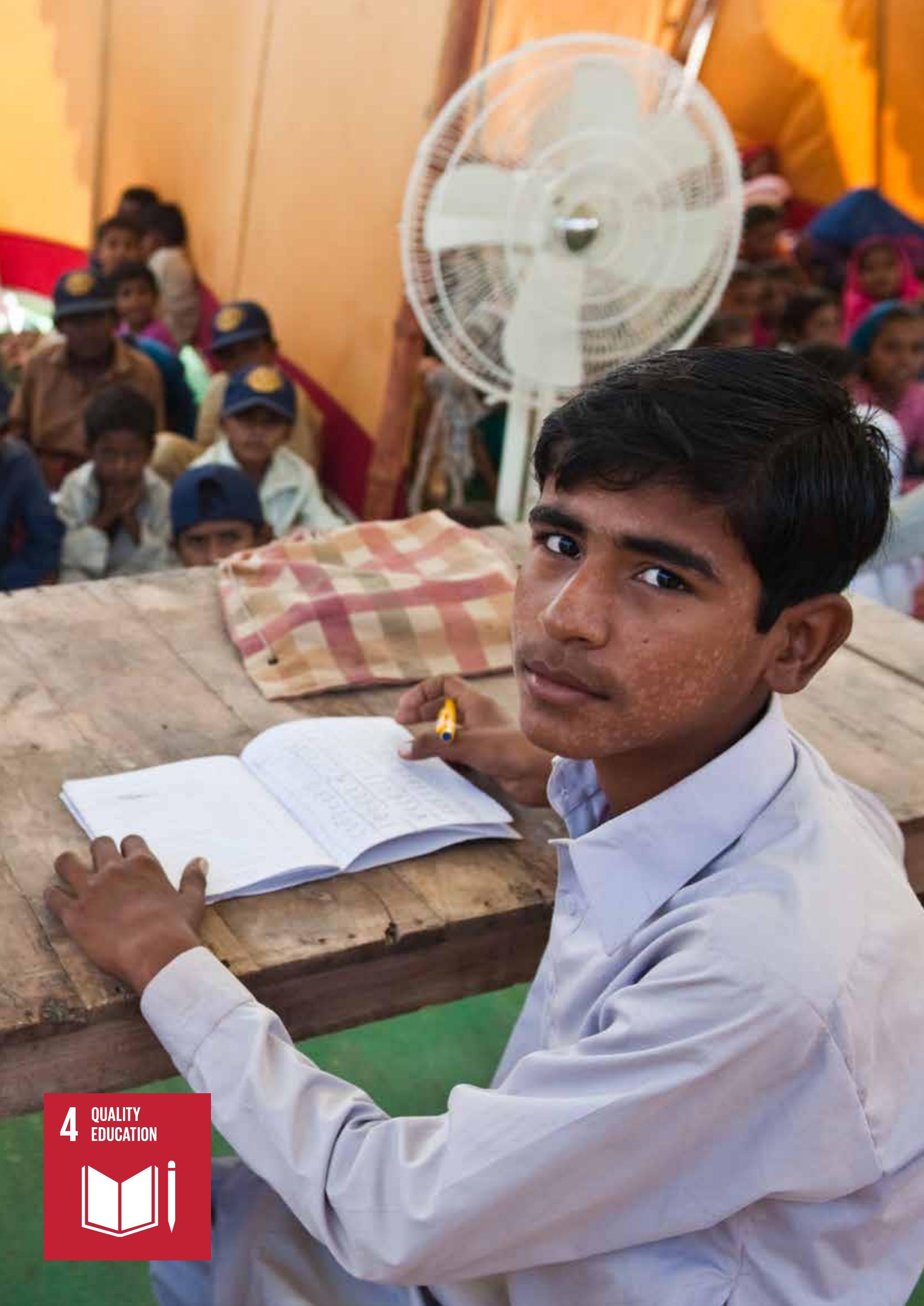




\section{4}

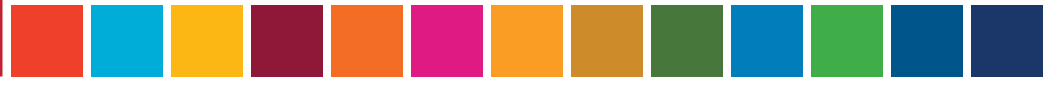

\section{Ensure inclusive and equitable}

quality education and promote lifelong learning opportunities for all

\section{OUTLOOK}

The prospects for achieving this goal have a good start due to near-universal primary school enrolment and gender parity achievements to date in Asia and the Pacific overall. Ensuring equal access for marginalized groups and quality dimensions of education will be major challenges, with investment needed to provide lifelong learning opportunities, the development of relevant skills and early childhood development and care.

으 THEPHOTO

Only 15 years old, Shahzaman Nazar Ali taught at a school run by volunteers at the Pakistan Navy Relief Camp during the 2009 floods 


\section{Ensure inclusive and equitable quality education and promote lifelong learning opportunities for all}

\section{INSIGHTS}

- Despite increases in government spending on education in some countries of the region, education is still not a priority in many national budgets. In some countries, international assistance makes a significant supplement to the education budget.

- Available data indicate that 44 countries in the region received official development assistance (ODA) for education from the donor community in 2014. Among them, India received the largest share of donors' education assistance in terms of total United States dollars received per year, followed by Pakistan, China and Bangladesh. ${ }^{1}$

- Early childhood interventions are necessary for all children because of the enormous impact on their readiness for primary school and then their transition to secondary education. Yet, large numbers of children continue to miss out, and inequality in opportunity is increasing for the poorest children, for children living in rural areas or slums and for children marginalized due to a disability or their ethnic origin, religion or language. ${ }^{2}$

- Children with disabilities make up a considerable proportion of marginalized groups. Early childhood services to assess and address disability in children as soon as possible helps children and their families improve their life outcomes.

- In many countries where the most important shortcomings in investment in education are seen, in particular the least developed countries, investment in education falls far short of the required level. Low human capital formation is a barrier to development.

- Technical and vocational education and training helps strengthen job-relevant skills and is becoming a strategic priority in many countries but lacks investment needed to improve. Greater employer engagement and better workplace linkages are key priorities. 


\section{BRIGHTSPOTS}

\section{Primary and secondary education}

- Most countries in the region have achieved or are close to achieving universal primary education. Nearly 78 million children across the region were enrolled in pre-primary education in 2013, almost double the number for 1999. The six most significant increases (latest year compared with 1999) ${ }^{3}$ were recorded in China, Kazakhstan, Malaysia, Mongolia, Nepal and Viet Nam, where the gross enrolment ratios increased by $40-75$ percentage points. ${ }^{4}$

- The transition from primary to secondary education and the completion of secondary education is also on the rise

\section{HOTSPOTS}

\section{Quality of education and relevant skills}

- Based on available data, 18.2 million children were not enrolled in primary school in the past few years. ${ }^{5}$ Bhutan, Cambodia, India, Tajikistan and TimorLeste recorded the lowest ratios of pre-primary enrolment, ranging from 10 per cent to 18 per cent. ${ }^{6}$

- Based on the latest data available, a considerable number of teachers in pre-primary, primary and secondary education do not have the necessary teacher training qualifications. In addition, the percentage of trained teachers in primary education is quite low in some countries, such as Bangladesh, Solomon Islands and Vanuatu. ${ }^{7}$

- Quality of education is a major concern. Results of international assessments indicate that learning outcomes in many developing countries in the region have stagnated, except in Viet Nam. Disparities between girls and boys in terms of education outcomes (proficiency level in mathematics, science and reading) are significant. ${ }^{8}$

- ODA to education is declining, with total assistance to the region dropping to $\$ 4.7$ billion in 2014 from $\$ 5.1$ billion in $2011 .^{9}$

- Traditional models of higher education institutions in Asia and the Pacific lack the ability to innovate and create knowledge-and to find innovative applications of what is learned, which is problematic in a dynamic region with a rapidly increasing number of middle-income countries. ${ }^{10}$ 


\section{EMERGINGISSUES}

- There is rising demand to strengthen the post-basic education system as primary education completion rates improve, coupled with demographic trends. The transition of many developing countries to middle-income status is creating pressure to improve employability and close skill gaps among graduates.

- Skills development will have an increasingly important role in regional integration, which will provide countries with a valuable opportunity for shared prosperity and more even economic development.

- Disadvantaged and marginalized youth will need mentoring to improve their learning outcomes and to provide the industry with a diverse talent pipeline.

- The education system is only as good as the teachers who provide hands-on instruction. Additional teachers are needed for universal primary and secondary education to replace or supplement the teaching workforce.

- There is a need to increase innovative financing on education projects by strengthening collaboration between governments, financial institutions and other stakeholders, including civil society, and by expanding access and the use of personal savings and loan products to help families plan for and finance education costs.

- Collaboration across the industry and exploration of good practices for advancing financial literacy is needed, both in schools and for men and women, including marginalized groups (such as people with disabilities, indigenous peoples and racial and ethnic minorities).

- Expanding health, life and livelihood insurance coverage in developing countries will enable reducing the risk of children missing school due to untreated medical conditions because they must care for a sick relative or they must undertake livelihood activities to supplement household income.

- Small and medium-sized enterprise entrepreneurs will need accounting, customer service and business management training, thereby building loyalty with their customers and helping them to attract new ones.

\section{TARGETS}

4.1 By 2030, ensure that all girls and boys complete free, equitable and quality primary and secondary education leading to relevant and effective learning outcomes

4.2 By 2030, ensure that all girls and boys have access to quality early childhood development, care and pre-primary education so that they are ready for primary education

4.3 By 2030, ensure equal access for all women and men to affordable and quality technical, vocational and tertiary education, including university

4.4 By 2030, substantially increase the number of youth and adults who have relevant skills, including technical and vocational skills, for employment, decent jobs and entrepreneurship 
4.5 By 2030, eliminate gender disparities in education and ensure equal access to all levels of education and vocational training for the vulnerable, including persons with disabilities, indigenous peoples and children in vulnerable situations

4.6 By 2030, ensure that all youth and a substantial proportion of adults, both men and women, achieve literacy and numeracy

4.7 By 2030, ensure that all learners acquire the knowledge and skills needed to promote sustainable development, including, among others, through education for sustainable development and sustainable lifestyles, human rights, gender equality, promotion of a culture of peace and non-violence, global citizenship and appreciation of cultural diversity and of culture's contribution to sustainable development

4.a Build and upgrade education facilities that are child, disability and gender sensitive and provide safe, non-violent, inclusive and effective learning environments for all

4.b By 2020, substantially expand globally the number of scholarships available to developing countries, in particular least developed countries, small island developing States and African countries, for enrolment in higher education, including vocational training and information and communications technology, technical, engineering and scientific programmes, in developed countries and other developing countries

4.c By 2030, substantially increase the supply of qualified teachers, including through international cooperation for teacher training in developing countries, especially least developed countries and small island developing States 


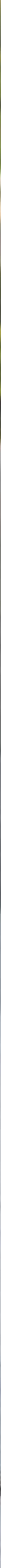




\section{5}

\section{Achieve gender equality and empower all women and girls}

\section{OUTLOOK}

Achieving this goal will be challenging. Gender-based inequalities continue to be a pivotal obstacle for the region, with women facing multiple forms of discrimination, socioeconomic and cultural barriers and serious threats to their security, which violate their basic rights and constrain their capacities. Gender gaps in economic and political participation persist, while pervasive trends in violence against women and girls remain an issue of grave concern. Without urgent action in advancing gender equality, the realization of the entire 2030 Agenda hangs in the balance.

\section{THEPHOTO}

A scholarship student at Ewha Woman's University in the Republic of Korea, the world's largest educational institute for women 


\section{Achieve gender equality and empower all women and girls}

\section{INSIGHTS}

- Aside from being a stand-alone goal, gender equality is a cross-cutting priority for the 2030 Agenda and the SDGs.

- Lessons learned from the Millennium Development Goals experience reiterate the proven synergy between gender equality and development outcomes. Available data highlight a general correlation between a country's ranking on the Human Development Index and the Gender Inequality Index. ${ }^{1}$

- Women have an integral role in helping countries achieve all the SDGs, with many targets specifically acknowledging women's empowerment as both the aim and part of the solution.

- Despite notable progress in some areas, such as girls' access to education (covered under SDG 4 ), stark gender-based disparities remain in relation to rights and opportunities.

- Comprehensive policy and legislative action is essential to protect women's rights across the region. Even though all but three countries have ratified the Convention on the Elimination of All Forms of Discrimination Against Women and an increasing number are adopting legal and policy measures on gender equality, challenges remain in terms of enforcement, implementation and monitoring.

- Monitoring progress and evidence-based policymaking are hampered by the non-availability of sufficient sex-disaggregated data for a number of countries in the region. Lack of comparable data (concepts, definitions and data collection methods vary across countries) hampers monitoring.

\section{BRIGHT SPOTS}

\section{Political participation}

- A few countries stand out for substantial improvements in their share of female parliamentary representation: It jumped in Nepal from 5.9 per cent in 2000 to 29.5 per cent in 2015, in Kyrgyzstan from 1.4 per cent to 23.3 per cent and in Singapore from 4.3 per cent to 25.3 per cent over the same time period.

- As of 2015, Timor-Leste had the highest rate of representation of women in national parliament, at 38.5 per cent, helped along no doubt by an electoral law requirement that one in every three candidates on political lists is a woman. New Zealand had the second-highest such representation in 2015 , at 31.4 per cent of seats held by women. ${ }^{2}$ 


\section{Sexual and reproductive health}

- As of 2015 , the demand for family planning satisfied with modern methods in the Asia-Pacific region stood at 86.3 per cent for married or in-union women of reproductive age, slightly above the 82.2 per cent world average. Despite progress at the regional level, this figure masks disparities in several countries, and challenges remain in reaching under served populations, particularly women residing in rural and remote areas, as well as adolescents and youth. ${ }^{3}$

\section{HOTSPOTS}

\section{Violence against women and girls and harmful practices}

- The incidence of child marriage as well as early and forced marriage persists. In Bangladesh, 52 per cent of women aged 20-24 years in 2013 had married before they were 18 years old, with approximately 18 per cent married before they were 15 years old. In countries as diverse as Bhutan, Kiribati, Marshall Islands, Pakistan, Papua New Guinea, Solomon Islands, Thailand and Vanuatu, between a quarter and a fifth of women had married before they were $18 .{ }^{4}$

- In countries for which data are available, a large proportion of women experienced physical and/or sexual intimate partner violence in the 12 months prior to data collection. According to available Demographic and Health Surveys and World Health Organization Studies, 44 per cent of women in Vanuatu in 2009, 36 per cent of women in Kiribati in 2008 and 31 per cent of women in Timor-Leste in 2010 reported such violence. ${ }^{5}$

\section{Women's economic participation, access to economic resources and unpaid care work}

- Gender parity in employment does not exist in most countries, regardless of the economic development level. ${ }^{6}$ Female-to-male labour force participation ratios have declined in the region, from 0.67 in 1990 to 0.61 in 2015.

- Women earn less than men in almost all Asian and Pacific countries with available data (the Philippines and Turkey are the exceptions). In more than half of these countries, the gender wage gap reported in 2015 was more than 20 per cent. ${ }^{8}$

- The large share of unpaid care and domestic work shouldered by women exposes them to time poverty and contributes to the persistent genderbased gap in labour force participation, activity rates and wages. Available data in some countries in the region indicate that women engage in ten times as much unpaid work as men. ${ }^{9}$ However, accurate comparisons are difficult to make due to non-standardized survey methodologies.

- Less than 10 per cent of agricultural land holders are women in Bangladesh (at 4.6 per cent in 2008), Fiji (at 3.6 per cent in 2009), the Islamic Republic of Iran (at 5.9 per cent in 2002) and Nepal (at 8.1 per cent in 2002). ${ }^{10}$ 
Discriminatory inheritance legislation remains an obstacle for women, with widows and daughters having no inheritance rights at all in some countries in the region. ${ }^{11}$

\section{Equal opportunity for leadership}

- Although overall trends show some progress, women's political representation levels in Asia and the Pacific continue to be low compared with other regions. In the majority of countries, women hold less than 30 per cent of seats in their national parliament. ${ }^{12}$ Overall in $2015,18.1$ per cent of national parliament seats in the region were held by women, up from only 13.1 per cent in 2000. ${ }^{13}$

- Data compiled in 2015 for 20 developing Asian economies showed that while women accounted for 40 per cent of the workforce, only 14.4 per cent of corporate boardroom members and senior managers were women. Kazakhstan and Viet Nam had a respectable female representation in private sector top management, each exceeding 30 per cent. The female share of top management in South-East Asia was above the Asian average of 14.4 per cent, led by the Philippines, Malaysia and Singapore. ${ }^{14}$

\section{EMERGINGISSUES}

- Changing demographic trends are likely to have differentiated impacts on men and women. With ageing populations in countries across the region, older women, owing to their longer life expectancy than men as well as their heightened vulnerability to neglect, violence and abuse, will need specific policy attention as a group that is often left "furthest behind". An ageing population also puts an added care burden on the shoulder of women. Another demographic concern is the specific needs of women and girl refugees and migrants who face additional challenges of psychosocial stress and trauma, health complications, physical harm, injury and multiple forms of discrimination, violence and exploitation, particularly when they are in transit.

- As the world's most disaster-prone region, Asia and the Pacific experience an immense toll caused by natural disasters, with women and girls more likely to be disproportionately affected due to sociocultural norms and the inequitable distribution of roles, resources and power. Continued efforts are needed towards ensuring gender-sensitive disaster risk reduction strategies that take into account both women's vulnerabilities in specific contexts while also highlighting their potential capabilities to prepare, confront and recover from disasters.

\section{TARGETS}

5.1 End all forms of discrimination against all women and girls everywhere

5.2 Eliminate all forms of violence against all women and girls in the public and private spheres, including trafficking and sexual and other types of exploitation

5.3 Eliminate all harmful practices, such as child, early and forced marriage and female genital mutilation 
5.4 Recognize and value unpaid care and domestic work through the provision of public services, infrastructure and social protection policies and the promotion of shared responsibility within the household and the family as nationally appropriate

5.5 Ensure women's full and effective participation and equal opportunities for leadership at all levels of decision-making in political, economic and public life

5.6 Ensure universal access to sexual and reproductive health and reproductive rights as agreed in accordance with the Programme of Action of the International Conference on Population and Development and the Beijing Platform for Action and the outcome documents of their review conferences

5.a Undertake reforms to give women equal rights to economic resources, as well as access to ownership and control over land and other forms of property, financial services, inheritance and natural resources, in accordance with national laws

5.b Enhance the use of enabling technology, in particular information and communications technology, to promote the empowerment of women

5.c Adopt and strengthen sound policies and enforceable legislation for the promotion of gender equality and the empowerment of all women and girls at all levels 
S.

R.

(1)

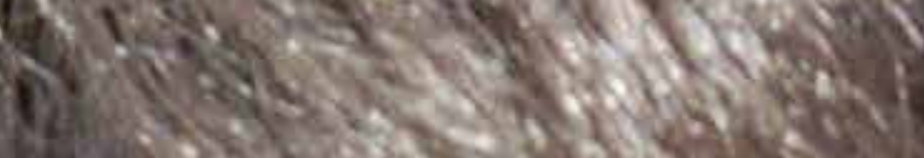

Nowite

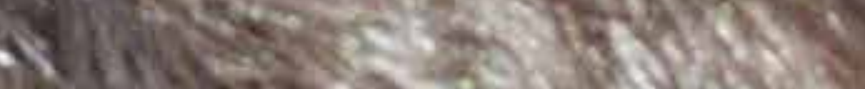

Whis

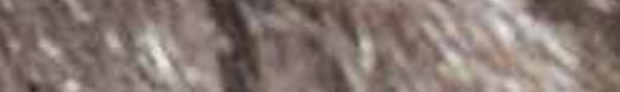

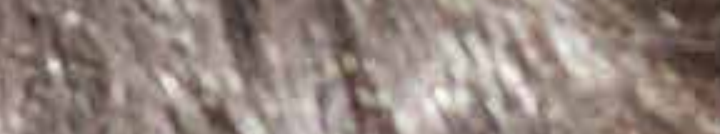

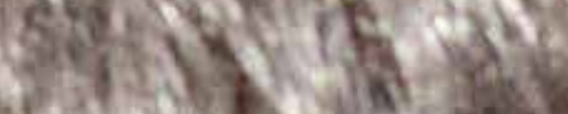

Q

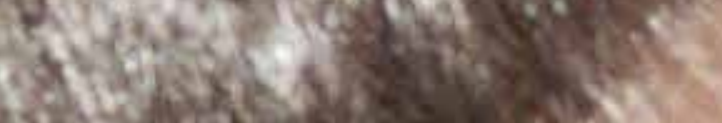

$6 \log ^{2}(2)$

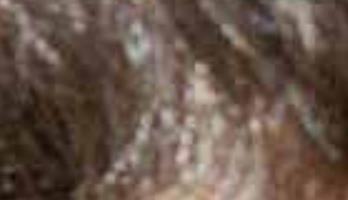

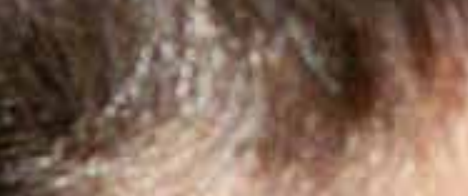
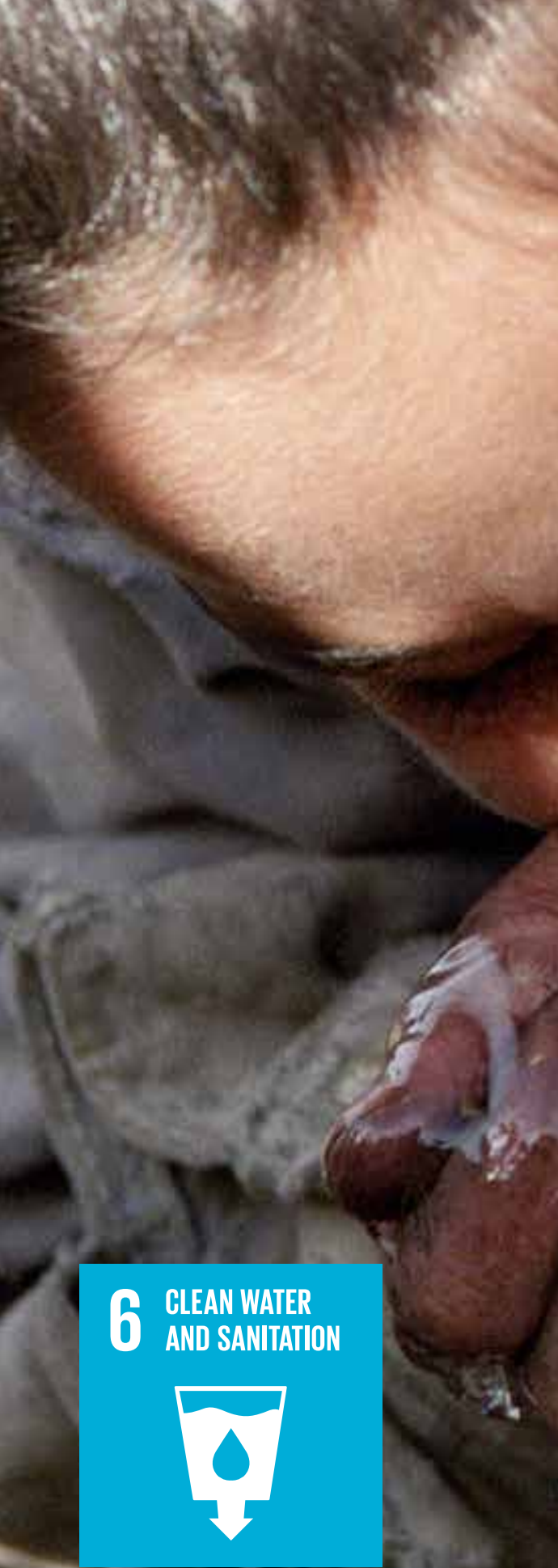

8
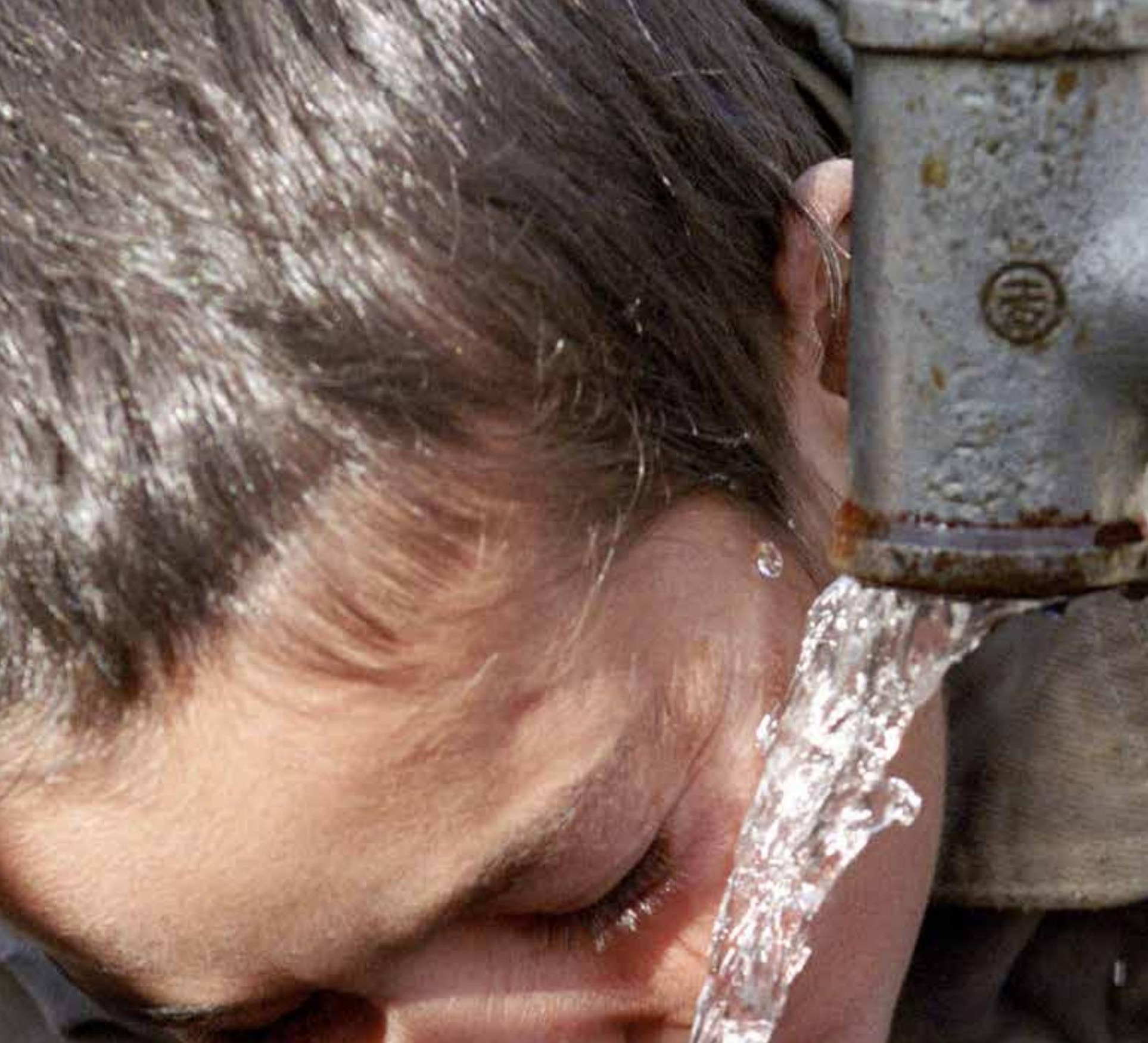

8 


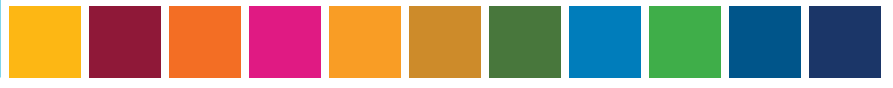

\section{Ensure availability and sustainable management of water and sanitation for all}

\section{OUTLOOK}

Critical challenges lie ahead for achieving this goal. Some 277 million people still lacked access to safe drinking water in 2015, ' and more than 80 per cent of the wastewater generated in developing countries was not treated. ${ }^{2}$ Around half of the rural population in the region has no access to improved sanitation. These conditions, compounded by the impacts of climate change (which might limit freshwater resources), will hamper achievement of SDG 6 if left unattended. Threats related to water scarcity, poor water quality and inadequate sanitation will negatively impact the achievement of other SDGs as well.

\section{THEPHOTO}




\section{Ensure availability and sustainable management of water and sanitation for all}

\section{INSIGHTS}

- Water quality and affordability and the regularity of water services are key considerations in the region.

- Many cities face vulnerabilities due to outdated water supply systems and inadequate capture and storage capacity, which will exacerbate water shortages in both large and medium-sized cities.

- There is unequal access to improved sanitation between urban and rural areas, with a gap that was approximately 30 per cent in 2015; since 2000, the proportion of people in rural areas with access to sanitation has increased by 0.8 per cent per annum, compared with 0.5 per cent per annum in urban areas.

- Compared with the other countries in the region, countries with special needs ${ }^{3}$ are lagging behind in areas related to attaining SDG 6 and relying on external financial support from donors. For example, in 2014 , more than $\$ 325$ million in official development assistance (ODA) was directed to provide a basic drinking water supply and basic sanitation, mainly in SouthEast, South and South-West Asian countries, while \$17.7 million in ODA was given to China and $\$ 1.2$ million in ODA was received by the Democratic People's Republic of Korea. In the same year, $\$ 14.8$ million in ODA for basic drinking water supply and basic sanitation was directed to Pacific countries, while $\$ 59$ million was directed to countries in North and Central Asia. ${ }^{4}$

\section{BRIGHT SPOTS}

\section{Access to safe water and sanitation}

- In 2015, almost 94 per cent of the region had access to an improved drinking water supply. ${ }^{5}$ The number of people using an improved drinking water supply increased by 20 per cent in South and South-West Asia and by 19 per cent in South-East Asia between 1990 and $2015 .{ }^{6}$

- Localized solutions towards wastewater treatment, such as decentralized wastewater treatment systems, are emerging at the technical and policy levels in South and South-East Asia.

- Singapore has achieved 100 per cent wastewater treatment, the only country to do so in the region.

- Integrated water resources management indicators are applied in Asian members of the Organisation for Economic Co-operation and Development, as proposed by the Network of Asian River Basin Organizations, which is a good practice for monitoring SDG target 6.5. 
- Basin management systems are in place, such as in the Mekong River Basin and the Aral Sea Basin, although they need to be further scaled up to ensure efficiency of water resource use and management.

\section{HOTSPOTS}

\section{Water quality and efficiency}

- A considerable proportion of wastewater in the region is not treated before being discharged or reused. Between 80 per cent and 90 per cent of the wastewater generated in the region's developing countries was discharged directly into water bodies without any treatment as of 2015.7 In Indonesia, only 14 per cent of wastewater was treated, while it was only 10 per cent in the Philippines, 9 per cent in India and 4 per cent in Viet Nam. ${ }^{8}$

- If groundwater resources continue to be used beyond sustainable limits, agricultural production in the region will be threatened, which is the main source of income for the majority of the region's population. ${ }^{9}$ The increase in demand for irrigation has led to severe groundwater stress in some areas. $^{10}$

- One in ten rural residents is still without access to safe drinking water, and around 30 per cent of the population living in landlocked developing countries in 2015 did not have access to safe drinking water. ${ }^{11}$

- Some countries in the region withdraw unsustainable proportions of their freshwater supply, exceeding half of the total water availability. For instance, the withdrawal rates were 51.1 per cent in Tajikistan in 2006, 67.8 per cent in the Islamic Republic of Iran in 2004 and 74.4 per cent (the highest) in Pakistan in 2008. ${ }^{12}$

\section{Access to improved sanitation}

- In 2012, 1.52 billion people in the region did not have access to improved sanitation. ${ }^{13}$ As of 2015 , around half of the rural population in the region had no access to it, and in some developing countries, the urban-rural difference was widening. An estimated 900 million people have gained access to improved sanitation since $2000 .^{14}$ 


\section{EMERGINGISSUES}

- Rapid urbanization is challenging the ability of municipalities to keep up with the rapidly growing demands on their freshwater supply.

- Saltwater is intruding in delta and coastal areas due to sea-level rise, requiring increased pumping for irrigation and for water supply.

- Persistent organic pollutants and other hazardous chemicals are making their way into water sources, like rivers, lakes and groundwater.

- The decline of glacier lakes is affecting Asia's major river basins, where 1.2 billion people live.

- Climate change impacts on the region's water resources will be important, but socioeconomic drivers on water requirements will also have a significant role in future management decisions. ${ }^{15}$

- Seven of the world's 15-biggest abstractors of groundwater are in Asia and the Pacific, and research suggests that groundwater use will increase by 30 per cent by $2050 .{ }^{16}$ The future impacts on quality, availability and the environment will pose important challenges for certain countries in the region.

\section{TARGETS}

6.1 By 2030, achieve universal and equitable access to safe and affordable drinking water for all

6.2 By 2030, achieve access to adequate and equitable sanitation and hygiene for all and end open defecation, paying special attention to the needs of women and girls and those in vulnerable situations

6.3 By 2030, improve water quality by reducing pollution, eliminating dumping and minimizing release of hazardous chemicals and materials, halving the proportion of untreated wastewater and substantially increasing recycling and safe reuse globally

6.4 By 2030, substantially increase water-use efficiency across all sectors and ensure sustainable withdrawals and supply of freshwater to address water scarcity and substantially reduce the number of people suffering from water scarcity

6.5 By 2030, implement integrated water resources management at all levels, including through transboundary cooperation as appropriate

6.6 By 2020, protect and restore water-related ecosystems, including mountains, forests, wetlands, rivers, aquifers and lakes

6.a By 2030, expand international cooperation and capacity-building support to developing countries in water-and sanitation-related activities and programmes, including water harvesting, desalination, water efficiency, wastewater treatment, recycling and reuse technologies

6.b Support and strengthen the participation of local communities in improving water and sanitation management 


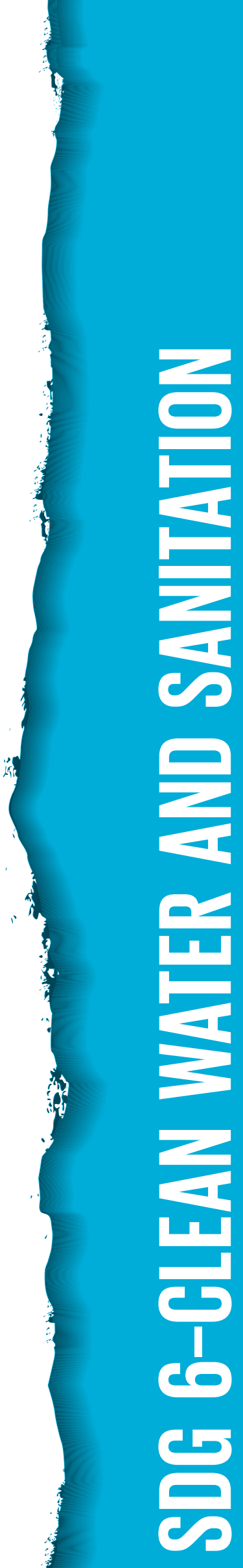




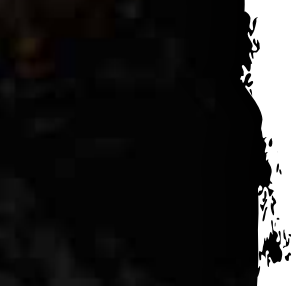 \\ . \\ .

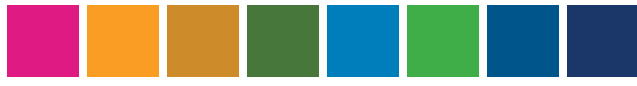 \\ Ensure access to affordable, reliable, sustainable and modern energy for all}

\section{OUTLOOK}

Progress in providing access to electricity is promising, though the universal provision of clean cooking solutions remains challenging. Energy demand in the Asia-Pacific region is rapidly growing, making it difficult to increase substantially the share of renewable energy in the energy mix despite major increases in absolute terms. Improvements in energy efficiency are encouraging, however, and efforts to manage consumption alongside efforts to promote increasingly lowcost clean technologies, reinforced by climate-related policies, hold significant promise.

\section{THEPHOTO}




\section{INSIGHTS}

\section{Access to energy services}

- In 2014, the average total electrification rate reached 92 per cent in the region, up from 75 per cent in 1990 . Since 2000 , the proportion of the region's population with primary reliance on clean fuels and technology for cooking has remained steady, at a 2 per cent annual growth rate. Yet, the gap in the provision of universal access to clean fuels and technology is not closing. By 2014, an average of only 57 per cent of the total population primarily relied on clean fuels and technology. ${ }^{1}$

\section{The share of renewable resources in the energy mix}

- Notwithstanding the growth of renewable energy utilization in the region in absolute terms, its share in the total primary energy supply is in a steady downward trajectory, with a decrease from 16.7 per cent in 1990 to 12.6 per cent in 2014. ${ }^{2}$ Fossil fuel-based economies in Asia have a relatively low rate of renewable energy uptake, and they have tended to further decrease the renewable energy share in the energy mix due to rapid growth in energy consumption. However, renewable energy installation is making significant gains in power production.

\section{Energy efficiency}

- Energy intensity has steadily declined across the region since the mid-1990s.

- The degree of energy efficiency uptake varies substantially across all of the ESCAP member States, yet the energy intensity indicator is gradually converging at a median value of 130 kilograms of oil equivalent per $\$ 1,000$ of GDP (in 2005 PPP). ${ }^{3}$

\section{Technological foresight, adequate economic incentives and strategic policy planning}

- Energy sectors within the region are transforming, with policy measures being implemented and the pace of reforms depending upon national circumstances and development priorities. Strong political commitment at the national level, broadly supported by regional and global initiatives, is warranted to pursue energy source and trade flow diversification, to improve energy efficiency, to enhance energy access and increase renewable energy sources in the energy mix and to launch new investments needed to support these processes. However, the results are uneven across the region.

- Despite significant technological innovation in many industries, international energy cooperation efforts to deploy innovative technologies are limited due to lack of a coherent approach among the region's countries. Progress could be facilitated by maximizing links with implementation of SDG 9 (on industry, innovation and infrastructure) and SDG 13 (on climate finance, capacity building and climate policy implementation). 
- Nearly all ESCAP member States have adopted and implemented policy incentives that will support attainment of the SDG 7 targets, such as those regarding access, energy efficiency and renewable energy. Most topperforming countries in the SDG 7 context have specific measures and programmes that facilitate further improvements in national energy systems while intensifying actions towards achievement of the targets.

\section{BRIGHT SPOTS}

\section{Access to energy services}

- Universal access to electricity has been achieved in many countries within the region, with many countries making significant gains. However, the region is extremely diverse, and the rate of electrification varies from country to country. Of the region's ESCAP member States, 31 countries have reached 100 per cent electrification, while the others mostly need time to finalize the electrification process under self-sustainment. Access to electricity has increased. Access to non-solid fuels and technology is also increasing. ${ }^{4}$

\section{Renewable energy}

- The potential in hydropower, solar and wind indicates potential for further renewable energy development and deployment in the region.

- The shares of such renewable energy sources as solar and solid biofuels (although the latter is widely considered as a non-clean source) are gaining higher use rates for electricity generation.

- Significant potential exists for enhanced international energy cooperation and development of cross-border power infrastructure that can transfer electricity surpluses, including those generated from renewable energy sources.

- The cost of electricity from renewable energy sources, such as solar and wind, are all declining globally and regionally. Renewable technologies have become the most economical solution for new capacity in a growing number of countries. In 2015, for the first time, investment in renewable energy (excluding large hydro) was greater in developing economies than in industrialized countries, with a large part of the record-breaking investment taking place in China. ${ }^{5}$

\section{Energy efficiency}

- The region's energy intensity decreased by an average of 3.1 per cent per year between 2000 and 2014, compared with 1.3 per cent per year globally. ${ }^{6}$ Energy-efficient technology in lighting, appliances and buildings continues to progress. A relative decoupling between total primary energy supply and GDP growth-with absolute decoupling referring to the ability of economies 
to grow without a corresponding increase in energy consumption-can be observed in the region as a result of multiple factors, including energy-efficiency improvements.

\section{HOTSPOTS}

\section{Access to energy services}

- Electrification rate indicators reveal a twofold decrease in the gap between urban and rural populations, from 94 per cent and 65 per cent in 1990 to 98 per cent and 83 per cent in 2014, respectively. Yet, in 2014, approximately 417 million people were still without access to electricity.

\section{Greening the energy mix}

- While the amount of renewable energy in Asia and the Pacific has increased in absolute terms and costs have fallen, the relative share of renewable energy in the region has fallen, from 16.7 per cent in 1990 to 12.6 per cent in $2014,{ }^{8}$ as a result of the high demand for energy in the region as a whole, which has often been met with domestic fossil fuel resources.

\section{Improved energy connectivity}

- There is still huge room for improvement in energy connectivity in the region. Except for a few sound regional cross-border energy infrastructure projects, the progress has been moderate in the region. Cross-border energy infrastructure investments remain low, despite the growing demand for energy and existing beneficial opportunities waiting to be tapped from the regional energy trade. ${ }^{9}$

\section{EMERGINGISSUES}

- Distributed generation and new electricity supply business models are and will keep on being a game changer for improving the quality of energy services.

- New energy storage systems and off-grid and smart-grid technologies can provide opportunities to substantially increase access to modern energy services in rural and remote areas.

- Fossil fuels will continue to dominate in an energy mix that is striving to meet the everincreasing energy demand in Asia and the Pacific.

- Although energy efficiency continues to improve globally and regionally and despite significant advances, the progress needs further acceleration in order to contribute to the achievement of SDG 7.

- Enhanced regional energy connectivity provides new opportunities for integration of renewable energy sources to the utility grid.

- There may be advantages and benefits to enhancing cross-border energy trade as one of the means of implementation for the SDG 7 targets, as long as these initiatives take into account social and environmental impacts. 


\section{TARGETS}

7.1 By 2030, ensure universal access to affordable, reliable and modern energy services

7.2 By 2030, increase substantially the share of renewable energy in the global energy mix

7.3 By 2030, double the global rate of improvement in energy efficiency

7.a By 2030, enhance international cooperation to facilitate access to clean energy research and technology, including renewable energy, energy efficiency and advanced and cleaner fossil-fuel technology, and promote investment in energy infrastructure and clean energy technology

7.b By 2030, expand infrastructure and upgrade technology for supplying modern and sustainable energy services for all in developing countries, in particular least developed countries, small island developing States and landlocked developing countries, in accordance with their respective programmes of support 


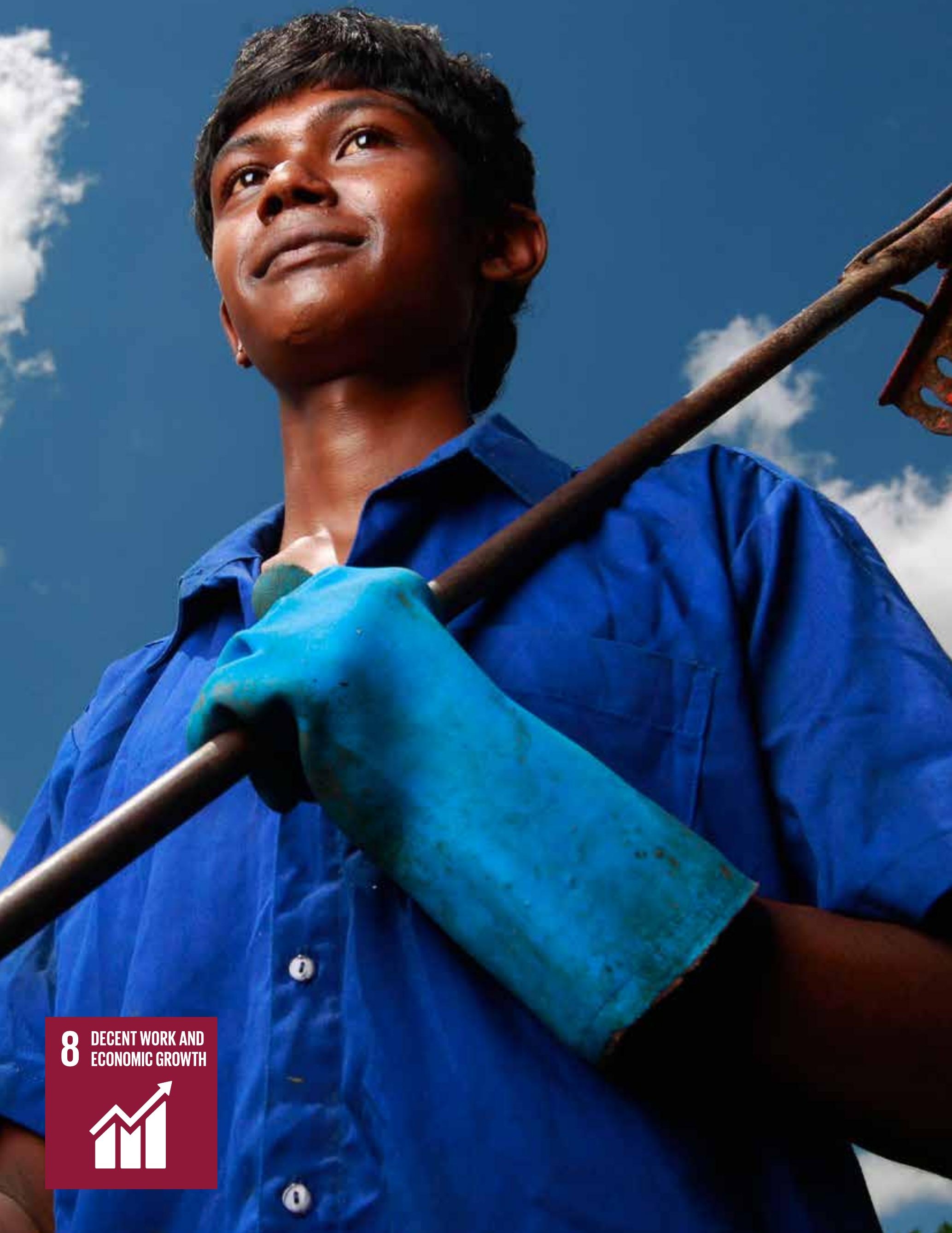




\section{8}

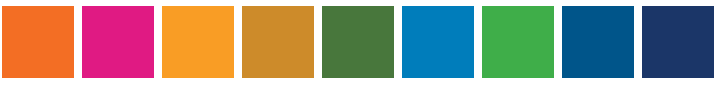

\section{Promote sustained, inclusive}

and sustainable economic

\section{growth, full and productive} employment and decent work for all

\section{OUTLOOK}

The prospects for achieving this goal are challenging-relatively strong economic growth has not translated into commensurate increases in decent jobs and higher wages for most economies. A large proportion of the labour force is informally employed, and youths are facing high unemployment or underemployment rates. At the same time, exploitive labour practices and disregard for labour rights and workplace safety are prevalent across the region. Social protection policies, including minimum wage provisions and social transfer programmes, are critical in meeting the needs of the most vulnerable populations.

A young worker benefits from improved waste management at the Integrated Resource Recovery Centre in Matale, Sri Lanka 

employment and decent work for all

\section{口 INSIGHTS}

- Since the 1990s, the Asia-Pacific region has experienced growth in both productivity and employment. Employment growth, however, has not kept pace with the economic growth. Providing employment and decent work for all workers is critical to ensure that growth is inclusive and sustainable and to lift millions of people out of extreme poverty in the region.

- The lack of decent jobs leads to vulnerable employment, which is more likely in informal employment characterized by low productivity, low pay and no social protection.

- The majority of people who are income poor and food insecure inhabit rural areas and rely on agriculture for their survival. A broad economic transformation is required to absorb surplus labour from agriculture to the non-agriculture sector. This would include strategies to raise agricultural productivity.

- Many economies need to accelerate efforts to expand their productive capacities, particularly in the least developed countries and the landlocked developing countries.

- Providing financial opportunities to small and medium-sized enterprises (SMEs) is important for fostering productivity. SMEs accounted for 98 per cent of all enterprises in Asia and, from 2007 to 2012, employed two-thirds of each national labour force, on average. ${ }^{1}$

- Trade can significantly expand demand for manufacturing products as well as services, thereby facilitating growth and providing an impetus for structural transformation, which is an important driver of development and productivity growth. The Aid for Trade initiative was introduced in 2005 to help developing countries fully engage in trade and maximize their gains by reducing trade costs and by reforming their trade and related policies to build the supplyside capacity and infrastructure that they need to compete internationally.

\section{BRIGHTSPOTS}

\section{Economic growth and financial inclusion}

- Several least developed countries in South-East Asia are growing rapidly. For instance, per capita incomes expanded annually by an average of 8.4 per cent in Myanmar and around 6.2 per cent in the Lao People's Democratic Republic and 5.3 per cent in Cambodia from 2006 to 2015..$^{2}$

- Access to financial services-as measured by the proportion of adults (15 years and older) with an account at a bank or other financial institution or with a mobile money service providerhas increased significantly in the region, from 48.8 per cent in 2011 to 61.4 per cent in 2014. ${ }^{3}$ 
- Labour productivity in terms of real GDP per employed person has risen over time. $^{4}$

- Several economies of the region have policies that link the quality of growth to better environmental performance, such as "green growth".

\section{Employment}

- The region's unemployment rate in the formal sector is low and has remained stable, within the range of 4.5 per cent to 4.6 per cent, since 2011. ${ }^{5}$ On average, there is little differential between female and male unemployment rates in the region's developing countries, when compared with developing regions elsewhere in the world. ${ }^{6}$ Yet, pronounced disparities in the unemployment rates (as of 2015) between men and women exist in some economies, such as Fiji, the Islamic Republic of Iran, New Caledonia, Pakistan and Sri Lanka. ${ }^{7}$

\section{Means of implementation}

- The developing countries of the region experienced an increase in Aid for Trade commitments, from $\$ 9.9$ billion in 2005 to $\$ 23.9$ billion in 2014 , while the actual disbursements increased from $\$ 6.6$ billion to $\$ 17.2$ billion. ${ }^{8}$ They experienced a higher annual average increase in Aid for Trade, compared with the global trends in Aid for Trade, both in terms of commitments and disbursements.

\section{HOTSPOTS}

\section{Economic growth and financial inclusion}

- The per capita economic growth in the region's least developed economies, landlocked developing countries and small island developing countries, averaged only 5.1 per cent from 2006 to 2015. Countries in the Pacific that have least developed country status had the lowest growth rates: On average per year from 2006 to 2015, the per capita growth in Tuvalu and Vanuatu was less than 2.2 per cent and 0.7 per cent, respectively, and it even contracted in Kiribati, by an annual average of 0.5 per cent. ${ }^{9}$

- The least developed countries in Asia and the Pacific have not, as a group, reached the target of 7 per cent growth of real GDP since 2009, with an average growth rate of 6.1 per cent over the past five years. ${ }^{10}$

- Productivity growth also declined in the aftermath of the 2008 economic and financial crises. Growth of total factor productivity declined by more than half in developing countries in the region, averaging at slightly less than 1 per cent between 2008 and 2014, while growth in labour productivity declined by more than 30 per cent, to 3.9 per cent in $2013 .^{11}$

- Despite increases in nominal wage levels, growth in real wages has not been commensurate with the increases in productivity levels. ${ }^{12}$ 
- The proportion of adults with an account at a bank or other financial institution is lowest in the least developed countries and has only increased marginally, from 26.8 per cent in 2011 to 27.3 per cent in $2014 .{ }^{13}$

- Although many countries adopted green growth strategies, overall the economic growth of the region is resource intensive (see the SDG 12 profile).

\section{Employment}

- Employment growth in 2015 was merely 1.1 per cent, or 21.3 million jobs, for the Asia-Pacific region. Job growth was notably weak, at 0.3 per cent, in East and North-East Asia, weighed down by both the decelerating economy in China and its ageing population. ${ }^{14}$

- A large portion of the region's labour force is employed in the informal economy.

- There are low levels of female labour force participation in some areas of the region, particularly in South and South-West Asia.

- The youth unemployment rate in 2016 was estimated at 11.8 per cent and was higher for young women (at 12.1 per cent) than for men (at 11.7 per cent). ${ }^{15}$ Young people in the labour force are 3.8 times more likely to be unemployed than their adult counterparts in the region. By subregion, the ratio is even higher in South-East Asia (at 5.4 times) and South Asia (at 4 times). ${ }^{16}$

\section{EMERGINGISSUES}

- The growing numbers of workers in vulnerable employment ${ }^{17}$ and working poor people require more attention. The vulnerable employment rate in the Asia-Pacific region was 54 per cent, or 1 billion workers, in 2015. ${ }^{18}$

- Women are more likely than men to be in vulnerable employment. In South Asia, for example, the vulnerable employment rate in $\mathbf{2 0 1 5}$ was $\mathbf{7 9 . 5}$ per cent for women and 71.1 per cent for men. In South-East Asia, the rates were 60.1 per cent and 52.8 per cent, respectively. ${ }^{19}$

- The share of young workers from poor households, defined as earning less than the $\$ 1.90$ extreme poverty line, was 14.2 per cent in 2015 , compared with 9.8 per cent for adult workers. The working youth poverty rate was particularly high in South Asia, at 21.6 per cent. ${ }^{20}$

- Active labour market policies are required to support employment in times of economic slowdown and to foster a virtuous cycle in which good-quality education and vocational training increases labour productivity that translates into higher wages. 


\section{TARGETS}

8.1 Sustain per capita economic growth in accordance with national circumstances and, in particular, at least 7 per cent gross domestic product growth per annum in the least developed countries

8.2 Achieve higher levels of economic productivity through diversification, technological upgrading and innovation, including through a focus on high-value added and labourintensive sectors

8.3 Promote development-oriented policies that support productive activities, decent job creation, entrepreneurship, creativity and innovation, and encourage the formalization and growth of micro-, small- and medium-sized enterprises, including through access to financial services

8.4 Improve progressively, through 2030, global resource efficiency in consumption and production and endeavour to decouple economic growth from environmental degradation, in accordance with the 10-Year Framework of Programmes on Sustainable Consumption and Production, with developed countries taking the lead

8.5 By 2030, achieve full and productive employment and decent work for all women and men, including for young people and persons with disabilities, and equal pay for work of equal value

8.6 By 2020, substantially reduce the proportion of youth not in employment, education or training

8.7 Take immediate and effective measures to eradicate forced labour, end modern slavery and human trafficking and secure the prohibition and elimination of the worst forms of child labour, including recruitment and use of child soldiers, and by 2025 end child labour in all its forms

8.8 Protect labour rights and promote safe and secure working environments for all workers, including migrant workers, in particular women migrants, and those in precarious employment

8.9 By 2030, devise and implement policies to promote sustainable tourism that creates jobs and promotes local culture and products

8.10 Strengthen the capacity of domestic financial institutions to encourage and expand access to banking, insurance and financial services for all

8.a Increase Aid for Trade support for developing countries, in particular least developed countries, including through the Enhanced Integrated Framework for Trade-related Technical Assistance to Least Developed Countries

8.b By 2020, develop and operationalize a global strategy for youth employment and implement the Global Jobs Pact of the International Labour Organization 


\section{Build resilient infrastructure, promote inclusive and sustainable industrialization and foster innovation}

\section{OUTLOOK}

Projected investment needs in Asia and the Pacific are substantial. Hundreds of millions of people in the region still live without access to basic infrastructure, including for connectivity. Improving the quality of available infrastructure, its resilience and environmental sustainability needs to be a priority for the region.' Progress on inclusive and sustainable industrialization and innovation has been uneven. Gaps are widening in some areas, such as manufacturing value-added per capita. Concerted efforts to keep developing countries from missing out on the New Industrial Revolution are needed. . While much remains to be done, support for innovation as measured in terms of spending on research and development has increased. 


\section{INSIGHTS}

- There has been significant progress in expanding infrastructure services in energy generation, information and communications technology (ICT), transport, water and water sanitation, but gaps remain in meeting the basic needs of poor households, particularly in rural areas, and in ensuring the quality and environmental sustainability of the built infrastructure. Connectivity infrastructure, such as roads and air transport, increased, while rail transport became less of a priority in the region.

- Infrastructure helps reduce poverty when integrated with wider development efforts. For example, road connectivity, energy and irrigation services can ease and reduce the costs of access to markets and jobs, but the impacts on poverty tend to be greater when combined with efforts to improve access to health care and education.

- An inclusive and sustainable industrial sector drives economic growth, job creation, social stability and environmental protection. Careful, inclusive and sustainable industrialization policies can help soothe critical issues confronting many countries in the region around jobs, informal employment, the middle-income trap and low levels of entrepreneurship. These policies should be designed to address sources of social grievances, such as youth unemployment, inequalities in the nature and extent of women's and men's engagement in economic activity and rapid urbanization.

- The contribution of manufacturing to employment creation is well documented. As of 2014, global employment in manufacturing was estimated at 482 million jobs, which included jobs in the formal and informal sectors as well as in manufacturing-related services. ${ }^{3}$ Manufacturing in emerging economies often combines high relative productivity with a strong capacity to absorb labour. $^{4}$

- Manufacturing also supports sustained rapid growth: Driven by manufacturing industries, 13 developing economies globally (several from the Asia-Pacific region) managed to sustain rapid growth of at least 7 per cent for 25 years or more after World War II. ${ }^{5}$ Structural changes in the economy, in conjunction with industrialization, can support the emergence of a middle class. Some countries in the region have substantially expanded the share of GDP from services sector, however, before expanding the role of industry. ${ }^{6}$

- Real value added per unit of $\mathrm{CO}_{2}$ emission tends to increase with rising real GDP per capita across various manufacturing industries. Measures to support the transition from dirty manufacturing to relatively green are needed. ${ }^{7}$

- Innovation has a critical role in driving industrialization, particularly in middle- and highincome countries. The New Industrial Revolution offers tremendous opportunities in the region, with countries like China, Japan, New Zealand and the Republic of Korea global leaders in additive manufacturing. ${ }^{8}$ 


\section{BRIGHT SPOTS}

\section{Upgrading infrastructure and retrofitting industries}

- There was significant progress in expanding infrastructure services in energy generation, ICT and transport. Access to paved roads increased from 16.3 kilometres to 19.2 kilometres per 10,000 people between 2009 and 2014. ${ }^{9}$ Air transport in terms of passengers carried grew at a faster rate than freight, at an annual average of 7 per cent in 2000 and of 3 per cent in $2015 .^{10}$

- As countries shift to less energy-intensive industries, cleaner fuels and technologies and stronger energy-efficiency policies, they are experiencing a reduction in the carbon intensity of their GDP.

- Access to ICT in the region has increased substantially. Nowadays, 45 per cent of the population in Asia and the Pacific has access to the internet through mobile telephones, and this is expected to increase to 70 per cent by $2020 .^{11}$ The majority of the region's population (62 per cent, or 2.5 billion people) subscribed to mobile telephone services in 2015 , a rate on par with the global average of 63 per cent. ${ }^{12}$

\section{Inclusive and sustainable industrialization}

- Asian developing countries have outperformed industrialized countries as well as developing countries in other regions in terms of their share of manufacturing employment in total employment (Asian developing countries' manufacturing employment share grew 73 per cent between 1970 and 2013, reaching a 15.7 per cent share in 2010-2013). ${ }^{13}$ There are five economies in the region (China, India, ${ }^{14}$ Indonesia, Japan and the Republic of Korea) that belong to the world's 15-top manufacturers, which together contribute 78.5 per cent of global manufacturing production. China, with an average annual growth rate of 10.6 per cent between 2005 and 2015 , has emerged as the world's largest manufacturer. ${ }^{15}$

- The creation of formal jobs through industrial development recently gained policy priority. The recognition of industry as a development accelerator has led to a revival of industrial policy, including in Bangladesh (Industrial Policy 2016), China (Made in China 2025), India (Make in India), Indonesia (Master Plan for the Acceleration and Expansion of Indonesia's Economic Development), Japan (New Robot Strategy) and the Republic of Korea (Manufacturing Innovation 3.0).

\section{Innovation}

- Investment in research and development has increased significantly in recent years. The number of researchers in the region has also increased. Continued efforts to support domestic technology development are needed.

- In 2014, research and development expenditure as a percentage of GDP doubled to 2 per cent after remaining relatively flat during the period 2006-2013, albeit at the same level as in 2000-2005. ${ }^{16}$

- The number of researchers rose by 19 per cent, from 686 per million inhabitants in 2000 to 846 in $2010 .{ }^{17}$

\section{HOTSPOTS}

\section{Resilient and sustainable infrastructure}

- The infrastructure investment needs of the region are diverse and substantial—projected by the 
ADB at about $\$ 26$ trillion between 2016 and 2030 in its developing member countries, particularly in power and transport. ${ }^{18}$ Infrastructure stock in ASEAN-5 (Indonesia, Malaysia, the Philippines, Singapore and Thailand) is 30 per cent below the benchmark for advanced economies, which is calculated at 70 per cent of GDP. ${ }^{19}$

- The region's $\mathrm{CO}_{2}$ emissions per one dollar of GDP (2011 PPP) have decreased, from 521.6 grams to 389.3 grams between 1990 and 2013 (a decrease of 25 per cent). However, this is still above the global average (at 312.9 grams in 2013). ${ }^{20}$ Separating economic growth from greenhouse gas emissions growth remains an imperative for the region.

- From 2011 to 2014 , the growth in total goods transported by railway remained relatively flat in Asia and the Pacific, registering at 10,570 million tonnes per kilometre in 2013 and 2014. In South Asia (where data are available), the number of passengers carried by railway peaked in 2007 and has continued to dip since then, settling at 20,619 million passengers per kilometre in 2011-2014. ${ }^{21}$

- Many Asian countries are struggling with the middle-income trap. Infrastructure investment, including to scale up cross-border and transboundary policy and infrastructure development that also considers human well-being, is needed to help countries escape this trap. ${ }^{22}$

\section{Inclusive and sustainable industrialization}

- The per capita gap of manufacturing value added (MVA) between least developing countries and high-income countries is widening. MVA as a proportion of GDP was 23.9 per cent in 2014 in the region on average, ranging from 8.4 per cent in the Pacific to 29.4 per cent in upper-middle-income economies. ${ }^{23}$

- Least developed countries in the region have increased their MVA share over the past 25 years, from 11.9 per cent in 1990 to 18.4 per cent in 2015. There remains a gap, however, with the uppermiddle-income and high-income countries (upper-middle-income countries' MVA share increased from 17.2 per cent to 29.5 per cent, while the share in high-income countries increased from 19.2 per cent to 20 per cent over the same period). ${ }^{24}$

- In terms of per capita MVA, the increase was much greater in high-income economies than in landlocked developing countries and least developed countries. MVA per capita in landlocked developing countries and least developed countries increased from $\$ 180$ to $\$ 235$ and $\$ 28$ to $\$ 112$, respectively, between 1990 and 2015. In high-income countries of the region, it increased from $\$ 4,890$ to $\$ 7,214$ over the same period. ${ }^{25}$

\section{Scientific research and technological capability}

- While investment in research and development has increased overall, it is uneven across countries. The share of GDP spent on research and development in lower-middle-income economies was 0.5 per cent in 2011 while it was 1.7 per cent in upper-middle-income economies in 2014. The figure is larger in high-income economies but with only marginal improvements since 1999 (2.7 per cent). ${ }^{26}$ The Republic of Korea, the leader in this area, spent nearly 4.3 per cent of its GDP on research and development in 2014, almost doubling the share since 1999. ${ }^{27}$

- With 5,544 researchers per one million inhabitants in 2014 (up from nearly 4,146 in 2000, or a 33.7 per cent increase), high-income countries in the region have a considerable edge over upper-middleincome economies, which had on average 1,262 researchers in the same year (up from 788 in 2000, or a 60 per cent increase) At the low end of the scale in 2014 was Georgia, with 585 researchers per one million inhabitants, while the Republic of Korea topped the high end, at 8,899 researchers. ${ }^{28}$ 


\section{EMERGINGISSUES}

- Growth-stimulating policies need to remedy slow employment creation. To a large extent, slow growth is caused by a services sector-driven growth pattern in South Asia; it is also affected by some capital- and energy-intensive manufacturing sectors that entrench the informality of the economies there (see also the SDG 8 profile). The revival of industrial policy in some countries is likely to support the creation of formal jobs, contributing to the reduction of poverty and inequality.

- Against the backdrop of rapid urbanization, holistic policies are needed to tap into cities' potential to concentrate economic activity and attract infrastructure investment and innovation while decreasing local environmental footprints.

- More extensive deployment of clean technologies will increase the likelihood of achieving the proposed SDG target of upgrading infrastructure and retrofitting industries to make them sustainable, with increasingly efficient use of resources and greater adoption of clean and environmentally sound technologies and industrial processes. Additional sources of infrastructure financing are available in the region as new financing institutions to overcome the gaps are created and existing development finance institutions seek to step up their support for sustainable infrastructure.

\section{TARGETS}

9.1 Develop quality, reliable, sustainable and resilient infrastructure, including regional and transborder infrastructure, to support economic development and human well-being, with a focus on affordable and equitable access for all

9.2 Promote inclusive and sustainable industrialization and, by 2030, significantly raise industry's share of employment and gross domestic product, in line with national circumstances, and double its share in least developed countries

9.3 Increase the access of small-scale industrial and other enterprises, in particular in developing countries, to financial services, including affordable credit, and their integration into value chains and markets

9.4 By 2030, upgrade infrastructure and retrofit industries to make them sustainable, with increased resource-use efficiency and greater adoption of clean and environmentally sound technologies and industrial processes, with all countries taking action in accordance with their respective capabilities

9.5 Enhance scientific research, upgrade the technological capabilities of industrial sectors in all countries, in particular developing countries, including, by 2030, encouraging innovation and substantially increasing the number of research and development workers per 1 million people and public and private research and development spending

9.a Facilitate sustainable and resilient infrastructure development in developing countries through enhanced financial, technological and technical support to African countries, least developed countries, landlocked developing countries and small island developing States

9.b Support domestic technology development, research and innovation in developing countries, including by ensuring a conducive policy environment for, inter alia, industrial diversification and value addition to commodities

9.c Significantly increase access to information and communications technology and strive to provide universal and affordable access to the Internet in least developed countries by 2020 


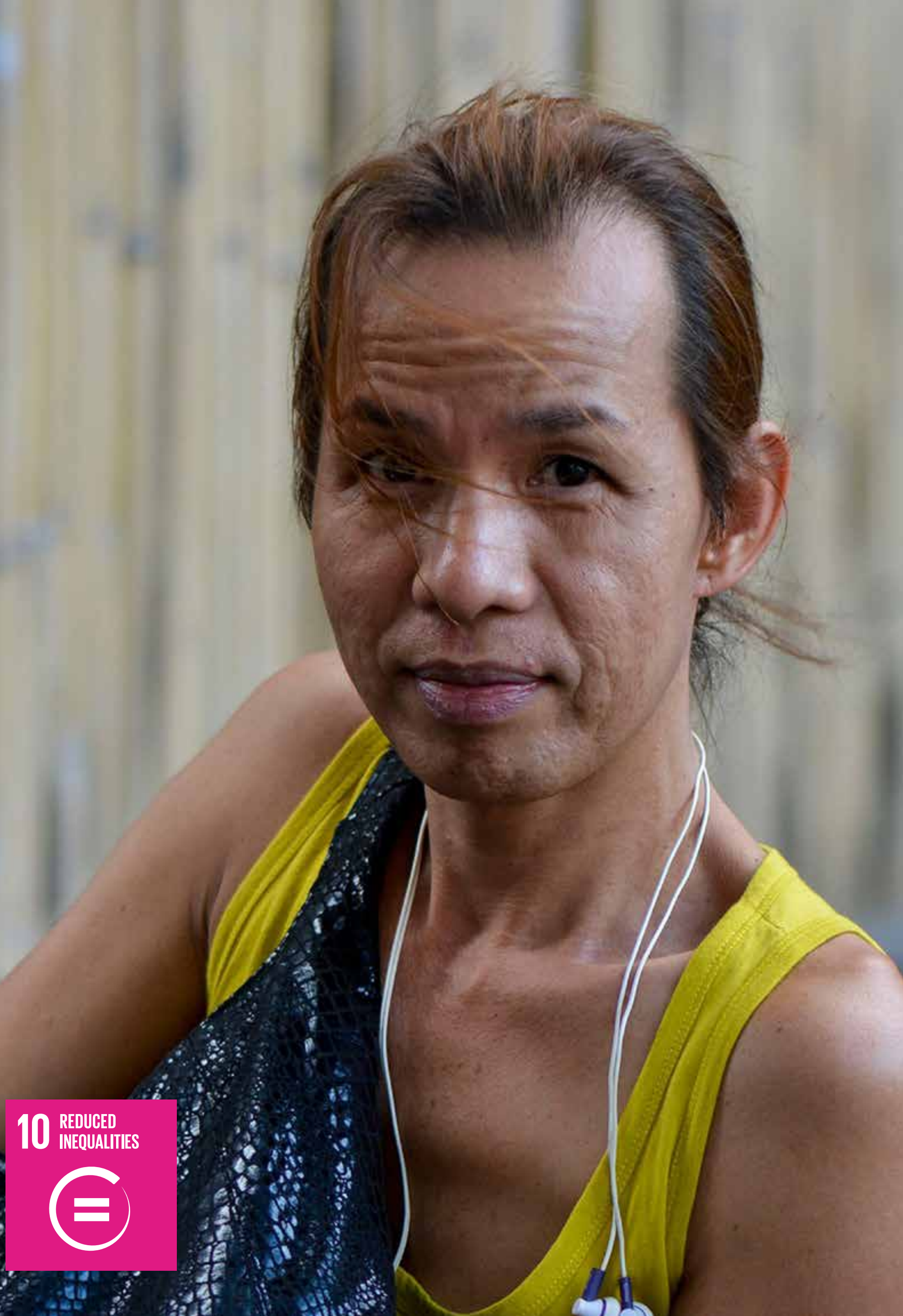




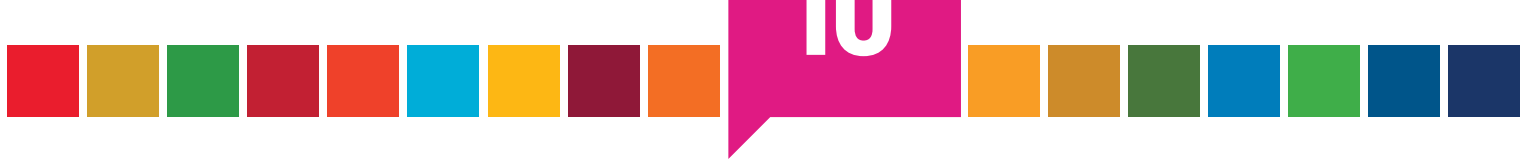

\section{Reduce inequality within and among countries}

\section{OUTLOOK}

While inequalities are increasing for the two most populous countries in the region (China and India), in two-thirds of the countries where data are available, inequalities are decreasing. Stronger efforts need to be taken to correct income and wealth inequalities that are perpetuated by unequal access to opportunities and services. Inequalities among countries in the region are gradually decreasing. However, stronger regional cooperation is needed to seal this trend, including facilitating labour mobility and better monitoring of the impact of investments, including foreign direct investment (FDI), on the poorest and most vulnerable workers.

\section{THEPHOTO}

"I want a whole world without discrimination. Being different means being hurt. On the inside, and maybe the outside as well. I pray it won't always be like that," pleads a man in Manila, Philippines 


\section{Reduce inequality within and among countries}

\section{INSIGHTS}

- "Leaving no one behind" will require, inter alia, greater attention to addressing the root causes of inequalities, including ensuring the social, economic and political inclusion of all people, irrespective of age, sex, disability, race, ethnicity, origin, religion or socioeconomic status; reversing discriminatory practices so that nobody is excluded; a mix of policies (especially fiscal, wage and social protection policies); inclusive growth policies; and to evenly level the playing field for everyone. ${ }^{2}$

- With production patterns becoming more technology and skill intensive, unskilled workers are trapped in poor or near-poor economic situations. Investment in relevant education and job skills is essential.

- Higher inequality is associated with worsening economic, social and environmental outcomes. Investment in the provision of basic services, such as a social protection floor, relevant and high-quality education, energy, water and sanitation infrastructure and nutrition, as outlined in SDGs 1-7, will have long-term benefits on economic growth, social cohesion and environmental sustainability.

- To identify and reach "those furthest behind", there is a need to close the data gap in relation to all the SDG indicators.

\section{BRIGHT SPOTS}

- In 14 of the 21 countries in the Asia-Pacific region for which data are available, "growth rates of household expenditure or income per capita among the bottom 40 per cent of the population and the total population" were higher than the per capita expenditure or income growth rate in these same countries. ${ }^{3}$

- Political commitment to social development has increased in many countries of the region, which has broadened coverage and increased spending on social protection as a result. The 21 countries in the region with available data have increased social protection spending as a share of total government expenditures over the past two decades. ${ }^{4}$

- The available data indicate that the labour share of GDP, comprising wages and social protection transfers, has increased in a few countries in the region, including Australia, Georgia and New Zealand. However, the share is decreasing in East and North-East Asia and in ESCAP high-income economies as a whole. ${ }^{5}$

- Good data are available to describe the proportion of members and voting rights of developing countries in international organizations. ${ }^{6}$ 


\section{HOTSPOTS}

\section{Inequality within countries}

- Economic growth in the region's most populous countries has driven down the poverty headcount significantly. But had the economic gains been more equally shared, poverty reduction would have been even more dramatic. ${ }^{7}$

- Income inequality, as measured by the Gini Index or the Palma Index, has stayed stubbornly high (above the world average) and even increased in China, India, Indonesia, the Philippines and the Russian Federation, among other countries. $^{8}$

- There is no data on the labour share of GDP in the majority of the countries in the region, although it is known that globally the trend is declining. It is possible that countries in which the share is consistently small also exhibit the largest share of workers in informal or vulnerable forms of work). ${ }^{9}$ This observation establishes a link between SDG 10 and SDG 8, particularly target 8.3.

- Circumstantial inequalities, such as unequal access to opportunities and services, including employment, education, health, water, sanitation and energy services, affect mostly women, people living in rural areas, urban slums, persons with disabilities, migrants and ethnic minorities.

\section{Inequality among countries}

- Global FDI inflows to the Asia-Pacific region have plateaued over the past three years, while official development assistance as a share of global assistance decreased from 24.1 per cent in 2009 to 21.1 per cent in $2014 .{ }^{10}$

- Least developed countries in the region have seen FDI inflows almost tripling within the past decade, although the share is still relatively small overall when compared with economies like China and India. ${ }^{11}$ Also, concerns have been raised about the quality of the jobs generated. 


\section{EMERGINGISSUES}

- Countries in the region are "growing old" before "growing rich", which will place a burden on social protection systems and may exacerbate inequalities, both within and between countries.

- The poorest and least educated workers do not have access to decent jobs or to formal employment. They are thus usually not covered by social protection programmes, in particular contribution-based schemes.

- Migrants are generally not included in public welfare schemes. However, stronger regional cooperation is needed to facilitate labour mobility and to better monitor the impact of investments, including FDIs, on the poorest and most vulnerable workers.

\section{(-) \\ TARGETS}

10.1 By 2030, progressively achieve and sustain income growth of the bottom 40 per cent of the population at a rate higher than the national average

10.2 By 2030, empower and promote the social, economic and political inclusion of all, irrespective of age, sex, disability, race, ethnicity, origin, religion or economic or other status

10.3 Ensure equal opportunity and reduce inequalities of outcome, including by eliminating discriminatory laws, policies and practices and promoting appropriate legislation, policies and action in this regard

10.4 Adopt policies, especially fiscal, wage and social protection policies, and progressively achieve greater equality

10.5 Improve the regulation and monitoring of global financial markets and institutions and strengthen the implementation of such regulations

10.6 Ensure enhanced representation and voice for developing countries in decision-making in global international economic and financial institutions in order to deliver more effective, credible, accountable and legitimate institutions

10.7 Facilitate orderly, safe, regular and responsible migration and mobility of people, including through the implementation of planned and well-managed migration policies

10.a Implement the principle of special and differential treatment for developing countries, in particular least developed countries, in accordance with World Trade Organization agreements

10.b Encourage official development assistance and financial flows, including foreign direct investment, to States where the need is greatest, in particular least developed countries, African countries, small island developing States and landlocked developing countries, in accordance with their national plans and programmes

10.c By 2030, reduce to less than 3 per cent the transaction costs of migrant remittances and eliminate remittance corridors with costs higher than 5 per cent 


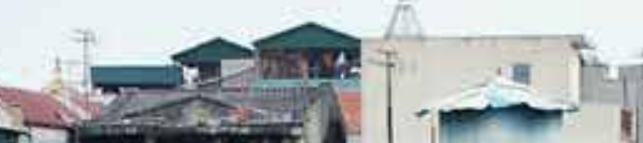

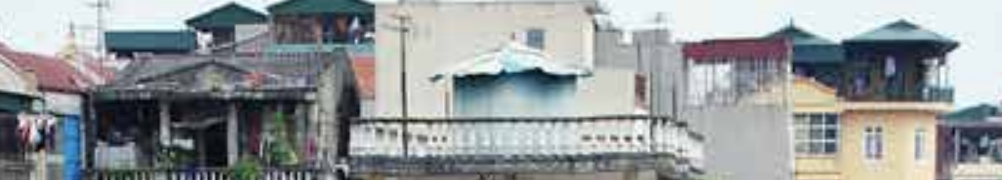
Ther

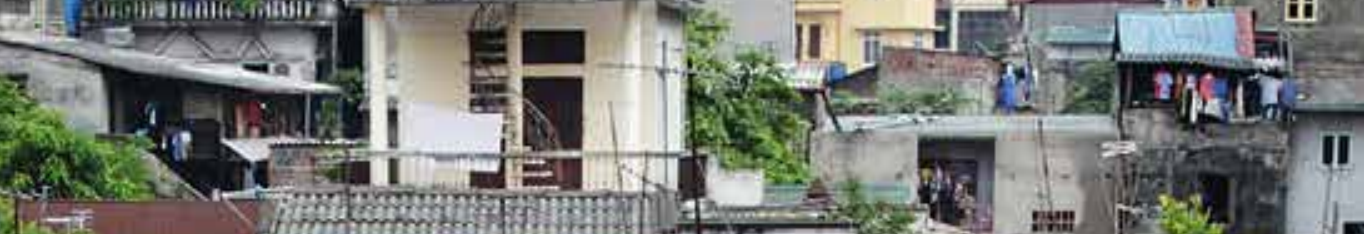
$\underbrace{2}_{1}$

8

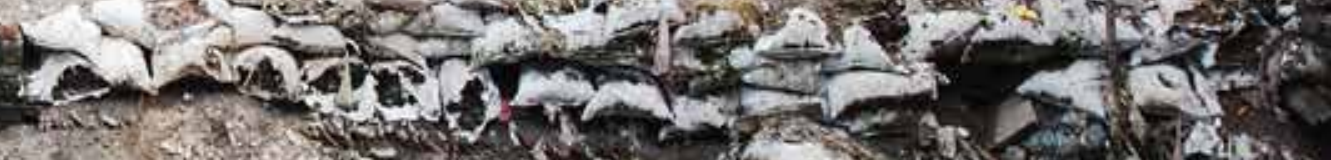
.

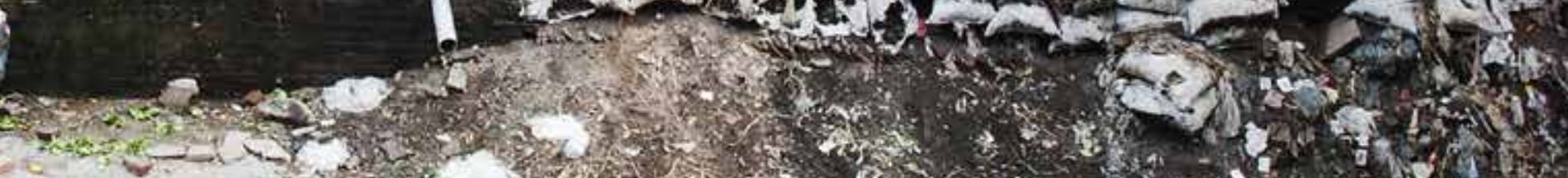

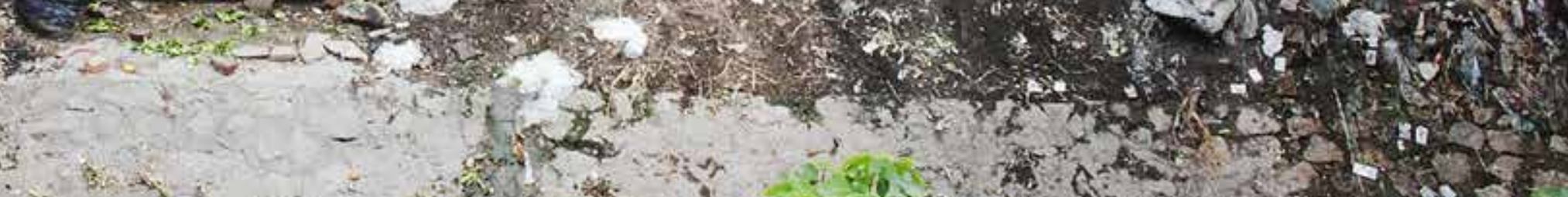

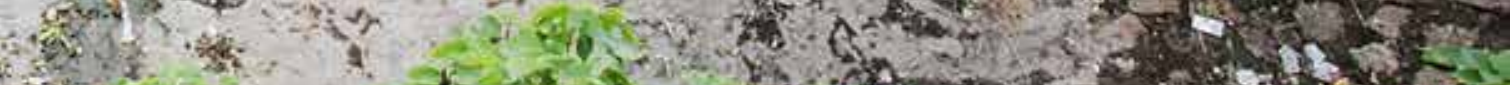

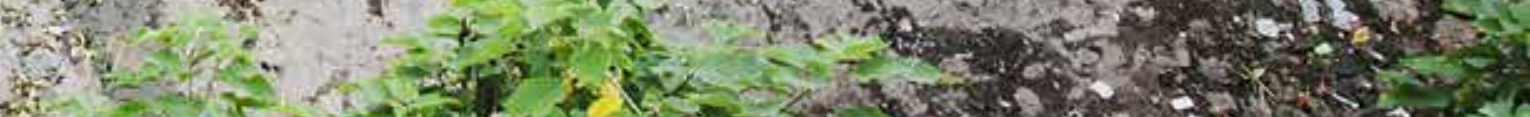

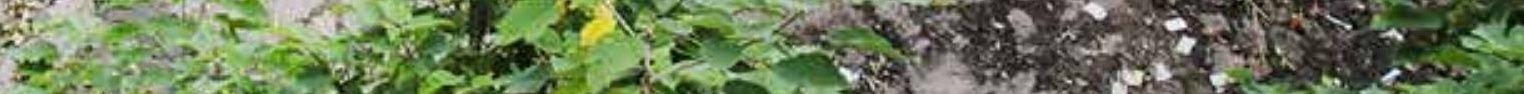

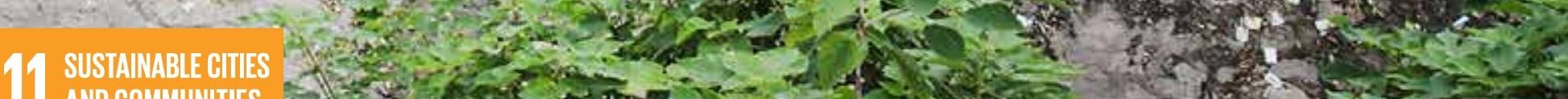

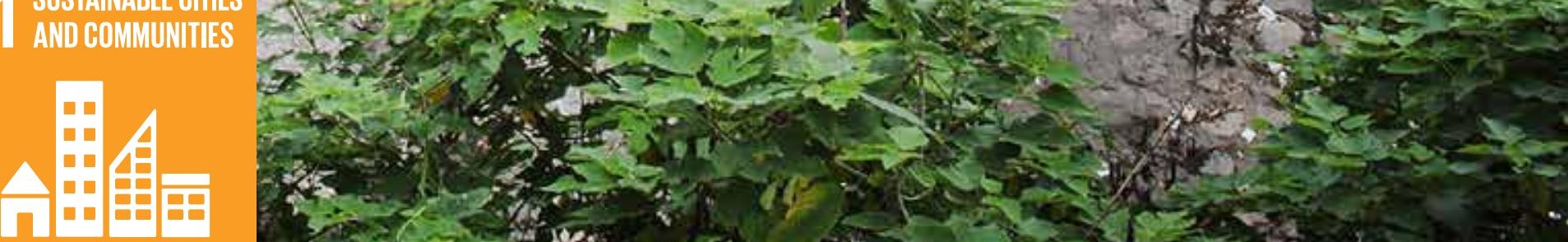
6. $6^{3}-140$ 


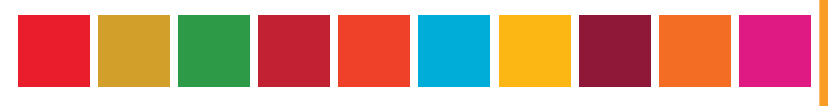

11

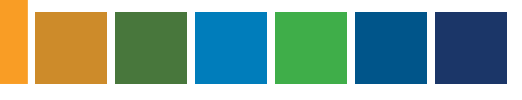

\section{Make cities and human settlements inclusive, safe, resilient and sustainable}

\section{OUTLOOK}

The prospects for achieving this goal are mixed, given the large number of people living in cities, ongoing urbanization and weak planning and management in most cities of Asia and the Pacific. The hurdles lie in meeting basic needs; providing housing, basic services and transport for the large numbers of people who are poor; and addressing the emerging issues of increasing exclusion and inequality, natural disasters, insecurity, resource efficiency and health pandemics. Cities have the potential to develop innovative solutions to the many challenges covered by the 2030 Agenda and to mobilize broad-based support for their implementation.'

\section{THEPHOTO}




\section{Make cities and human settlements inclusive, safe, resilient and sustainable}

\section{INSIGHTS}

- The Asia-Pacific region is home to 53.5 per cent of the global urban population. ${ }^{2}$ In $2016,48.7$ per cent of the region's 4.3 billion population lived in urban areas. By 2018 , half of the region's population will be urban residents. ${ }^{3}$ Cities account for as much as an estimated 80 per cent of the region's economic output. ${ }^{4}$ Thus, the economic performance of cities drives the region's prosperity, which is why it is so important that it is inclusive and environment friendly.

- Cities account for 60-80 per cent of global energy consumption and generate more than 70 per cent of the human-induced greenhouse gas emissions, primarily through the consumption of fossil fuels for energy supply and transportation. ${ }^{5}$ Transport emissions have more than doubled since 1970 and are projected to increase at a faster pace than emissions from other energy end-use sectors, reaching about 12 gigatonne of $\mathrm{CO}_{2}$ a year by $2050 .{ }^{6}$ Unplanned urban sprawl has contributed to the accelerated growth in emissions in the region's developing countries.

- Urban areas in the region generate about 1.21 million tonnes of municipal solid waste a day. By 2025 , this amount will more than double, to 2.65 million tonnes daily. ${ }^{7}$ Waste collection rates in developing countries are low, and collected waste is dumped, highlighting an urgent need for improved solid waste management in urban centres. ${ }^{8}$

- According to the World Health Organization (WHO) 2014 report on the 100 most polluted cities, nearly 70 of them were in Asia and only a few in Europe or the United States. ${ }^{9}$ The region, however, also has some of the most successful green cities (and nation state), such as Hong Kong, China, Seoul and Singapore, with low transport emissions. Even in these cities, the demand for green public spaces is on the rise.

- The high density of people, jobs and assets that make cities so successful also make them extremely vulnerable to disaster risks. For example, the 2015 earthquakes in Nepal claimed 9,100 lives, collapsed more than 30 monuments (including UNESCO heritage sites in the Kathmandu Valley) and an additional 120 monuments incurred partial damage. ${ }^{10}$ There is lack of sufficient urban data on possible loss and damage, including on the preservation of the world's cultural and natural heritage. To improve their resilience against disasters, however, some cities have engaged in participatory planning, data collection and assessing the likely impact of climate change-related risks.

\section{BRIGHTSPOTS}

- In 2015, the share of urban populations in the region with access to improved water sources was 97.2 per cent. ${ }^{11}$ 
- With the emerging transboundary challenges, cities offer a new force of good governance. ${ }^{12}$ City leaders are coming together to act on global issues, such as climate change. Such initiatives include the Global Parliament of Mayors, the EU Covenant of Mayors and its Compact of Mayors, the 100 Resilient Cities, the C40 Cities Climate Leadership Group and the ASEAN Cities Mayors Forum.

- Information technology offers significant opportunities for cities to enhance the quality, performance and interactivity of their urban services, to reduce costs and resource consumption and to improve contact between citizens and government. Of particular relevance are emerging developments with respect to smart cities, smart energy grids, high-speed (5G) digital connectivity and the internet of things.

\section{HOTSPOTS}

\section{Housing, basic services and slums ${ }^{13}$}

- In 2014 , an estimated 440 million people, representing about 26.9 per cent of the region's total urban population, lived in slums or informal settlements, ${ }^{14}$ which are characterized by housing that is non-durable or overcrowded, lacking in access to improved water and sanitation facilities and lacking security against eviction. This included nearly two-thirds of the urban population in Afghanistan and Bangladesh, while in Cambodia and Nepal, it was more than half of the urban populations. ${ }^{15}$ Although the proportion of people living in a slum is decreasing in all subregions, the absolute number is increasing in many cities. ${ }^{16}$

- Even though the region has made significant progress in access to safe drinking water, progress with sanitation has been much slower and varies across the subregions, ranging in 2015 from 49.1 per cent in South and South-West Asia and 72.3 per cent in South-East Asia to 79.6 per cent in East and North-East Asia. ${ }^{17}$

\section{Inclusive and sustainable urbanization}

- Many cities exceed the WHO standard of annual mean concentration of 10 micrograms and 20 micrograms of PM2.5 particles and PM10 particles per cubic metres of air volume, respectively. The annual mean concentration of PM2.5 and PM10 in cities ${ }^{18}$ varies from 5.8 and 9.6 micrograms in Australia to 101.2 and 281.8 micrograms per cubic meter in Pakistan, respectively. Other countries with higher PM2.5 concentrations include Mongolia (at 64.1 micrograms), India (at 58.8 micrograms), China (at 41.3 micrograms) and Turkey (at 38.9 micrograms). ${ }^{19}$

- Evidence from 191 Demographic and Health Surveys conducted over the past several years shows that infants and children residing in slums have substantially greater incidence of diarrheal illness than their urban peers and are less likely to survive to their fifth birthday. ${ }^{20}$ The urban poor in the region's industrialized countries also face marked disparities in health and well-being. ${ }^{21}$ 


\section{EMERGINGISSUES}

- Cities face converging challenges, including migration and population growth, changes in family structure, increases in informal settlements, vulnerability to climate change and disasters, exclusion, rising inequality and rising insecurity. With the growth of the middle class in cities, emissions and wastes are likely to increase unless there is change in production and consumption patterns.

- Rising inequality, competition over scarce resources (such as land), impunity from the law and weak city governance could increase the risk of violence and potential breakdowns in law and order. The fear of crime and violence continues to be pervasive in cities and is one of the top concerns in citizens' everyday lives.

\section{TARGETS}

11.1 By 2030, ensure access for all to adequate, safe and affordable housing and basic services and upgrade slums

11.2 By 2030, provide access to safe, affordable, accessible and sustainable transport systems for all, improving road safety, notably by expanding public transport, with special attention to the needs of those in vulnerable situations, women, children, persons with disabilities and older persons

11.3 By 2030, enhance inclusive and sustainable urbanization and capacity for participatory, integrated and sustainable human settlement planning and management in all countries

11.4 Strengthen efforts to protect and safeguard the world's cultural and natural heritage

11.5 By 2030, significantly reduce the number of deaths and the number of people affected and substantially decrease the direct economic losses relative to global gross domestic product caused by disasters, including waterrelated disasters, with a focus on protecting the poor and people in vulnerable situations

11.6 By 2030, reduce the adverse per capita environmental impact of cities, including by paying special attention to air quality and municipal and other waste management

11.7 By 2030, provide universal access to safe, inclusive and accessible, green and public spaces, in particular for women and children, older persons and persons with disabilities

11.a Support positive economic, social and environmental links between urban, peri-urban and rural areas by strengthening national and regional development planning

11.b By 2020, substantially increase the number of cities and human settlements adopting and implementing integrated policies and plans towards inclusion, resource efficiency, mitigation and adaptation to climate change, resilience to disasters, and develop and implement, in line with the Sendai Framework for Disaster Risk Reduction 2015-2030, holistic disaster risk management at all levels

11.c Support least developed countries, including through financial and technical assistance, in building sustainable and resilient buildings utilizing local materials 


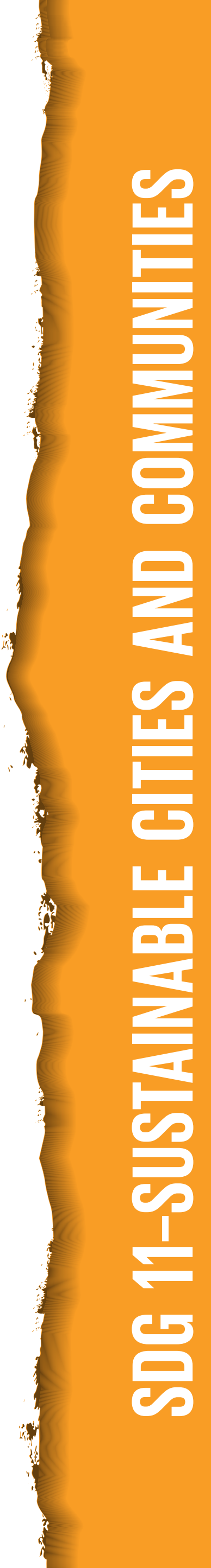





\section{Ensure sustainable consumption and production patterns}

\section{INSIGHTS}

- The Asia-Pacific region continues to be the fastest-growing and most dynamic production hub among the regions in the world. It is the production centre for food and exports for twothirds of the world's population. These drivers are resource-intensive, with the environmental costs of their inefficiencies not reflected in the price of goods. Nor is a sufficient level of profit from export-driven economic growth reinvested in managing the environmental impacts of production.

- The urgency of transforming the economic strategies and business models in the region is crucial to achieving SDG 12, and the entire range of physical and socioeconomic factors that underpin consumption and production patterns, including infrastructure, lifestyles and economic structures. This underscores the importance of going after the root causes of unsustainable consumption and production patterns across the SDGs, particularly SDG 8 and SDG 9, by embedding the environmental impacts in employment and economic growth policies.

- The highest potential for resource-efficiency gains exists in developing economies that are locked into inefficient, resource-intensive consumption and production patterns. With appropriate green economy policies, incentives and access to technology, there is scope for increasing efficiency gains in these countries. But early action is needed to avoid further lock-in to inefficient technologies and infrastructure.

- National Environmental Economic Accounting can be used as a tool for internalizing the cost of using environmental resources and the resulting waste and emissions into economic decision-making. Examples include the assessment of trends in the use and availability of natural resources, the extent of emissions and discharges into the environment resulting from economic activity and the amount of economic activity undertaken for environmental purposes. $^{1}$

\section{BRIGHTSPOTS}

\section{Sustainable management and efficient use of natural resources}

- The intensity of domestic material consumption, calculated as direct import plus domestic materials extraction, minus direct exports, increased by 23 per cent in the region as a whole between 2000 and 2015. However, in all subregions, there was a marked reduction in domestic material consumption between 2000 to 2015 (South-East Asia by 15 per cent, South and South-West Asia by 31 per cent, North and Central Asia by 25 per cent and Pacific islands by 21 per cent) compared with the increasing global average of 8 per cent between 2000 and $2010 .^{2}$ The exception to this downward regional trend is East and North-East Asia, which grew by 76 per cent between 2000 and 2015 (see the SDG 7 profile for energy intensity trends). 


\section{Waste reduction and management}

- There is a growing movement towards sustainable and low chemical-input agriculture, as well as green chemistry methods and material innovation to remove toxins from the value chain. An example is the initiative by 13 countries to adopt a new set of safety and quality standards for machinery manufactured, traded and used in the Asia-Pacific region. ${ }^{3}$

- The number of countries in the region committing to at least one international environmental agreement on hazardous waste and other chemicals has increased. There are signs that awareness and use of techniques to incentivize and reward sustainable consumption and production behaviour is increasing.

\section{HOTSPOTS}

\section{Sustainable management and efficient use of natural resources}

- The Asia-Pacific region requires two times the input of resources than what the rest of the world requires to produce one unit of GDP.4 In 2010, the region's GDP required the use of 2.4 kilograms of materials per unit of GDP, compared with the global average of 1.3 kilograms per unit of GDP. Without a decoupling of GDP growth from resource use, the region is likely to be using 80 billion tonnes of materials by $2050,{ }^{6}$ with severe environmental and social impacts and looming shortage.

- The region's domestic material consumption increased at an average annual rate of 5.6 per cent between 2000 and 2015, more than five times the population growth rate. Various factors contributed to this increase, including rapid industrialization, urbanization and massive infrastructure and transport development.?

- In absolute terms, domestic material consumption has more than doubled, from 22,887 million tonnes in 2000 to 51,369 million tonnes in 2015, with most of the growth coming from East, North-East and South-West Asia. ${ }^{8}$

\section{Waste reduction and management}

- Total greenhouse gas emissions of economies in Asia and the Pacific in 2012 were 26,725 million tonnes of $\mathrm{CO}_{2}$ equivalent, reflecting around a 4 per cent average rate of annual increase since $2000 .{ }^{9}$ This is despite the decrease of emissions intensity by 44 per cent, from 1.9 tonnes in 2003 to 1 tonne per $\$ 1,000$ GDP in $2011 .^{10}$

- Urban areas in the region generate about 1.21 million tonnes of municipal solid waste a day. By 2025, this amount will more than double, to 2.65 million tonnes daily. ${ }^{11}$ In the past five years (2010-2015), e-waste from East and South-East Asia grew by 63 per cent. ${ }^{12}$ 
- Each year, an estimated one third of all food produced worldwide-equivalent to 1.3 billion tonnes and worth around $\$ 1$ trillion-ends up in the bins of consumers and retailers or spoiled due to poor transportation and harvesting practices. ${ }^{13}$ In the region, it is estimated that $15-50$ per cent of fruits and 12-30 per cent of grains are lost between the producer and the market. ${ }^{14}$

- Given the realization that plastic is now turning up in 100 per cent of fish catch in some regions of Asia and in sea salt and that the quantity of plastic in the ocean's gyres is growing, some observers are considering plastic pollution a crisis on the scale of a "global threat", comparable with global climate change, food insecurity and water scarcity. ${ }^{15}$ Weak statistical capacity to monitor the extent of marine pollution, particularly microplastics, and its implications hinder policy development to fully tackle this issue.

- A large part of both the positive and negative contributions to advancing SDG 12 will come from private businesses and consumers, which suggests a renewed commitment to effectively implement a "penalize or reward" policy regime appropriate to the scale of operations and types of goods and services.

\section{Institutionalizing policy and action}

- Only a minority of industries and businesses in the region have implemented measures to support conscious consumer behaviour change, such as environmental labelling and consumer information services. In 2016, businesses from only 23 of the Asia-Pacific regional member States have participated in the global voluntary Corporate Sustainability Reporting initiative, accounting for 35 per cent of the global total. Making information accessible to both consumers and producers will empower consumers to make more sustainable choices.

- Developing Asian countries accounted for close to a third of global subsidies on fossil fuel consumption in 2012, equivalent to about 1.5 per cent of GDP. Removal of such subsidies would result in the decrease of demand and use of fossil fuels. Reduction of fossil fuels can lead to considerable financial savings for governments. For example, in the Islamic Republic of Iran, fossil fuel use reductions led to a savings of $\$ 5.3$ billion; in Indonesia, it saved $\$ 10$ billion in one year. These funds can be reinvested into social development policies, as was done in Indonesia.

- Fossil fuel subsidies also support the production of cheap chemicals, and the carbon footprint of chemicals is substantial. Virtually all chemicals are sourced from fossil fuels.

- The economic value attributable to ecotourism has been underestimated in traditional national income accounting, thereby hindering a complete valuation of tourism for the benefit of cultural heritage protection and poverty reduction.

- Technical and statistical capacity issues impede the monitoring of the sustainability of production and consumption patterns. Reliable data on food waste and loss, household solid waste generation, industrial waste and effluents management and treatment are poor or nonexistent for most countries in the region. 


\section{EMERGINGISSUES}

- Recent studies traced high chemical inputs for food production to damaging impacts on the health of consumers in the region and abroad. These impacts are not yet fully documented, however, because of the time required for the problems to fully manifest and develop.

- Chemical management is therefore critical in the Asia-Pacific region, especially chemicals from plastic and textile industry waste, mercury and dioxin emissions. Regional cooperation is needed to create a framework for influencing multinational corporations to avoid their use of chemicals and non-organic packaging, which are prohibited in other regions.

- Water pollution from untreated wastewater in the region is exceeding the capacity for purification of rivers and lakes, thus calling for a better understanding of the contemporary water cycle. Action to improve the effectiveness of toxic waste and pollutants management is important.

- Requiring the business sector to apply lifecycle analysis to their products, materials used and services will trigger important changes in the value chain. These changes could be a game changer in terms of reducing wasteful lifestyles and improve environmental and social sustainability and overall well-being.

\section{TARGETS}

12.1 Implement the 10-Year Framework of Programmes on Sustainable Consumption and Production Patterns, all countries taking action, with developed countries taking the lead, taking into account the development and capabilities of developing countries

12.2 By 2030, achieve the sustainable management and efficient use of natural resources

12.3 By 2030, halve per capita global food waste at the retail and consumer levels and reduce food losses along production and supply chains, including post-harvest losses

12.4 By 2020, achieve the environmentally sound management of chemicals and all wastes throughout their life cycle, in accordance with agreed international frameworks, and significantly reduce their release to air, water and soil in order to minimize their adverse impacts on human health and the environment

12.5 By 2030, substantially reduce waste generation through prevention, reduction, recycling and reuse

12.6 Encourage companies, especially large and transnational companies, to adopt sustainable practices and to integrate sustainability information into their reporting cycle

12.7 Promote public procurement practices that are sustainable, in accordance with national policies and priorities

12.8 By 2030, ensure that people everywhere have the relevant information and awareness for sustainable development and lifestyles in harmony with nature

12.a Support developing countries to strengthen their scientific and technological capacity to move towards more sustainable patterns of consumption and production

12.b Develop and implement tools to monitor sustainable development impacts for sustainable tourism that creates jobs and promotes local culture and products

12.c Rationalize inefficient fossil-fuel subsidies that encourage wasteful consumption by removing market distortions, in accordance with national circumstances, including by restructuring taxation and phasing out those harmful subsidies, where they exist, to reflect their environmental impacts, taking fully into account the specific needs and conditions of developing countries and minimizing the possible adverse impacts on their development in a manner that protects the poor and the affected communities 


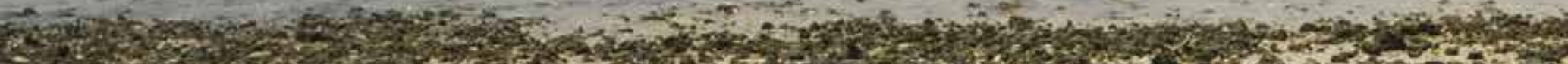

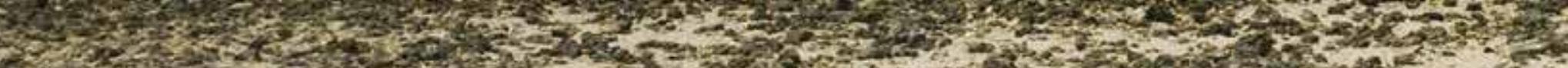

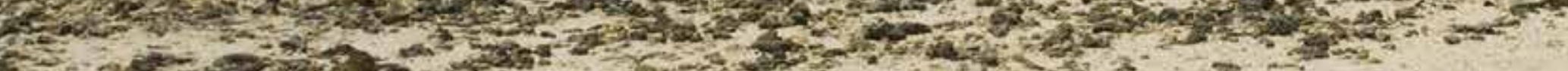

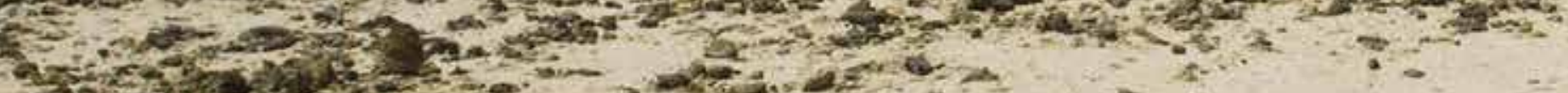

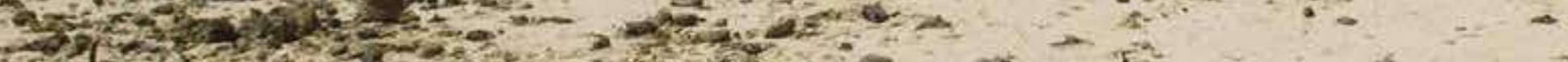

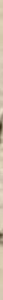

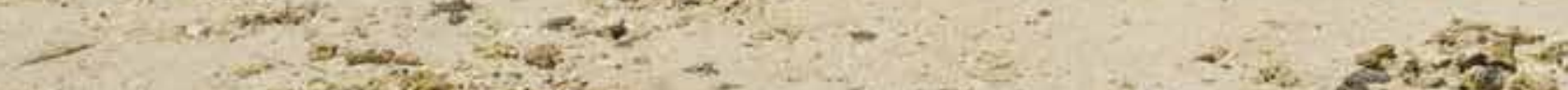

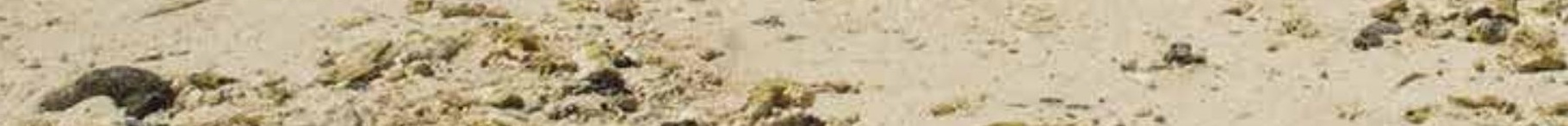

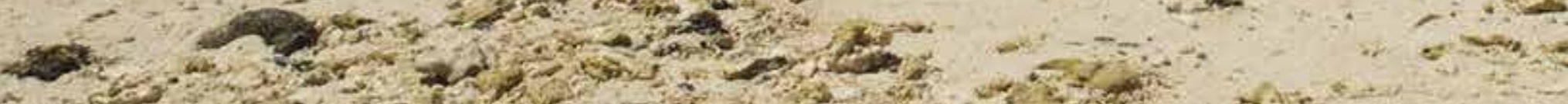

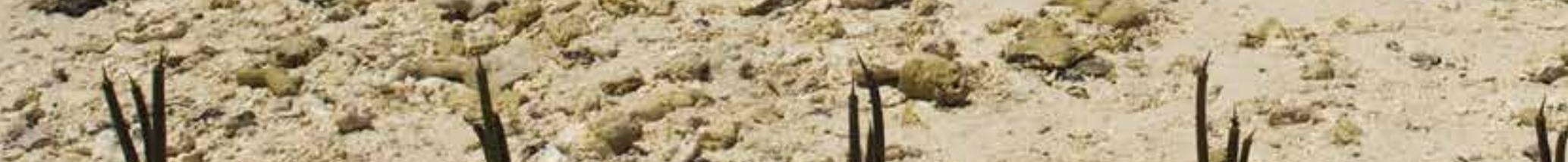

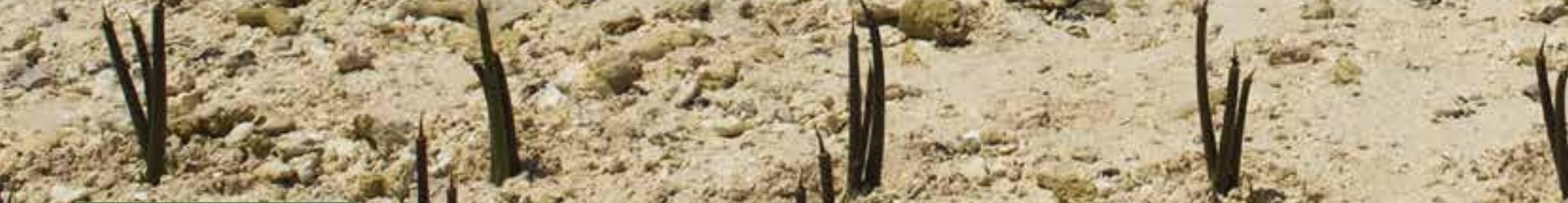
25 (5) ACIION

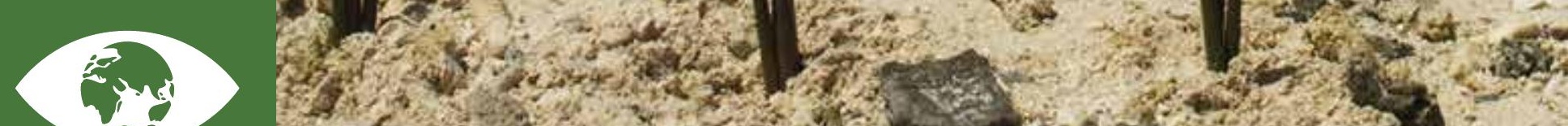

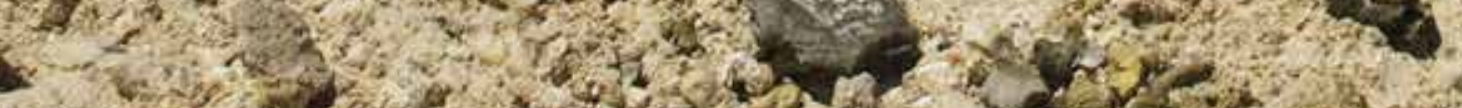



impacts ${ }^{1}$

\section{OUTLOOK}

The prospects for achieving the goal are mixed. Progress will be boosted by entry into force of the Paris Agreement, along with efforts to scale up financial resources and technological innovation. Given the high growth of greenhouse gas emissions in the region, topping 4 per cent on average, ${ }^{2}$ and the high levels of human and economic vulnerability to climate change impacts, the urgency of increasing mitigation and adaptation actions cannot be overestimated.

\section{THEPHOTO}

Mangrove shoots planted on Tarawa, an atoll in the Pacific island nation of Kiribati, in an attempt to
mitigate the impacts of rising sea levels 


\section{Take urgent action to combat climate change and its impacts}

\section{INSIGHTS}

- SDG 13 focuses on strengthening resilience and adaptive capacity, integrating climate change into national planning, improving awareness and institutional capacities on climate change and mobilizing climate finance. Actions contributing to the achievement of this goal span at least three other internationally agreed agendas and frameworks - the Paris Agreement, the Sendai Framework for Disaster Risk Reduction 2015-2030 and the Addis Ababa Action Agenda.

- SDG 13 does not explicitly address the drivers of greenhouse gas emissions or the vulnerabilities of societies to climate change impacts - these must be managed across the entire 2030 Agenda.

- Many countries have already taken significant institutional and policy action on climate conditions, but concerted efforts are still needed to ensure that they achieve and exceed their objectives and focus on the specific vulnerabilities of different population groups and communities.

- The goal of mobilizing $\$ 100$ billion annually by $2020^{3}$ from public and private sources to support climate action in developing countries is a political benchmark for assessing progress on climate finance. There is some evidence that industrialized countries are making progress towards this goal. But the investment needs far exceed this amount, and the Paris Agreement sets a goal that all finance flows should be consistent with a pathway towards low-emission and climate-resilient development-in the context of sustainable development priorities. There are huge opportunities to make progress towards this goal in Asia and the Pacific, including through partnerships with small and medium-sized enterprises, with direct public and private finance towards solutions to climate change.

\section{BRIGHT SPOTS}

\section{Strengthen resilience and adaptive capacity}

- As of March 2017, 39 ESCAP member countries had ratified the Paris Agreement and submitted their Nationally Determined Contributions containing their climate change agendas and priorities. ${ }^{4}$ Many of these Nationally Determined Contributions include an adaptation component. While the actions to which countries are committing are significant, more will need to be done in subsequent iterations to succeed in avoiding the worst impacts of climate change.

- As of 2015, 18 ESCAP member countries had national disaster risk reduction strategies. ${ }^{5}$ There have been considerable advances in preparedness and early warning activities-at least 14 countries now have an operational national early warning system for weather- and climate- 
related hazards, and approximately the same number maintain a disaster loss database. ${ }^{6}$ Many countries in the region also have a strong tradition of community-based disaster risk management.

\section{Integration of climate change measures into national policies, strategies and planning}

- Some 26 countries in the region explicitly mentioned sector-based policies to achieve their climate change goals in their Nationally Determined Contributions, and 17 countries stated that they had or were developing long-term low-emissions development strategies, suggesting that these countries are intent on integrating climate change measures into their policies, strategies and planning.

- Many countries in the region are engaged in the National Adaptation Plan process, which is expected to result in the integration of adaptation into medium-term planning and budgeting. Sri Lanka was one of the first countries to submit its plan to the United Nations Framework Convention on Climate Change (UNFCCC). ${ }^{7}$

\section{Education and awareness raising}

- There is a range of government, civil society and private sector activities across the region. Several countries have incorporated climate education into the formal school curriculum, including Bangladesh, China, India, Indonesia, the Philippines, the Republic of Korea, Tuvalu and Viet Nam. ${ }^{8}$ Progress on this target will depend partly on the level of action taken under article 6 of the UNFCCC (and based on Principle 10 of the Rio Declaration ${ }^{9}$ ) on the importance of achieving education, training and public awareness and participation in environmental decision-making at both the global and local levels.

\section{Climate finance}

- As of October 2016, the Green Climate Fund, a mechanism within the UNFCCC to assist developing countries in mitigation and adaptation responses, had raised $\$ 10.3$ billion in pledges. ${ }^{10}$ As of 2016 , the Green Climate Fund had approved $\$ 1.2$ billion for 27 projects, of which nine are in Asia and the Pacific. The key issue is going to be how to ensure that allocation and disbursement are scaled up significantly.

- The 2016 Biennial Assessment of Climate Finance Flows noted that industrialized countries reported $\$ 25.4$ billion in 2013 and $\$ 26.6$ billion in 2014 in bilateral public finance to the UNFCCC, representing an increase of about 50 per cent. ${ }^{11}$ Industrialized countries also released a road map towards the $\$ 100$ billion goal in which they stated that they will seek to increase public finance from the current level of about $\$ 41$ billion to $\$ 67$ billion by 2020 and to leverage additional private finance. ${ }^{12}$

- The use of green bonds-debt instruments targeted to green investmentsas an alternative to conventional bank project finance has taken off in the region. In total, the region generated around $\$ 308$ billion in climate-aligned bonds, ${ }^{13}$ or 44 per cent of the global total. ${ }^{14}$ 


\section{HOTSPOTS}

\section{Strengthen resilience and adaptive capacity}

- The region, which bears the brunt of the world's large-scale catastrophic disasters, experienced 155 disasters in 2015 alone, with an estimated 6,721 fatalities and around \$32,578 million in economic damages. ${ }^{15}$ Indirect losses were even higher, as well as an ongoing erosion of development assets, such as local infrastructure, dwellings, schools, health facilities and roads, that were repeatedly hit by severe weather and climate events. ${ }^{16}$ These numbers are likely to be underestimates because there has been no systematic assessment of the cost of all disasters that have struck the region, especially slow-onset disasters, such as droughts, heat waves, forest fires and haze. ${ }^{17}$

\section{Integration of climate change measures into national policies, strategies and planning}

- Although many countries have climate adaptation plans, many of them are not fully funded.

- Although efforts to integrate climate change measures, including disaster risk reduction, into national policies and planning processes are growing, sector-based implementation (such as building and infrastructure codes, land-use planning and zoning) has been much slower. ${ }^{18}$ There is a particular need to align infrastructure and development planning processes with climate change mitigation and resilience strategies.

\section{Climate finance}

- Despite progress in spending climate finance, there is a need to ensure that this funding is predictable and able to address the risks that impede greater investment in climate change solutions and that it is used effectively in countries that need it most.

- Accounting for finance to address climate change remains a challenge, although progress in reporting continues to be made. Many governments in the region are leading the way in monitoring climate expenditures in their budgets and more broadly within their countries.

- Climate finance flows predominantly support mitigation. Continued efforts to scale up adaptation support, particularly for least developed and small island developing countries in the region, are needed.

\section{EMERGINGISSUES}

- Although the Paris Agreement creates a framework in which all countries commit to climaterelated action, collective pledges are far short of achieving the greenhouse gas emission reductions required to keep climate change below $2^{\circ} \mathrm{C}$ (targeting $1.5^{\circ} \mathrm{C}$ ). This means that further iterations of the Nationally Determined Contributions need to be much more ambitious and the search for rapid mitigation strategies will assume greater importance in the coming years.

- Adaptation has limits-there will be losses and damages that people cannot completely prevent. New mechanisms to cope with loss and damage are being explored, including risk and insurance transfer measures. 
- The issue of climate-induced displacements may become a human crisis. Loss of territories in the Pacific due to sea-level rise ${ }^{19}$ can pose new international policy dilemmas that touch upon sovereignty, legal, social and cultural issues.

- People and their assets are increasingly exposed to climate changeinduced hazards. A primary driver of increased exposure in the region has been rapid and unplanned development in hazard-prone areas, driven in part by heavy urbanization.

- The work on achieving SDG 13 in the context of all SDGs has the opportunity to lay the groundwork that would enable countries in the region to advance their adaptation and mitigation efforts.

\section{TARGETS}

13.1 Strengthen resilience and adaptive capacity to climate-related hazards and natural disasters in all countries

\subsection{Integrate climate change measures into national policies, strategies and planning}

13.3 Improve education, awareness-raising and human and institutional capacity on climate change mitigation, adaptation, impact reduction and early warning

13.a Implement the commitment undertaken by developed-country parties to the United Nations Framework Convention on Climate Change to a goal of mobilizing jointly $\$ 100$ billion annually by 2020 from all sources to address the needs of developing countries in the context of meaningful mitigation actions and transparency on implementation and fully operationalize the Green Climate Fund through its capitalization as soon as possible

13.b Promote mechanisms for raising capacity for effective climate change-related planning and management in least developed countries and small island developing States, including focusing on women, youth and local and marginalized communities 


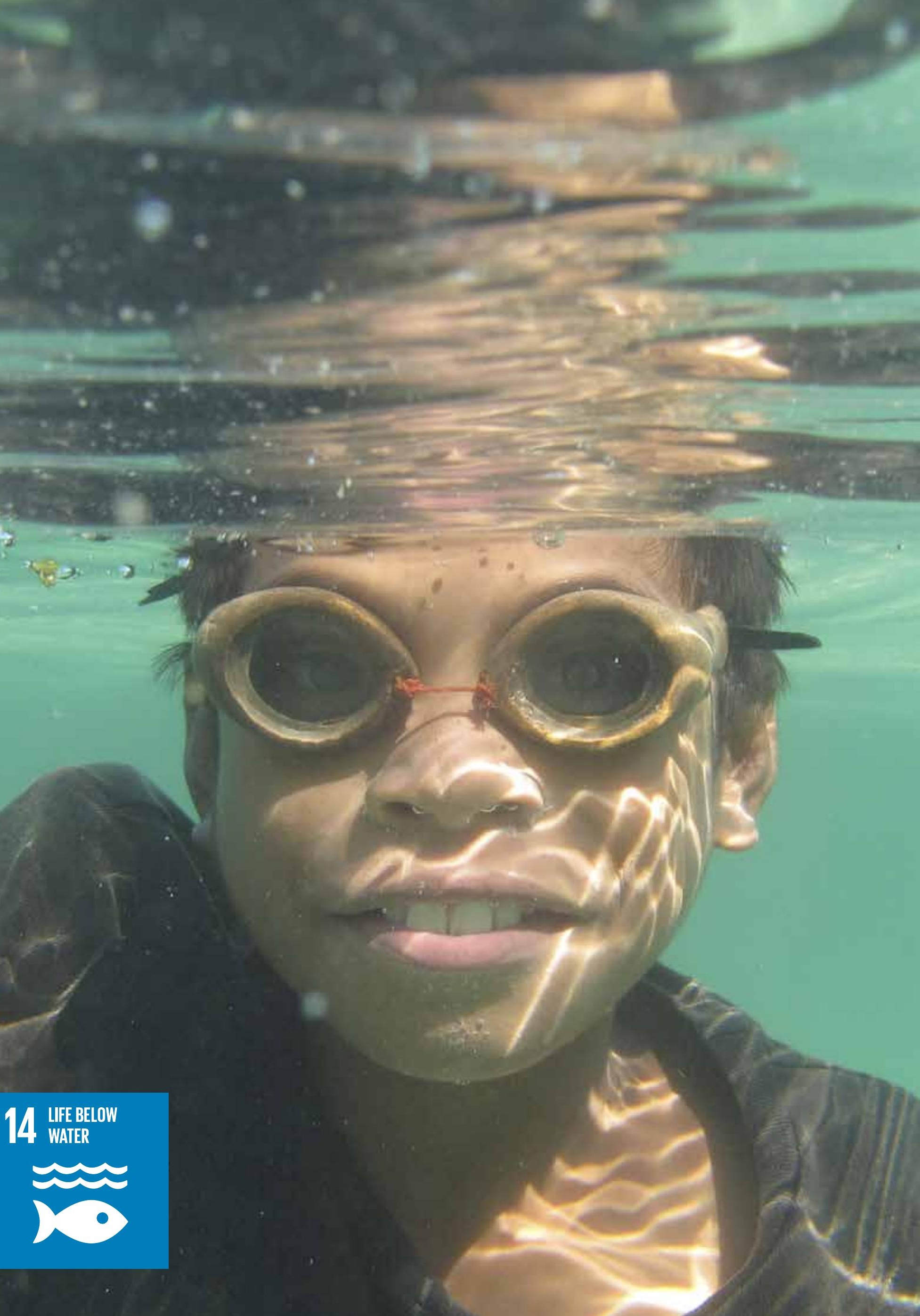




\section{Conserve and sustainably use the oceans, seas and marine resources for sustainable development}

\section{OUTLOOK}

The prospects for the achievement of this goal hinge on successful conservation and sustainability of marine and coastal ecosystems while maintaining the economic, food security and livelihood benefits of marine resources. Oceans, seas and coastal systems provide invaluable support to the planet for food security, transport, energy, tourism and many of the most critical ecosystem services, including climate. However, climate change, overfishing, habitat change, invasive species introduction and pollution arising from poor management practices and market failures are threatening ocean health, with serious harmful and irreversible consequences. 


\section{Conserve and sustainably use the oceans, seas and marine resources for sustainable development}

\section{INSIGHTS}

- About 85 per cent of the global fish stocks are fully fished, over fished or have collapsed. ${ }^{1}$ The contribution of fisheries as a vital resource for livelihoods, employment, nutrition and opportunities for economic growth faces serious risks. The main drivers of overfishing must be tackled, such as fishing vessel overcapacity, perverse subsidies and illegal, unreported and unregulated fishing. There are also serious human rights violations in the fisheries industry, including human trafficking and labour exploitation, that must be confronted.

- As much as an estimated 40 per cent of the world's oceans are heavily affected by human activities, ${ }^{2}$ including nutrient-based pollution, marine debris and plastics and loss of coastal habitats, resulting in coastal hypoxia and loss of marine biodiversity and other ecosystem goods and services. These reflect poor management practices and underscore the need to directly target land-ocean interaction.

- Warmer air and sea surface temperatures, ocean acidification and rising sea levels are expected to cause significant loss of coral reefs, mangroves, seagrass and intertidal habitats. Such losses will further threaten ecosystem health and expose coastal populations to increased harm from natural disasters, threats to basic human rights (such as food and fresh water) and population displacement. The small island developing States of the Pacific are most vulnerable to the impacts of climate change and require the most urgent attention.

- For comprehensive future monitoring of SDG 14, statistics are needed on a broader range of benefits and challenges related to conservation and the sustainable use of marine resources. Current scientific knowledge on the complex marine ecosystems is too limited to develop complete coverage of indicators for monitoring ocean sustainability, compounded by the limited data for existing indicators.

\section{BRIGHT SPOTS}

\section{Conservation and sustainability of marine and coastal ecosystems}

- Fisheries management and the economic value derived from fisheries for small island developing States is improving in the region. Conventional fisheries management is shifting from an orientation towards single-species maximization (such as maximum sustainable yield) to an ecosystem approach that is broader in scope, encompassing biological, environmental, economic and social objectives.

- A growing number of marine protected areas have been created to protect threatened species and important habitats. Many countries in the region have started protecting large expanses of their coastal and oceanic waters; the most notable is Palau, which recently enacted the Palau National Marine Sanctuary Law, which declares 80 per cent of its waters as a no-take 
fishing zone. ${ }^{3}$ The Coral Triangle Initiative on Coral Reefs, Fisheries and Food Security, a multilateral partnership, aims to contribute towards achieving SDG 14 targets by sustaining marine and coastal resources (participating countries are Indonesia, Malaysia, Papua New Guinea, the Philippines, Solomon Islands and Timor-Leste).

- Strengthening the United Nations Convention on the Law of the Sea and the negotiation of a new global treaty for the conservation of oceans and seas presents an opportunity to close current gaps in ocean governance. At the same time, support for country compliance with existing regional and global multilateral agreements provides a framework for achieving the SDG targets.

- The durability of most plastics combined with inadequate end-of-life management has resulted in marine plastics and microplastics becoming a global problem. ${ }^{4}$ The Ocean Cleanup is developing advanced technologies to remove about half of the "Great Pacific garbage patch" in ten years.

\section{Use of coastal and marine resources}

- Efforts to improve economic benefits from fisheries among small island developing States in the Pacific have made some progress. The strengthening of the Vessel Day Scheme, ${ }^{5}$ for instance, has increased the access-fee revenue paid by tuna fishing vessels, ${ }^{6}$ from $\$ 60$ million in 2010 (when the scheme reached full implementation) to more than $\$ 400$ million in 2015. ${ }^{7}$ Revenues are expected to increase further as the eight countries in that scheme continue to negotiate higher fees within the context of the Western and Central Pacific Fisheries Convention to ensure resource sustainability. There have been numerous attempts in all Pacific island countries to encourage small-scale fishers to harvest larger amounts of tuna.

\section{HOTSPOTS}

\section{Harvesting and overfishing}

- Effectively addressing overfishing is likely to be the biggest challenge, considering the complexity of the drivers. Reducing illegal, unreported and unregulated fishing requires political will. Weak laws, poor governance and ineffective fisheries management have made coastal fisheries in most of the region largely open access and overfished. Some countries, such as Indonesia, have taken strong positive action.

- Governance of the fisheries sector is generally poor, and in some countries, it is undermined by corruption. Many governments have neglected the management and sustainability of coastal fisheries, which thus threatens the food security and livelihoods of coastal communities.

- With high unemployment, particularly among youth in the Pacific, the fisheries sector has been an employer of last resort, and limits to entry are unlikely in the face of widespread unemployment and underemployment. 


\section{Climate change impacts}

- Climate-related variables are worsening and endangering the lives, livelihoods, food security and other ecosystem services of the small island developing States and the regions with large riverine and low-lying coastal areas, such as Bangladesh and Viet Nam.

- Sea levels are now rising at an accelerating rate. Unless greenhouse gas emissions are drastically reduced by 2050 , sea levels will rise by a metre by $2100 .^{8}$ Continual global warming is putting at risk coral reefs, which are the most productive coastal ecosystems. More intense and more frequent typhoons and cyclones are increasing the loss of life and destroying natural and economic assets.

\section{Marine pollution}

- Reduction of land-based pollution and marine debris, including ocean plastics, poses challenges to the overarching goal of industrialization by most Asian countries. The coasts will continue to be pollution sinks without dramatic consumption or waste management changes.

\section{Coastal and marine conservation}

- While the geographic extent of marine-protected areas has increased by roughly sevenfold (between 2000 and 2014), ${ }^{9}$ the areal coverage still falls below the target. Most marine protected areas are largely "paper parks" with non-existent management plans; where they exist, implementation is hampered by lack of funds.

\section{EMERGINGISSUES}

- Rather than a comprehensive global regime for conserving marine ecosystems in areas beyond national jurisdiction, there is currently a complex patchwork of regional agreements on fisheries and specific frameworks that address some threats to marine biodiversity (such as marine pollution). Discussions on a new global treaty to protect marine biodiversity called for at the Rio+20 summit represent a significant opportunity to take on this challenge.

- While Fiji, Papua New Guinea, Solomon Islands, Tonga and Vanuatu are emerging as world leaders in the granting of licences for the mining of seabed minerals (only Papua New Guinea has granted licences for exploitation, the remaining licences are exploratory), the management and regulation of deep seabed mining according to the precautionary principle is a critical emerging issue in the Pacific. Domestic environmental management appears currently inadequate to ensure the protection of marine ecosystems.

- The leaders of the Forty-Seventh Pacific Islands Forum welcomed the Paris Agreement and reiterated that achieving the goal of limiting global temperature increases to $1.5^{\circ} \mathrm{C}$ above preindustrialized levels is an existential matter for many Forum members but must be addressed with urgency. 


\section{TARGETS}

14.1 By 2025, prevent and significantly reduce marine pollution of all kinds, in particular from land-based activities, including marine debris and nutrient pollution

14.2 By 2020, sustainably manage and protect marine and coastal ecosystems to avoid significant adverse impacts, including by strengthening their resilience, and take action for their restoration in order to achieve healthy and productive oceans

14.3 Minimize and address the impacts of ocean acidification, including through enhanced scientific cooperation at all levels

14.4 By 2020, effectively regulate harvesting and end overfishing, illegal, unreported and unregulated fishing and destructive fishing practices and implement science-based management plans, in order to restore fish stocks in the shortest time feasible, at least to levels that can produce maximum sustainable yield as determined by their biological characteristics

14.5 By 2020, conserve at least 10 per cent of coastal and marine areas, consistent with national and international law and based on the best available scientific information

14.6 By 2020, prohibit certain forms of fisheries subsidies which contribute to overcapacity and overfishing, eliminate subsidies that contribute to illegal, unreported and unregulated fishing and refrain from introducing new such subsidies, recognizing that appropriate and effective special and differential treatment for developing and least developed countries should be an integral part of the World Trade Organization fisheries subsidies negotiation

14.7 By 2030, increase the economic benefits to small island developing States and least developed countries from the sustainable use of marine resources, including through sustainable management of fisheries, aquaculture and tourism

14.a Increase scientific knowledge, develop research capacity and transfer marine technology, taking into account the Intergovernmental Oceanographic Commission Criteria and Guidelines on the Transfer of Marine Technology, in order to improve ocean health and to enhance the contribution of marine biodiversity to the development of developing countries, in particular small island developing States and least developed countries

14.b Provide access for small-scale artisanal fishers to marine resources and markets

14.c Enhance the conservation and sustainable use of oceans and their resources by implementing international law as reflected in the United Nations Convention on the Law of the Sea, which provides the legal framework for the conservation and sustainable use of oceans and their resources, as recalled in paragraph 158 of "The future we want" 


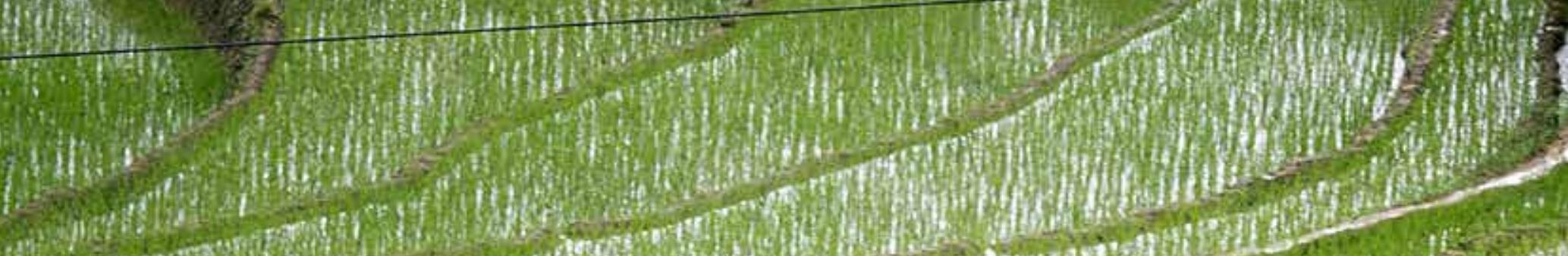

202.

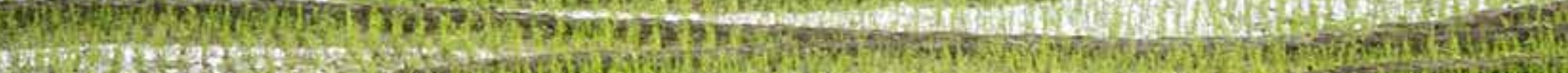

(2)

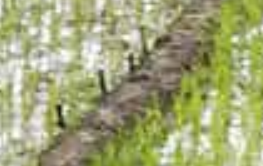

SW

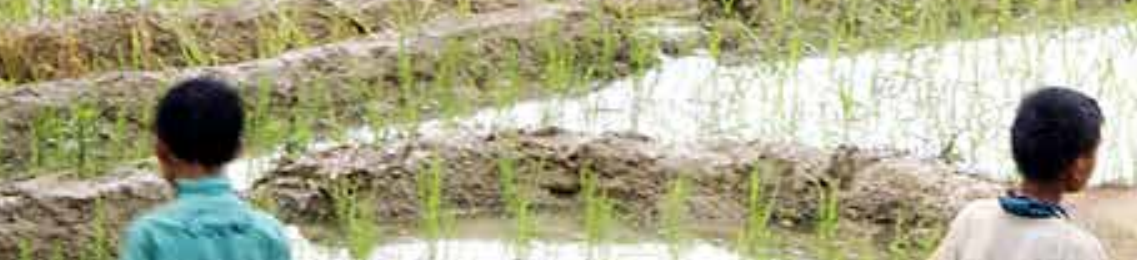

(2)

andin:

2.2

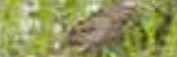

$\frac{1}{3} \sin ^{2}$

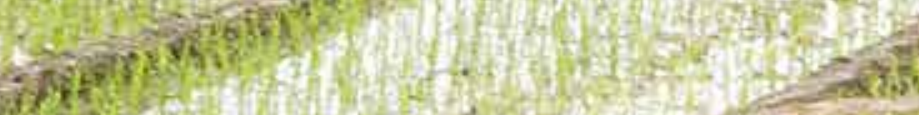
chisg:

a to?

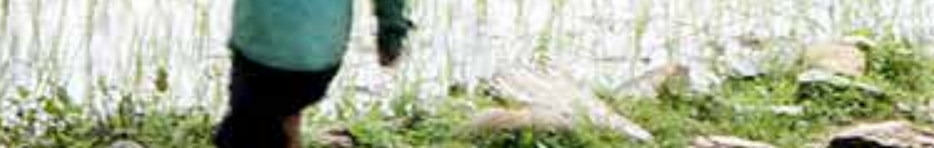

S.

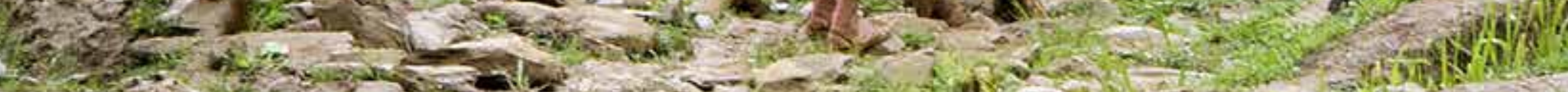

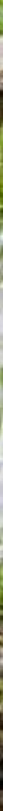


 \\ Protect, restore and promote sustainable use of terrestrial ecosystems, sustainably manage forests, combat desertification, and halt and reverse land degradation and halt biodiversity loss}

\section{OUTLOOK}

Rapid and continuing land use change and increases in demand for natural resources and arable land present serious challenges for the sustainable use of terrestrial ecosystems in the region. Although total forest cover has increased slightly due to increased forest plantation, biodiversity-rich primary forests are still under pressure. The region accounts for about one third of all threatened species; however, there are programmes achieving success in stopping habitat destruction and in reducing the menace to threatened species (tigers and snow leopards, in particular). 


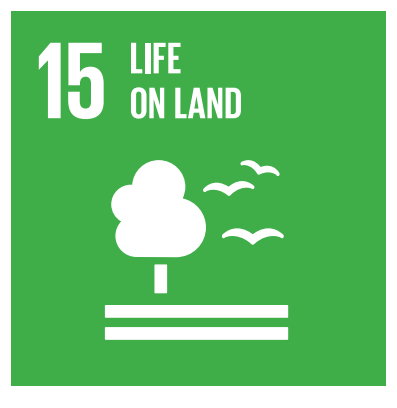

\section{Protect, restore and promote sustainable use of terrestrial ecosystems, sustainably manage forests, combat desertification, and halt and reverse land degradation and halt biodiversity loss}

\section{INSIGHTS}

- Terrestrial ecosystems are linked to the other goals through the range of essential ecosystem services provided to people and to economies-provisioning services (fresh water, food, fibres, fuel, pharmaceuticals); regulating services (climate regulation; disaster risk reduction); cultural services (spiritual enrichment, recreation, aesthetic benefits); and supporting services (nutrient and water cycling). ${ }^{1}$ Biodiversity loss, ecological degradation and water-related disaster risks are growing in areas affected by forest loss.

- Rural livelihoods are intimately impacted by the health of terrestrial ecosystems. The drivers of land-use change vary between subregions, and degradation of terrestrial ecosystems entails forgone benefits in terms of the multiple services provided by terrestrial ecosystems, including for rural livelihoods, disaster risk reduction, water supply, food security and carbon sequestration.

- Although terrestrial protected areas are expanding, progress is slow, and capacity to sustainably manage these areas may not be keeping up. Key strategies to increase protected areas include expanding the role of the private sector and communities through innovative and diverse participatory governance models, such as community conservation areas and biodiversity heritage sites. Involvement of a diverse range of stakeholders to effectively support the management of protected areas will be critical so that they become more than just "paper parks".

- Socioeconomic threats to terrestrial ecosystems can be addressed by integrating ecosystem values into planning. Efforts in this direction need to be stepped up. The increasing demand for the non-monetary values of terrestrial ecosystems can provide incentives for their conservation and sustainable use.

- The risks of invasive species are growing as globalization proceeds. Invasive species impact natural resource-based livelihoods, such as fishing and food production.

- Access to and the sharing of benefits from terrestrial ecosystems is likely to become increasingly inequitable, given the increased demand for ecosystem services and the constrained natural resource base. Focusing on the implementation of global frameworks, such as the Nagoya Protocol on Access and Benefit Sharing, is important to ensure the fair and equitable use of benefits, especially from genetic resources. 


\section{BRIGHT SPOTS}

\section{Sustainable terrestrial ecosystems}

- In 2014 , almost half of the region (24 countries) ${ }^{2}$ had protected terrestrial areas, totalling almost 3.2 million square kilometres and accounting for 13.9 per cent of the land in these countries. ${ }^{3}$ Bhutan and Brunei Darussalam have protected areas that are more than 40 per cent of their surface area (Bhutan at 49.2 per cent and Brunei Darussalam at 36.4 per cent in 2014), ${ }^{4}$ while China and India have made progress in expanding forest and protected area coverage.

- There are positive trends in reforestation and afforestation that are resulting in substantial increases in secondary-forest cover. In many countries, ambitious national biodiversity targets have been established in National Biodiversity Strategies and Action Plans as instruments for implementing the Convention on Biological Diversity.

- There are good regional examples of countries participating in global conservation efforts and addressing threatened species issues, such as the Global Tiger Recovery Programme and the Global Snow Leopard Ecosystem Protection Programme, in which all tiger and snow leopard range countries have strong participation.

\section{HOTSPOTS}

\section{Primary forests}

- Between 2000 and 2015, roughly 135,333 square kilometres of natural forest area (calculated as forest area minus planted forest) was lost in the region, roughly three times the size of Denmark, and accounting for 10.6 per cent of the world's total natural forest loss. The largest loss was registered in South-East Asia, which lost around 158,862 square kilometres of natural forest area within the same period. ${ }^{5}$

- The Asia-Pacific region's share of protected terrestrial areas is smaller than the global average and is far below the 17 per cent global Aichi Biodiversity Targets of the Convention on Biological Diversity. In 2012, the share was 11.5 per cent, compared with 14.3 per cent worldwide. Afghanistan and the Maldives had the lowest percentage of protected terrestrial areas, with less than 1 per cent. ${ }^{6}$

\section{Habitat degradation and biodiversity loss}

- In 2016, the five countries in the Asia-Pacific region with the largest number of threatened species were Australia, China, India, Indonesia and Malaysia. ${ }^{7}$ 


\section{EMERGINGISSUES}

- Globally, large-scale acquisitions of land by overseas investors are concentrated in SouthEast Asia and Africa. The disadvantages of these investments outweigh the benefits to local communities, among other impacts. Some forms of agricultural investments-notably largescale investments in land concentrated in South-East Asia and Africa ${ }^{8}$ —can entail significant risks, reducing access to natural resources and cause the loss of livelihoods, especially where land rights are unclear and governance is weak. ${ }^{9}$ Enclave projects with few links to the surrounding rural economy and investments that shift labour from traditional livelihood activities to the production of non-edible or export crops may also present significant risks to food security and livelihoods. ${ }^{10}$

- Large-scale destruction and conversion of primary forests due to the increase in the production of commodities, such as palm oil, combined with the lack of application of environmental standards, legal loopholes, corruption (weak governance and private rent capture) will further have a detrimental effect on ecosystems and the livelihoods of local communities.

- Reconciling the exploitation of natural resources, such as mineral resources, with sustainability will require strengthening institutions that facilitate dialogue and the wide participation of local communities and stakeholders (including the private sector).

- A primary issue concerning threatened species (such as elephants, rhinos, pangolins, tigers and snow leopards) and biodiversity in general is that of unsustainable and/or illegal trade in wildlife and forest products. The value of illegal wildlife trade is estimated at $\$ 7$ billion to $\$ 10$ billion globally, making it the fourth most lucrative crime, with rapidly growing economies in the region driving it. Wildlife trade robs countries of natural capital while negatively impacting national and local revenues.

\section{TARGETS}

15.1 By 2020, ensure the conservation, restoration and sustainable use of terrestrial and inland freshwater ecosystems and their services, in particular forests, wetlands, mountains and drylands, in line with obligations under international agreements

15.2 By 2020, promote the implementation of sustainable management of all types of forests, halt deforestation, restore degraded forests and substantially increase afforestation and reforestation globally

15.3 By 2030, combat desertification, restore degraded land and soil, including land affected by desertification, drought and floods, and strive to achieve a land degradation-neutral world

15.4 By 2030, ensure the conservation of mountain ecosystems, including their biodiversity, in order to enhance their capacity to provide benefits that are essential for sustainable development

15.5 Take urgent and significant action to reduce the degradation of natural habitats, halt the loss of biodiversity and, by 2020, protect and prevent the extinction of threatened species

15.6 Promote fair and equitable sharing of the benefits arising from the utilization of genetic resources and promote appropriate access to such resources, as internationally agreed 
15.7 Take urgent action to end poaching and trafficking of protected species of flora and fauna and address both demand and supply of illegal wildlife products

15.8 By 2020, introduce measures to prevent the introduction and significantly reduce the impact of invasive alien species on land and water ecosystems and control or eradicate the priority species

15.9 By 2020, integrate ecosystem and biodiversity values into national and local planning, development processes, poverty reduction strategies and accounts

15.a Mobilize and significantly increase financial resources from all sources to conserve and sustainably use biodiversity and ecosystems

15.b Mobilize significant resources from all sources and at all levels to finance sustainable forest management and provide adequate incentives to developing countries to advance such management, including for conservation and reforestation

15.c Enhance global support for efforts to combat poaching and trafficking of protected species, including by increasing the capacity of local communities to pursue sustainable livelihood opportunities 


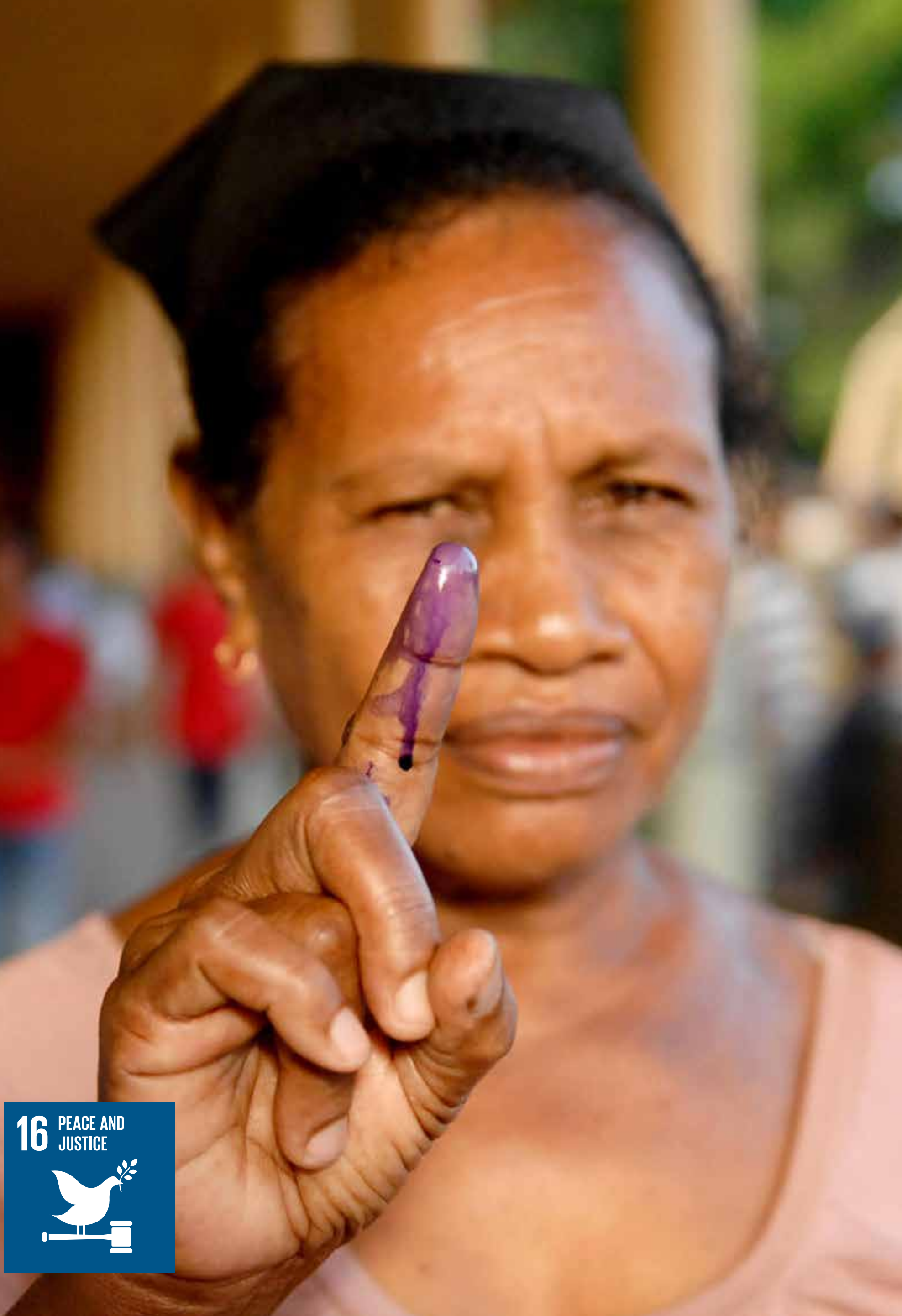




\section{Promote peaceful and} inclusive societies for sustainable development, provide access to justice for all and build effective,

\section{accountable and inclusive} institutions at all levels

\section{OUTLOOK}

The starting point for achieving this goal is challenging. Poor governance in the region has a negative impact on sustainable development and is a major factor contributing to growing inequalities,' political, social and economic marginalization and the exclusion of different segments of the population. ${ }^{2}$ Discrimination and marginalization are at the root of the increased radicalization of youth and the increasing violent extremism in the region. Without addressing the underlying governance challenges and strengthening systems and institutions, countries will face immense difficulties in achieving the other 16 SDGs. 


\section{INSIGHTS}

- Peaceful and inclusive societies are fundamental for sustainable development. Better governance systems allow for the development of people-centric policies, social inclusion and effective, transparent, accountable and responsive institutions, all of which are important for sustainable development. ${ }^{3}$ Existing methodologies and capacities to measure effectiveness, accountability, inclusion and responsiveness of institutions are limited, however. Systematic methodologies need to be developed to measure the indicators for SDG targets 16.6 and 16.7. Countries and stakeholders need to be supported to collect comparable and disaggregated data. The data also would be useful for monitoring targets for SDGs 1, 3, 4, 7, 10 and 11.

- Corruption is a major driver of inequality in the region. ${ }^{5}$ An estimated 40 per cent of investments in electricity, water and sanitation are lost due to corruption. ${ }^{6}$ Illicit financial flows from the region accounted for about 40 per cent of the total illicit outflows from developing countries from 2004 to 2013.7 Illicit financial flows severely limit the overall finances available for development and significantly offset international commercial resource inflows (such as foreign direct investment) into the region. ${ }^{8}$ (Illicit financial flows are discussed in SDG 17 Finance). SDG target 16.5 calls for reducing corruption and bribery in all their forms.

- SDG 16 has one composite target on reducing all forms of violence and related deaths. Its indicators currently focus on measuring intentional homicide (as proposed under the International Classification of Crime for Statistical Purposes). There are calls for reporting conflict-related deaths separately because it is a "distinct phenomena with differing root causes as well as varying levels of precision in measurement". ${ }^{9}$ Conflict-related deaths do not overlap with intentional homicides.

- In the estimates of forced labour, which is a proxy for human trafficking, the Asia-Pacific region has the largest number of victims, at 11.7 million people in 2012. Efforts to determine the prevalence of modern slavery (another proxy for human trafficking) suggest a larger number. SDG targets 5.2, 8.7 and 16.2 directly address human trafficking; these targets cut across issues, from poverty, inequality, decent work and corruption to migration, gender, youth, climate and conflict. Indicator 16.2 .2 on the number of victims of human trafficking per 100,000 population by sex, age and form of exploitation reflects a need for much more significant efforts to identify and assist victims of trafficking.

- The dearth of data is a severe limitation for making sense of the complex governance challenges and limits the monitoring of SDG 16 targets and indicators. Investing in data collection (with a human rights-based approach) and using the disaggregated data are essential. Involving non-state actors to collect and provide supplementary data could solve some of the challenges. 


\section{BRIGHT SPOTS}

\section{Safe societies}

- In 2012, the latest year for which comparable data are available for all regions of the world, Asia and the Pacific had 2.8 homicides per 100,000 population, far less than the global average of 5.4 homicides per 100,000 population Several countries and areas in Asia and the Pacific have some of the lowest homicide rates in the world, such as Singapore and Japan, at 0.3 per 100,000 population in 2014; and Hong Kong, China, at 0.9 per 100,000 population in $2013 .{ }^{10}$

\section{Rule of law and access to justice}

- The region had the smallest number of people in prisons in 2014 , when compared with other regions globally, at 93.2 prisoners per 100,000 population (the global average is 140.3 prisoners per 100,000 population. ${ }^{11}$ However the figures vary greatly among the subregions, ranging from 48.7 in South and South-West Asia to 145.1 in South-East Asia. ${ }^{12}$

- The Coordinated Mekong Ministerial Initiative Against Trafficking (COMMIT) Process has increased regional cooperation to address human trafficking in the Mekong subregion and collect relevant data. The efforts to address trafficking for labour exploitation in the fisheries industry, for example, reflect an understanding of the complexities in the forced labour phenomenon of migrant workers and its interaction with environmental degradation, decent work, corruption and labour migration. ${ }^{13}$

\section{Effective and inclusive societies}

- The best proxy information on legal identity is the available data on birth registration coverage, although such data do not exist for all countries in the region and are rarely collected on a routine basis. Latest country data show that the proportions of children younger than 5 years whose births have been registered remain low in Afghanistan (at 37 per cent in 2011), Bangladesh (at 37 per cent in 2013) and Pakistan (at 33.5 per cent in 2013). ${ }^{14}$ In 2014, the Asian and Pacific Civil Registration and Vital Statistics Decade 2015-2024 was proclaimed and efforts are being made to "get everyone in the picture". Data on birth registrations will be increasingly available through this initiative. ${ }^{15}$

\section{HOTSPOTS}

\section{Rule of law and access to justice}

- On average between 2012 and 2014, more than 450,000 prisoners in the region were held without trial or awaited trial, with a low in Georgia of 4.2 per cent of all prisoners to a high of more than 60 per cent of all prisoners in the Philippines (61.6 per cent) and in India (67.6 per cent). In India, that figure equates to more than a quarter of a million prisoners. ${ }^{16}$ 


\section{Effective and inclusive institutions}

- LGBTI (lesbian, gay, bisexual, transgender and/or intersex) people face widespread and often multiple forms of discrimination and exclusion in all contexts. The exclusion of LGBTI people from the design, implementation and monitoring of laws and policies that affect them perpetuates their social and economic marginalization. ${ }^{17}$

- Overall, women's political participation continues to be low, compared with other regions (see the SDG 5 profile). ${ }^{18}$

- Youth have low political participation. Of the 45 countries in the region surveyed, the proportion of parliamentarians younger than 30 in lower and single houses was 1.1 per cent for Asia and 0.6 per cent for the Pacific, both of which are less than the global average of 2.1 per cent. ${ }^{19}$

- With countries adopting restrictive laws that limit the space for civil society to operate and inclusion in decision-making processes, civil society engagement and participation is shrinking. ${ }^{20}$

\section{Safe societies}

- Many female victims of intimate partner or family-related homicides are found in Asia and the Pacific; the estimated total number of such deaths was 19,900 in 2012, or 46 per cent of all estimated intimate partner or family-related homicides worldwide. ${ }^{21}$

- In South and East Asia and the Pacific, economic forces are driving human trafficking, with 64 per cent of identified victims trafficked into forced labour, servitude and slavery. ${ }^{22}$ Eighty-three per cent of the identified victims of trafficking in the region are women or girls, compared with 60 per cent globally. And 40 per cent of the identified victims in South Asia and 30 per cent in East Asia are children. ${ }^{23}$

- At least 13 countries are considered in a status between warning and high alert on the Fragile States Index..$^{24}$

\section{EMERGINGISSUES}

- Increased marginalization and exclusion of young people is creating conditions for the rise of violent extremism in the region. Opportunities need to be created for young people to engage in mainstream political and economic processes.

- There are 95 million international migrants in the region, with many more internally displaced. ${ }^{25}$ Climate change and other shocks are expected to further exacerbate conditions that could force millions of people to migrate. More needs to be done to improve safety nets and protect people's basic rights. 


\section{TARGETS}

16.1 Significantly reduce all forms of violence and related death rates everywhere

16.2 End abuse, exploitation, trafficking and all forms of violence against and torture of children

16.3 Promote the rule of law at the national and international levels and ensure equal access to justice for all

16.4 By 2030, significantly reduce illicit financial and arms flows, strengthen the recovery and return of stolen assets and combat all forms of organized crime

16.5 Substantially reduce corruption and bribery in all their forms

16.6 Develop effective, accountable and transparent institutions at all levels

16.7 Ensure responsive, inclusive, participatory and representative decision- making at all levels

16.8 Broaden and strengthen the participation of developing countries in the institutions of global governance

16.9 By 2030, provide legal identity for all, including birth registration

16.10 Ensure public access to information and protect fundamental freedoms, in accordance with national legislation and international agreements

16.a Strengthen relevant national institutions, including through international cooperation, for building capacity at all levels, in particular in developing countries, to prevent violence and combat terrorism and crime

16.b Promote and enforce non-discriminatory laws and policies for sustainable development 


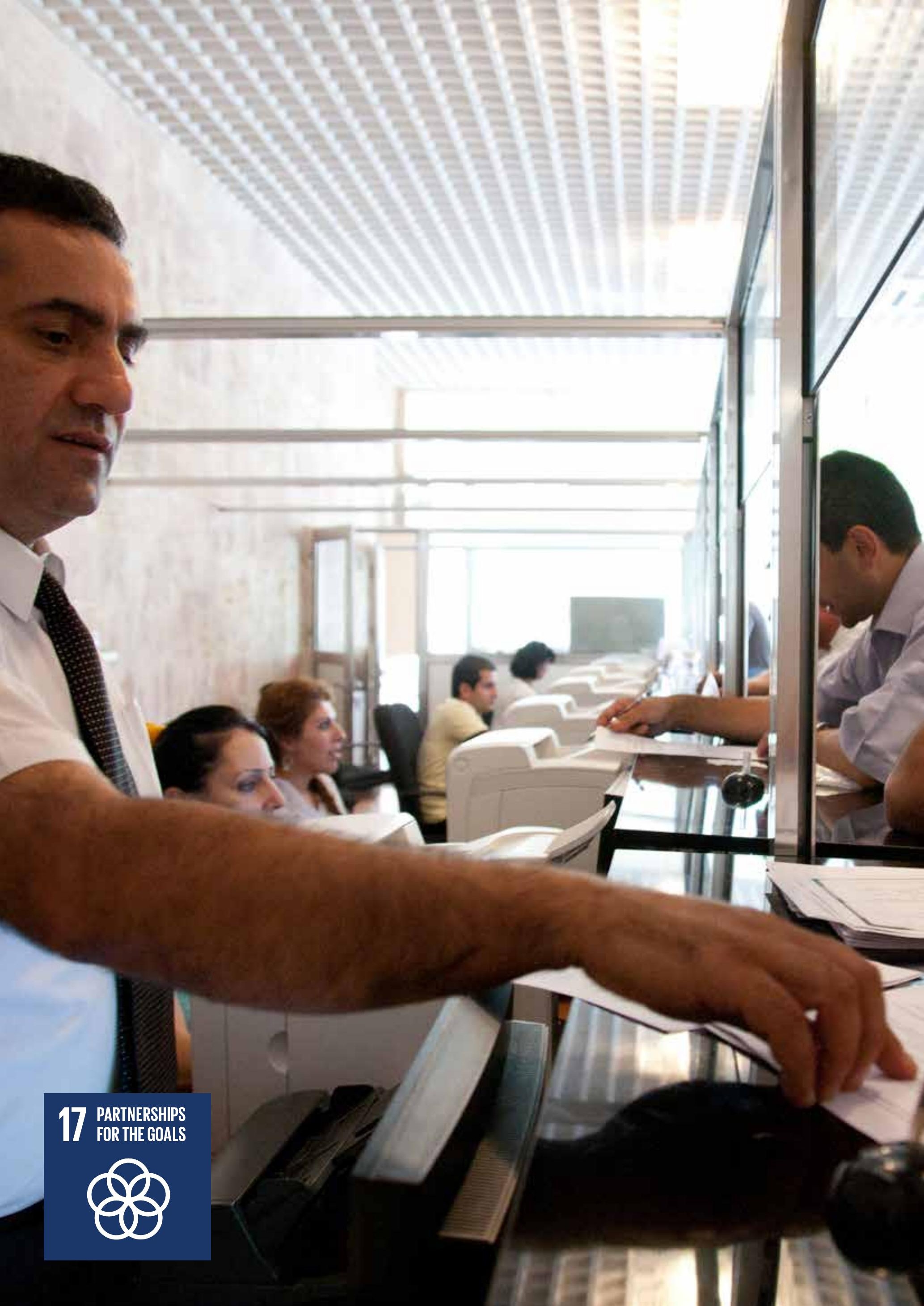


-1 (1 (1 口 (1) प

Strengthen the means of implementation and revitalize the Global Partnership for Sustainable Development

\section{Finance}

\section{OUTLOOK}

Financial resources across the region as a whole are strengthening rapidly and diversifying — savings are growing, a vibrant private finance sector is emerging in many countries, and governments are recognizing the need for stronger domestic resource mobilization efforts. Nevertheless, SDG implementation requires continued fiscal and public sector reforms, alongside improved systems of taxation and collection in most countries. The availability of concessional and risk-tolerant finance (including official development assistance) will be a key factor in helping countries make progress on the SDGs, particularly in countries with special needs, such as least developing countries and small island developing countries. 


\section{Strengthen the means of implementation and revitalize the Global Partnership for Sustainable Development}

\section{INSIGHTS}

- Total financing (domestic public and private and external public and private) grew from \$4 trillion in 2005 to $\$ 8.9$ trillion in 2014 . $^{1}$ Domestic resources (public domestic and private domestic) are driving the increase in the overall envelope of available funds. In 2014, domestic resources accounted for 89 per cent of all resources. ${ }^{2}$

- Financing flows that support development across the region have been diversifying over the past two decades. Between 2012 and 2014, the region had a total of $\$ 6.2$ trillion in private savings, $\$ 3.5$ trillion in sovereign wealth and pension funds and $\$ 1.3$ trillion in insurance premiums. $^{3}$

- Remittances as foreign direct investment (FDI) have overtaken official development assistance (ODA) in importance, and public finance has grown in terms of share of GDP. In lowermiddle-income countries, public sector and ODA financing have contracted slightly, although remittance flows and FDI increased slightly. Financing for development in upper-middleincome countries, by contrast, has been lifted by public sector financing and a steady flow of FDI. ${ }^{4}$

- While ODA and other official flows of funds are now relatively modest, compared with other sources of finance, it is still an important source of support for many countries in the region. One third of the total ODA flows in 2015 went to developing countries in the region. ODA also continues to have an important role in the least developed and small island developing countries. The ODA that Afghanistan, Kiribati, Marshall Islands, Federated States of Micronesia, Nauru and Tuvalu each received in the past decade totalled more than 20 per cent of their annual GDP. ${ }^{5}$

- To better utilize all types of financing resources and to better manage the complexity overall, countries need to concentrate on adapting their policy frameworks, institutional arrangements and their systems of financial management and monitoring.

\section{BRIGHTSPOTS}

\section{Domestic resource mobilization}

- In 2014, around 22 countries in Asia and the Pacific had tax-to-GDP ratios greater than 15 per cent, while some Central Asian and Pacific countries went beyond 20 per cent. The Addis Tax Initiative, a partnership among countries to support transparent, fair and efficient tax systems, holds promise for better domestic resource mobilization efforts. Of its 37 member countries and regional organizations, six are from the region (Australia, Georgia, Indonesia, the Republic of Korea, the Philippines and Solomon Islands). 
- In 2015, four of the ten economies globally with the highest gross domestic saving ratio were in the Asia-Pacific region, averaging more than 40 per cent of their GDP: Macau, China, at 64 per cent; Brunei Darussalam, at 55 per cent; Singapore, at 53.7 per cent; and China, at 49 per cent. These economies also outperformed the world average, at 24 per cent, and the Organisation for Economic Co-operation and Development's (OECD) average, at 21 per cent. ${ }^{6}$ Transfers from developing countries with savings surpluses also contribute towards raising the global savings pool.

- Domestic resource mobilization is central to the Addis Ababa Action Agenda. In the outcome document, countries agreed to a range of measures for widening the revenue base, improving tax collection and combating tax evasion and illicit financial flows. Countries also reaffirmed their commitment to ODA, particularly for least developed countries, and pledged to increase South-South cooperation.

\section{Official development assistance}

- Total ODA to the region nearly tripled between 2000 and 2015 in constant terms, growing much faster than the total for all developing countries.

- In 2015, ODA from all donors reporting to the OECD Development Assistance Committee totalled $\$ 62$ billion, the highest ever reached since 2000 in real terms. The sources of assistance included China, Thailand and Turkey-developing countries that are now donors.

\section{Additional financial resources and management}

- New banks that pool public financing have been created, including the New Development Bank and the Asian Infrastructure Investment Bank, complementing regional and national initiatives. ${ }^{7}$ Longer-standing banks are innovating to increase the amount of financing they can make available. Infrastructure financing has been a particular focus for development finance institutions in the region.

- To improve the coherent management of all sources of finance, there is increasing interest by countries to establish an integrated national financing framework, as called for in the Addis Ababa Action Agenda.

\section{口OTSPOTS}

\section{Domestic resource mobilization}

- The tax-to-GDP ratio in the region is less than the global average, reinforcing the need for stronger government efforts to mobilize domestic resources. The region only marginally outperformed Africa's tax-to-GDP ratio in 2013 and underperforms generally, when compared with all other regions of the world. More than $\$ 250$ billion could be mobilized just by closing tax gaps in the region's developing countries. ${ }^{8}$ 
- Afghanistan, Bangladesh, India, Indonesia and Myanmar are some of the countries with a low tax-to-GDP ratio, ${ }^{9}$ which will constrain future resource mobilization.

- Direct taxes on income as a proportion of total tax revenue are small, and taxes on wealth and property remain limited. There is interest in more effective taxation of industries, including extractive industries.

\section{Official development assistance}

- Traditional ODA from industrialized countries has fallen short of the targeted 0.7 per cent of their gross national income. Total ODA from OECD Development Assistance Committee countries as a share of their gross national income was 0.3 per cent in 2015 . Seven countries met the target: Denmark, Luxembourg, the Netherlands, Norway, Sweden, the United Arab Emirates and the United Kingdom. ${ }^{10}$ Advocacy for industrialized countries to meet the target of 0.7 per cent of gross national income for ODA remains crucial.

\section{Illicit financial flows}

- From 2004 to 2013, illicit financial flows averaged around 3.8 per cent of GDP in Asia and have grown by 8.6 per cent over the past decade. Eight of the 15 countries with the highest average illicit financial flows globally are in the Asia region. ${ }^{11}$

- Illicit financial flows, estimated at $\$ 482$ billion in 2013 , comprise about 40 per centof the total for all developing countries and stunt the region's potential. Tax avoidance, tax evasion, transfer pricing abuses and trade mis-invoicing account for nearly two-thirds of the illicit financial flows. ${ }^{12}$

\section{EMERGINGISSUES}

- The trends affecting the finance landscape in the region include the fluctuating commodity prices and continuing uncertainty in energy markets, global political developments (including in the European Union and the United States) and economic developments, particularly economic contraction in China and demonetization in India.

- High external debt, comprising more than 40 per cent of GDP in landlocked developing countries, ${ }^{13}$ and rising household debt in such countries as Malaysia and Thailand, are concerns.

- Efforts to ensure that increased availability of climate finance from diverse sources will flow towards investment needs to address climate change are crucial (see the SDG 13 profile).

- The current period of low energy prices presents transformational opportunities for reducing or eliminating perverse subsidies, including for fossil fuels.

- The impacts of efforts to update the measurement of ODA while ensuring that commitments to deliver grant and concessional resources are met, ensuring the coherence of tax regimes and stemming illicit financial flows, as well the ongoing strengthening of public financial management, will influence the capacity of the region to meet the financing requirements for achieving the SDGs. 


\section{TARGETS}

\section{Finance}

17.1 Strengthen domestic resource mobilization, including through international support to developing countries, to improve domestic capacity for tax and other revenue collection

17.2 Developed countries to implement fully their official development assistance commitments, including the commitment by many developed countries to achieve the target of 0.7 per cent of gross national income for official development assistance (ODA/GNI) to developing countries and 0.15 to 0.20 per cent of ODA/GNI to least developed countries; ODA providers are encouraged to consider setting a target to provide at least 0.20 per cent of ODA/ GNI to least developed countries

17.3 Mobilize additional financial resources for developing countries from multiple sources

17.4 Assist developing countries in attaining long-term debt sustainability through coordinated policies aimed at fostering debt financing, debt relief and debt restructuring, as appropriate, and address the external debt of highly indebted poor countries to reduce debt distress

17.5 Adopt and implement investment promotion regimes for least developed countries 


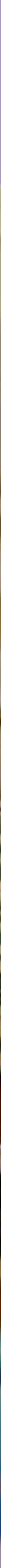


-1 (1 (1 $\square$ $\square+10 \square \square$ 17

\section{Strengthen the means of} implementation and revitalize the Global Partnership for Sustainable Development

\section{Technology}

\section{OUTLOOK}

The prospects for achieving this goal are positive. There is potential for the region to take a leading role in global and regional science, technology and innovation (STI) cooperation to benefit least developed countries and other developing countries, given that the region is home to some of the most technologically advanced and innovative countries in the world. But considering that the region also encompasses some of the most technologically deprived countries, technology transfer policies and strategies are in need of innovation themselves if the region as a whole is to reap the benefits of the technological revolution. 


\section{Strengthen the means of implementation and revitalize the Global Partnership for Sustainable Development}

\section{INSIGHTS}

- This goal focuses on international partnership and its use for technological innovation, covering the terms of transfer and the global Technology Facilitation Mechanism—rather than STI capacity within each country. However, the absorptive capacity ${ }^{1}$ of countries is important to consider in this context because it determines the degree to which countries benefit from access to STI cooperation.

- The debate on international technology cooperation has long been dominated by one-way technology transfer. Ensuring that STI cooperation contributes to the achievement of the 2030 Agenda requires a re-orientation towards more collaboration and technology sharing. ${ }^{2}$

- There is increasing advocacy around redefining the parameters of technology transfer, dissemination and diffusion so that they contribute to sustainable development. The success of technology cooperation will be increasingly defined in terms of how it can also deliver social inclusiveness and environmental sustainability-beyond the traditional economic-based metrics. ${ }^{3}$ Technology and its benefits need to reach the poorest households, consistent with the "leaving no one behind" aspiration of the 2030 Agenda.

- Cooperation by national governments (including through education spending) with academia and the private sector (including support from philanthropy) on new technologies can support innovation. This collaboration can also support a renewed and widespread focus on long-term investments in research, capacity building, sustainable innovation and technology. There also is an important role for open platforms for sharing scientific knowledge and collaboration. ${ }^{4}$

- Technologies available in the public domain could support technological development in poorer countries. Lack of knowledge about these technologies and capacity to use them, however, are important constraint. ${ }^{5}$

- Successful adaptation by countries of technologies from the rest of the world requires more advanced education and well-trained and highly skilled knowledge workers. This speaks to the expanded education focus of SDG 4, which goes beyond formal education. 


\section{BRIGHTSPOTS}

\section{International cooperation on science, technology and innovation}

- A number of multistakeholder mechanisms dealing with STI have been established at the United Nations, including the Technology Facilitation Mechanism at the global level. In contrast to previous STI cooperation mechanisms, the recently established ones include representatives beyond member States and recognize the role of indigenous knowledge. This inclusive and multistakeholder approach bodes well for ensuring that various perspectives are represented in shaping United Nations' priorities and programmes. $^{6}$

- The region has large potential to lead regional and global STI cooperation:

- Research and development expenditure: The region's share of world expenditure on $R \& D$ rose from 35.3 per cent in 2007 to 42.1 per cent in 2013.

- Research capacity: The region's percentage share of global researchers rose from 41 per cent in 2007 to 44 per cent in $2013 .{ }^{8}$

- Frontier technologies: China, Japan and the Republic of Korea are among a small group of countries that are driving innovation in frontier technologies, including robotics and 3D printing. Chinese applicants, for instance, account for more than a quarter of patents worldwide in robotics and 3D printing - the largest share among all countries as of 2015. ${ }^{9}$ These technologies will have a profound impact on the types of jobs in both industrialized and developing countries. In many developing countries without a legacy of technology systems, frontier technology is much easier to implement.

- Environmental technologies: Japan accounted for approximately 22 per cent of environment-related technologies developed worldwide as of 2012, with Australia, China, India, Indonesia, New Zealand, the Republic of Korea, the Russian Federation and Turkey accounting for approximately 15 per cent. ${ }^{10}$ This is a specific group of technology called for in SDG target 17.7.

- Technology hubs: There are 287 technology hubs in South and SouthEast Asia, a number that is growing on a weekly basis. ${ }^{11}$ 


\section{HOTSPOTS}

\section{Access to science, technology and innovation}

- Although there are already a number of STI platforms in many ESCAP subregions (Association of Southeast Asian Nations, the South Asian Association for Regional Cooperation and the Asia-Pacific Economic Cooperation), they are unconnected and do not include many economies, such as many Pacific island countries. A total of 19 countries do not belong to any cooperation platform or mechanism. ${ }^{12}$

- Eight countries rank in the top quartile of the Global Innovation Index, while nine countries rank in the bottom quartile. ${ }^{13}$ Many countries have no expenditure on R\&D at all. ${ }^{14}$

- Access to information and communications technology is the backbone of an innovative economy (and is also considered a means of achieving SDG 9); yet, the region is one of the most digitally divided in the world ${ }^{15}-72$ per cent of fixed-broadband subscribers reside in North and North-East Asia. ${ }^{16}$ In other parts of the region, regulatory shortcomings and affordability impact fixed-broadband penetration.

- Research inequalities remain, with 95 per cent of the region's researchers located in just five countries. ${ }^{17}$

\section{EMERGINGISSUES}

- Technology and innovation may result in some displacement of jobs by smart machines and innovative processes. While the adoption of new technology may result in job creation and an increase in productivity in many sectors, it will not be automatically inclusive if the displaced workers are not able to adapt or move to other sectors. ${ }^{18}$ These changes underscore the importance of retooling workers with knowledge-based skills so they can adapt to automation and technology-led business models.

- Traditional thinking that technological innovation only comes from higher education institutions is increasingly challenged by the swift transformation and creation of knowledge outside these institutions. Industry practitioners and field experts have been important technology innovators. A broader and more inclusive process of technology support and education is increasingly required.

- To complement national efforts, the potential of subnational cooperation (between cities) to provide a viable vehicle for technology cooperation deserves further consideration. The similarities of socioeconomic circumstances and challenges encountered between two cities could provide a more compelling case for technology cooperation than broader national interests. $^{19}$

- Future developments in the trade and foreign direct investment regimes will be critical in the evolution of intellectual property regulations that can facilitate wider access to technology without stifling the competition that drives innovation. 


\section{TARGETS}

\section{Technology}

17.6 Enhance North-South, South-South and triangular regional and international cooperation on and access to science, technology and innovation and enhance knowledge sharing on mutually agreed terms, including through improved coordination among existing mechanisms, in particular at the United Nations level, and through a global technology facilitation mechanism

17.7 Promote the development, transfer, dissemination and diffusion of environmentally sound technologies to developing countries on favourable terms, including on concessional and preferential terms, as mutually agreed

17.8 Fully operationalize the technology bank and science, technology and innovation capacitybuilding mechanism for least developed countries by 2017 and enhance the use of enabling technology, in particular information and communications technology 

-1 (1 (1 $\square$ प1口 17

\section{Strengthen the means of} implementation and revitalize the Global Partnership for Sustainable Development

\section{Trade}

\section{OUTLOOK}

The starting point looks good, but there is substantial uncertainty due to the global economic conditions, lack of progress in multilateral trade liberalization, potential weakening of the global trade regime under the World Trade Organization due to parallel trade liberalization initiatives and pressures for use of more protectionist measures. Least developed countries remain particularly vulnerable to external shocks, and their production structure constrains them from fully benefiting from trade. The potential contribution of agriculture as an instrumental sector for poverty reduction is limited by both tariff and non-tariff measures affecting agricultural trade and production. 


\section{Strengthen the means of implementation and revitalize the Global Partnership for Sustainable Development}

\section{$\square$ INSIGHTS}

- The high growth rates of exports in least developed countries and developing countries between 2000 and 2010 were mainly enabled by high commodity prices and rising demand from emerging markets (especially China). Both drivers have since weakened. Global and regional economic headwinds will impact, to a large extent, the feasibility of achieving these targets.

- More and much better data are needed to track other factors (beyond tariff rates) that impact market access for developing countries. Small island developing countries and least developed countries continue to be affected by non-tariff measures and high trade costs. Systematic collection of data and analysis of non-tariff measures is needed. Full implementation of the World Trade Organization's Trade Facilitation Agreement can potentially reduce trade costs for developing countries in Asia and the Pacific by up to 17 per cent. ${ }^{1}$ Yet, no indicators currently proposed take into account the reduction of trade costs.

- Greater attention need to be given to the recent developments in international trade policies, in order to maintain and improve the preferential market access of least developed countries.

- Services and services trade are irreplaceable factors that enable industrialization and deeper production and export diversification of developing and least developed countries. Around 30 per cent of the current Asia-Pacific industrial exports depends on services inputs, and many least developed countries with no access to efficient services remain excluded from production networks. ${ }^{2}$

- To effectively harness trade in a way that will contribute towards achieving all the SDGs, countries need to continue their commitment towards promoting a universal, rules-based, open, non-discriminatory and equitable multilateral trading system.

\section{BRIGHTSPOTS}

\section{A rules-based, open, non-discriminatory and equitable multilateral trading system}

- Weighted tariffs applied by the economies in the region are falling (in the subsectors analysed-agriculture, industrial and petroleum products)—but are higher in the agriculture sector, on average.

- The increasing number of regional trade agreements and expanding generalized schemes of preference available to least developed and developing countries are likely to promote continued decreases in tariffs. ${ }^{3}$ 


\section{Expanding share of developing country exports ${ }^{4}$}

- Developing countries of Asia and the Pacific have increased their share in world merchandise exports, from 24.4 per cent in 2005 to 33.2 per cent in 2015, and have recorded an increase in the share of their services exports, from 14.4 per cent to 23.6 per cent over the same period. ${ }^{5}$ This remarkable increase was driven by only a few high-performing economies, especially China. If the contribution of China is excluded, the share of developing countries in the region in world merchandise exports in 2015 becomes 19.7 per cent, and the share of services export becomes 17.6 per cent. ${ }^{6}$ Developing economies in the region include major export-oriented economies, like Hong Kong, China, the Republic of Korea and Singapore, which inflates export shares.

\section{HOTSPOTS}

Least developed country exports and market access, especially for agricultural products

- Least developed countries within the region accounted for only 0.2 per cent of global exports (goods and services combined) in 2015. There has been a substantial slowdown in the growth rate of this share since 2010, compared with the 2005-2010 period.?

- The 2030 Agenda targets the doubling of the world exports share of least developed countries by 2020 . ESCAP, however, showed in $2015^{8}$ that some least developed countries might fail to reach this target. Based on the historical growth rates, the target seems attainable for such countries as Bangladesh, Cambodia, the Lao People's Democratic Republic, Solomon Islands and Timor-Leste. This target will be ambitious for other least developed countries, such as Afghanistan, Bhutan, Kiribati, Myanmar, Nepal, Tuvalu and Vanuatu.

- On average, developing countries, least developed countries and small island developing countries of the region experienced a fall in tariff rates imposed by industrialized countries between 2002 and 2013. But the tariffs levied by industrialized countries on agricultural exports were higher than the average tariffs, and declines in the tariffs on agricultural exports were lower than the average decline in tariffs. In 2014, agriculture exports from developing countries and least developed countries of East Asia and SouthEast Asia encountered the highest average tariffs in industrialized country markets, when compared with tariffs on agriculture exports originating from developing countries and least developed countries in other regions. ${ }^{9}$

- There is an increasing trend in the use of non-tariff measures across the agriculture and non-agriculture sectors. 


\section{EMERGINGISSUES}

- Trade-related indicators within the SDG framework do not fully capture many significant emerging issues, such as services trade restrictions, non-tariff measures, quality of exports or e-commerce. These indicators need to be closely monitored.

- The number of preferential trade agreements, which tend to exclude least developing countries, is on the rise. This may lead to erosion in the relative preference margin obtained by least developed country exports ${ }^{10}$ and can emerge as an important impediment in the expansion of exports from least developed countries.

- The increasing use of non-tariff measures presents a big challenge to market access for exports from developing countries, including least developed countries. ${ }^{11}$

- Digital trade, or e-commerce, is emerging as an important enabler of trade. Countries need to evaluate their readiness and capability to develop digital trade and monitor its impact on sustainable development.

- Services trade has been gaining prominence in terms of its role in facilitating global trade and global value chains. SDG indicators do not take into account services trade restrictiveness, and this needs to be monitored.

- Given the focus of the 2030 Agenda on environmental dimensions, there will be increased trade of environmental goods and services that will help reduce environmental damage, contribute to environmental monitoring and make the production system (including energy production) and consumption systems more environment friendly. This could be a new trade opportunity facilitated by the 2030 Agenda.

- Plurilateral trade negotiations are expected to gain more prominence, and their impact on the multilateral global trading system needs to be closely watched.

\section{TARGETS}

\section{Trade}

17.10 Promote a universal, rules-based, open, non-discriminatory and equitable multilateral trading system under the World Trade Organization, including through the conclusion of negotiations under its Doha Development Agenda

17.11 Significantly increase the exports of developing countries, in particular with a view to doubling the least developed countries' share of global exports by 2020

17.12 Realize timely implementation of duty-free and quota-free market access on a lasting basis for all least developed countries, consistent with World Trade Organization decisions, including by ensuring that preferential rules of origin applicable to imports from least developed countries are transparent and simple, and contribute to facilitating market access 


\section{Conclusions}

This assessment for the achievement prospects of the SDGs takes into account the official indicators agreed by the Inter-Agency and Expert Group on SDG Indicators (IAEG-SDG) as of December 2016. But it also relies on expert interpretation and insights to provide a snapshot of the region's potential to achieve the SDGs.

The SDGs are diverse and interlinked, and within each goal, the targets are themselves varied. Practical methods, tools and indicators to capture the links (for example, the nexus between climate, land use, energy and water strategies) must be better used and operationalized at the country level. There are also numerous blind spots-targets that countries may not know enough about at the moment. Partnerships in follow-up and review are needed to mobilize the investment required to effectively track progress on the SDGs.

The preparation of this report was constrained by indicator and data gaps. Many of these gaps will be addressed as the work of the IAEG-SDG continues. But this will take time. Technical and institutional innovations in data gathering can capture perspectives and trends beyond the official statistics. To carry out effective follow-up and review for the SDGs, governments need to better use the multidisciplinary expertise that exists across their structures and seek access to expertise that strengthens their capacity to develop integrated policies and strategies.

Moving forward, it is important to engage the whole range of stakeholders in developing a bettershared understanding of future challenges. The perspectives captured in this report can serve as a starting point for dialogue with stakeholders in various regional forums, such as the Asia-Pacific Forum on Sustainable Development, and at the national level. Many of the cross-cutting issues highlighted can benefit from regional action, peer learning and cooperation. By providing a basis for regional dialogue, the knowledge products of the ESCAP, ADB and UNDP partnership will extend meaningful support to national implementation efforts as well as to regional peer learning. 


\section{Endnotes}

\section{NO \\ POVERTY \\ min}

1. Other forms of poverty exist beyond income poverty, and they are related to the lack of access to education and health services, modern energy services, safe drinking water, sanitation and adequate food and nutrition. Climate-related impacts and natural disasters can worsen the deprivation of vulnerable groups and marginalized communities of people from the public provisioning of development-oriented services.

2. PPP=purchasing power parity.

3. Calculated by ESCAP. Due to changes in the methodology applied for the China 2013 household survey, on which poverty data for that year are based, the comparability with previous years is subject to caution. For further information, please see World Bank, Poverty and Shared Prosperity 2016: Taking on Inequality (Washington, D.C., 2016).

4. Based on data from UNDP on multidimensional poverty. Available from http://hdr.undp.org/en/composite/MPI (accessed 19 December 2016). See also http://hdr.undp.org/sites/default/files/hdr2015_technical_notes.pdf.

5. ESCAP, Time for Equality (Bangkok, United Nations, 2015).

6. World Bank, Poverty and Shared Prosperity 2016. Taking on Inequality (Washington, D.C., 2016); A. Castañeda, and others, Who Are the Poor in the Developing World? Policy Research Working Paper 7844 (Washington, D.C., World Bank, 2016).

7. ESCAP, Statistical Database based on World Bank, Development Research Group. Available from http://data. unescap.org (accessed 15 February 2017).

8. ibid.

9. ibid.

10. ibid.

11. ibid.

12. ESCAP, Statistical Database, based on International Labor Organization - ILOSTAT. Available from http://data. unescap.org (accessed 15 December 2016).

13. M. Garschagen, and others, World Risk Report 2015 (Berlin and Bonn, Alliance Development Works and United Nations University - Institute for Environment and Human Security, 2015).

14. Calculated as people affected, injured and made homeless.

15. ESCAP, Statistical Database, based on Emergency Events Database. Available from http://data.unescap.org (accessed 15 December 2016). 


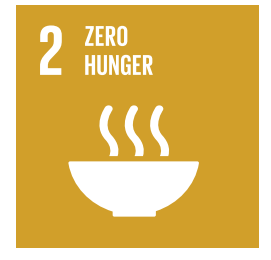

1. Three anthropometric measures are used to measure undernourishment. These are height for age, weight for age and weight for height. The impact of price variation and/or natural calamity are generally reflected in weight for age, or wasting.

2. FAO, The State of Food Insecurity in the World 2003: Monitoring Progress Towards the World Food Summit and Millennium Development Goals (Rome, 2003).

3. ESCAP, Statistical Database, based on United Nations Statistics Division MDG Indicators Database. Available from http://data.unescap.org (accessed 15 December 2016).

4. ESCAP, Statistical Yearbook for Asia and the Pacific 2015 (Bangkok, United Nations, 2015).

5. FAO, Statistical Yearbook for Asia and the Pacific 2014 (Bangkok, United Nations, 2014).

6. T. Reardon, “Asia agrifood system's 5 linked transformations: Implications for agricultural research and development studies”, paper presented at the CGIAR-ISPC Workshop, Boston, MA, 25-26 January 2013.

7. ESCAP, Statistical Database, based on United Nations Statistics Division MDG Indicators Database. Available from http://data.unescap.org (accessed 15 December 2016).

8. FAO, Asia and the Pacific: Regional Overview of Food Insecurity (Bangkok, 2016).

9. ESCAP, Statistical Yearbook for Asia and the Pacific 2015 (Bangkok, United Nations, 2015).

10. ESCAP Statistical Database, based on UNICEF data. Available from http://data.unescap.org (accessed 15 December 2016).

11. ibid.

12. FAO, Asia and the Pacific: Regional Overview of Food Insecurity (Bangkok, 2016).

13. UNEP, GEO-6: Regional Outlook for Asia and the Pacific (Bangkok, 2016).

14. ESCAP, Statistical Yearbook for Asia and the Pacific 2015 (Bangkok, United Nations, 2015).

15. FAO, Statistical Yearbook for Asia and the Pacific 2014 (Bangkok, 2014).

16. FAO, State of Food and Agriculture, 2016 (Rome, 2016).

17. Afghanistan, $98.6 \%$ (2000); Bhutan, $94.1 \%$ (2008); India, $90.4 \%$ (2010); Islamic Republic of Iran, $92.2 \%$ (2004); Kyrgyzstan, 93 \% (2006); Lao People's Democratic Republic, $91.4 \%$ (2005); Nepal, 98.1\% (2006); Pakistan, $94 \%$ (2008); Tajikistan, $90.9 \%$ (2006); Thailand, $90.4 \%$ (2007); Timor-Leste $91.4 \%$ (2004); Turkmenistan $94.3 \%$ (2004); Viet Nam, $94.8 \%$ (2005). See FAO, AQUASTAT. Available from www.fao.org/nr/ water/aquastat/main/index.stm (accessed 23 January 2017).

18. FAO, Statistical Yearbook for Asia and the Pacific 2014 (Bangkok, 2014).

19. B. Lipinski, and others, "Reducing food loss and waste", Working Paper, Installment 2 of Creating a Sustainable Food Future (Washington, D.C., World Resources Institute, 2013). Available from www.worldresourcesreport.org.

20. FAO, Asia and the Pacific: Regional Overview of Food Insecurity (Bangkok, 2016). 
1. OECD, Demographic and Health Survey and Multiple Indicator Cluster Survey data, 2005-2013, as cited in WHO and OECD, Health at a Glance Asia Pacific (Bangkok, 2014).

2. WHO, General government health expenditure as percentage of GDP for ASEAN countries, from the Global Health Expenditure Database. Available from http://apps.who.int/nha/database/ViewData/Indicators/en (accessed 15 December 2016).

3. IEG World Bank, IFC and MIGA, Delivering the Millennium Development Goals to Reduce Maternal and Child Mortality - A Systematic Review of Impact Evaluation Evidence (Washington D.C., World Bank, 2015).

4. WHO, World Malaria Report 2016 (Geneva, 2016), pp. 40, 46.

5. ESCAP, Statistical Yearbook for Asia and the Pacific 2015 (Bangkok, United Nations, 2015).

6. ibid.

7. ESCAP, Statistical Database, based on UNICEF. Available from http://data.unescap.org/escap_stat/ (accessed 15 December 2016).

8. PPP=purchasing power parity. ESCAP, Statistical Yearbook for Asia and the Pacific 2015 (Bangkok, United Nations, 2015).

9. Reference is to the WHO "Asia" region, consisting of South-East Asia and the Western Pacific. WHO, Global Tuberculosis Report 2016 (Geneva, 2016).

10. There were 4.74 million cases in South-East Asia and 1.59 million in the Western Pacific (WHO regions). There were an estimated 6.9 million new TB cases in 2015 in the combined WHO region for Asia and the Pacific (WPRO, SEARO, Afghanistan and Pakistan). WHO, Global Tuberculosis Report 2016 (Geneva, 2016).

11. UNAIDS, The GAP Report (Geneva, 2016).

12. UNAIDS, Fact sheet. Available from www.unaids.org/sites/default/files/media_asset/UNAIDS_FactSheet_en.pdf; UNAIDS, Global Report 2016 (Geneva, 2016).

13. UNAIDS, The Gap Report (Geneva, 2014).

14. S. Mattke, and others, "Improving access to medicines for non-communicable diseases in the developing world", Rand Health Occasional Paper (California, 2011).

15. ESCAP, Statistical Database, based on data from the WHO. Available from http://data.unescap.org (accessed 15 December 2016).

16. ESCAP, Statistical Database, based on SDG indicators global database. Available from http://data.unescap.org (accessed 15 December 2016).

17. Combined figures for low- and middle-income countries in the WHO WPRO and SEARO regions. Available from www.who.int/mediacentre/news/releases/2016/deaths-attributable-to-unhealthy-environments/en/ (accessed 19 December 2016). 
1. ESCAP, Statistical Database. Available from http://data.unescap.org (accessed 15 December 2016).

2. UNESCO, Education for All 2000-2015: Achievements and Challenges (Paris, 2015).

3. UNESCO, Online database. Available from www.uis.unesco.org/datacentre/pages/browseeducation.aspx (accessed 15 December 2016).

4. ESCAP, Statistical Database. Available from http://data.unescap.org (accessed 15 December 2016).

5. Adding the three regions together: East Asia and the Pacific (6.5 million) + South and West Asia (11.4 million)+ Central Asia $(0.3$ million $)=18.2$ million. See UNESCO, Institute for Statistics Database. Available from http:// data.uis unesco.org (accessed 21 November 2016).

6. ESCAP, Statistical Database. Available from http://data.unescap.org (accessed 15 December 2016).

7. Institute for Statistics, UIS fact sheet, No. 39 (Paris, UNESCO, 2016).

8. Xin Ma, "Gender differences in learning outcomes", paper commissioned for UNESCO, EFA Global Monitoring Report 2008: Education for All by 2015: Will We Make It? (Paris, 2007). Available from http://unesdoc.unesco.org/ images/0015/001555/155593e.pdf.

9. ESCAP, Statistical Database. Available from http://data.unescap.org (accessed 15 December 2016).

10. J. Sarvi, and H. Pillay, Innovations in Knowledge and Learning for Competitive Higher Education in Asia and the Pacific region (Manila, ADB, 2015).

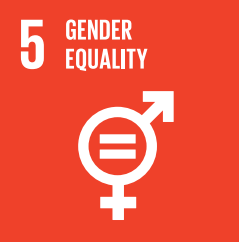

1. ESCAP, Gender Equality and Women's Empowerment in Asia and the Pacific: Perspectives of Governments on 20 Years of Implementation of the Beijing Declaration and Platform for Action (Bangkok, United Nations, 2015).

2. Unless otherwise noted, data on national parliaments refer to representation in single or lower houses of parliament as tracked by the Inter-Parliamentary Union Database. Available from www.ipu.org/wmn- e/classif. htm (accessed 13 December 2016).

3. Calculated based on ESCAP-provided Tier 1 data sets. Available from http://data.unescap.org (accessed 15 December 2016).

4. UNICEF, Global databases, based on Demographic and Health Surveys, Multiple Indicator Cluster Surveys and other nationally representative surveys. Available from http://data.unicef.org/ (accessed 13 December 2016).

5. United Nations Statistics Division Violence against Women data portal. Available from http://unstats.un.org/ unsd/gender/vaw/index.html (accessed 10 March 2017).

6. Data on employment sex ratio, by income category for countries/areas, for 1995, 2000 and 2013 are from ESCAP, Statistical Yearbook for Asia and the Pacfic 2015 (Bangkok, United Nations, 2015) figure 1, p. 2. Available from www.unescap.org/sites/default/files/SDGs_05_SYB2015.pdf.

7. Calculated based on ESCAP, Statistical database. Available from http://data.unescap.org (accessed 15 December 2016).

8. ESCAP, Statistical Yearbook for Asia and the Pacific 2015 (Bangkok, United Nations, 2015).

9. United Nations, Statistics Division time-use data portal. Available from http://unstats.un.org/unsd/gender/ timeuse/ (accessed 13 December 2016). 
10. FAO, Gender and Land Rights Database. Available from www.fao.org/gender-landrights-database/data-map/ statistics/en/ (accessed 13 December 2016).

11. World Bank, Women, Business and the Law Database. Available from http://wbl.worldbank.org/ (accessed 13 December 2016).

12. By international consensus, this figure is considered significant to ensure meaningful change.

13. See the Inter-Parliamentary Union Database. Available from www.ipu.org/wmn-e/classif.htm (accessed 13 December 2016).

14. ADB, Asian Development Outlook 2015 Update: Enabling Women, Energizing Asia (Manila, 2015).

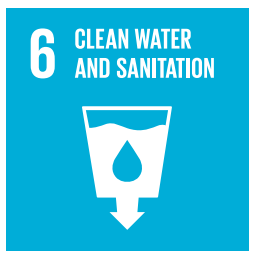

1. ESCAP, Statistical Yearbook for Asia and the Pacific 2015 (Bangkok, United Nations, 2015).

2. E. Corcoran, and others, eds., Sick Water? The Central Role of Wastewater Management in Sustainable Development: A Rapid Response Assessment (Nairobi, UNEP and UN-Habitat, 2010). Available from www.unep. org/pdf/SickWater_screen.pdf.

3. ESCAP, Asia-Pacific Countries with Special Needs. Development Report 2016 on Adapting the 2030 Agenda for Sustainable Development at National Level (Bangkok, 2016). Available from www.unescap.org/resources/asiapacific-countries-special-needs-development-report-2016-adapting-2030-agenda.

4. OECD, "Data”. Available from https://data.oecd.org/ (accessed 13 December 2016).

5. ESCAP, Statistical Database. Available from http://data.unescap.org (accessed 15 December 2016).

6. ibid.

7. ESCAP, UN-Habitat and AIT, Policy Guidance Manual on Wastewater Management with a Special Emphasis on DEWATS (Bangkok, 2015). Available from www.unescap.org/sites/default/files/manual_part1and2_16july15.pdf.

8. ADB, Asia Water Development Outlook 2016 (Manila, 2016).

9. WWAP, The United Nations World Water Development Report 2015: Water for a sustainable world (Paris, UNESCO, 2016).

10. T. Shah, "Groundwater and human development: Challenges and opportunities in livelihoods and environment", Water, Science \& Technology, vol. 51, No. 8 (2005), pp. 27-37.

11. OECD, "Data". Available from https://data.oecd.org/ (accessed 13 December 2016).

12. FAO, AQUASTAT database. Available from www.fao.org/nr/water/aquastat/data/query/index.html?lang=en (accessed 13 December 2016).

13. ESCAP, Statistical Database. Available from http://data.unescap.org (accessed 15 December 2016).

14. United Nations, Millennium Development Goals Indicators. Available from http://mdgs.un.org/unsd/mdg/Data. aspx (accessed 13 December 2016).

15. C. Fant, and others, "Projections of water stress based on an ensemble of socioeconomic growth and climate change scenarios: A case study in Asia", PLoS ONE, vol. 11, No. 3 (2016). e0150633.

16. ADB, Asia Water Development Outlook 2016 (Manila, 2016). 


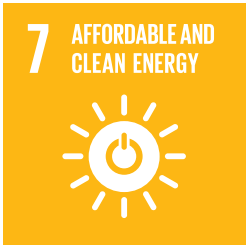

1. ESCAP, Statistical Database, based on Global Tracking Framework Consortium. Available from http://data. unescap.org (accessed 15 December 2016).

2. ESCAP, Statistical Database, based on International Energy Agency data. Available from http://data.unescap.org (accessed 15 December 2016).

3. PPP=purchasing power parity. ESCAP, Asia Pacific Energy Portal. Available from http://asiapacificenergy.org (accessed 15 December 2016).

4. ESCAP, Asia Pacific Energy Portal. Available from http://asiapacificenergy.org (accessed 15 December 2016).

5. Frankfurt School-UNEP Collaborating Centre for Climate and Sustainable Energy Finance, Global Trends in Renewable Energy Investment (Frankfurt, 2016). Available from www.fs-unep-centre.org.

6. ESCAP calculations, based on data from World Bank, Global Tracking Framework Report 2017 (forthcoming).

7. ibid.

8. ESCAP, Statistical Database, based on International Energy Agency data. Available from http://data.unescap.org/ escap_stat/ (accessed 15 December 2016).

9. ESCAP, Towards A Sustainable Future: Energy Connectivity in Asia and the Pacific Region (Bangkok, United Nations, 2016).

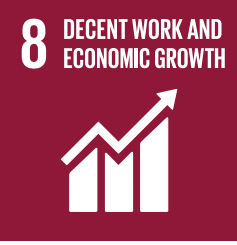

1. ADB, Key Indicators for Asia and the Pacific 2013 (Manila, 2013).

2. ESCAP, Statistical Database, based on UNSD National Accounts Main Aggregates Database. Available from http://data.unescap.org (accessed 20 February 2017).

3. ESCAP, Statistical Database, based on World Bank, Global Financial Inclusion Database. Available from http:// data.unescap.org (accessed 15 December 2016).

4. ADB, Key Indicators for Asia and the Pacific Special Supplement: Framework of Inclusive Growth Indicators. (Manila, 2014).

5. ESCAP, Statistical Database, based on ILO, Key Indicators of the Labour Market, Ninth Edition. Available from http://data.unescap.org/escap_stat/ (accessed 15 December 2016).

6. ibid.

7. ADB, Key Indicators for Asia and the Pacific 2016 (Manila, 2016). Available from www.adb.org/publications/ series/key-indicators-for-asia-and-the-pacific.

8. ESCAP, Statistical Database, based on OECD data. Available from http://data.unescap.org (accessed 15 December 2016).

9. ESCAP, Statistical Database, based on UNSD National Accounts Main Aggregates Database. Available from http://data.unescap.org/escap_stat/ (accessed 15 December 2016). 
10. ibid.

11. ESCAP, Economic and Social Survey of Asia and the Pacific 2016 (Bangkok, United Nations, 2016).

12. ibid.

13. ESCAP, Statistical Database, based on World Bank, Global Financial Inclusion Database. Available from http:// data.unescap.org/escap_stat/ (accessed 15 December 2016).

14. ESCAP, Economic and Social Survey of Asia and the Pacific 2016 (Bangkok, United Nations, 2016).

15. ESCAP, Statistical Database, based on ILO, Key Indicators of the Labour Market, Ninth Edition. Available from http://data.unescap.org (accessed 15 December 2016).

16. ESCAP, Economic and Social Survey of Asia and the Pacific 2016 (Bangkok, United Nations, 2016).

17. Vulnerable employment is defined as the sum of the employment status groups of own-account workers and contributing family workers. Workers in vulnerable employment are less likely to have formal work arrangements and are thus more likely to lack elements associated with decent employment, such as adequate social security and recourse to effective social dialogue mechanisms. Vulnerable employment is often characterized by inadequate earnings, low productivity and difficult conditions of work that undermine workers' fundamental rights. ILO, Global Employment Trends (Geneva, 2010).

18. ESCAP, Economic and Social Survey of Asia and the Pacific 2016 (Bangkok, United Nations, 2016).

19. ibid.

20. ibid.

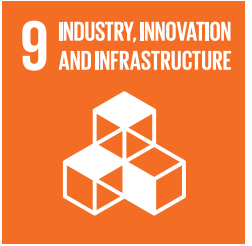

1. For a more detailed discussion on infrastructure trends and prospects in the region, see ESCAP, ADB, UNDP, Eradicating Poverty and Promoting Prosperity in a Changing Asia-Pacific (Bangkok, 2017).

2. The New Industrial Revolution is an umbrella term that captures the ongoing industrial development characterized by connectivity between people, things and resources, supported by new developments in information technology and advanced manufacturing. This process also includes a blurring of lines between the physical and digital worlds and between different economic sectors, such as services and industry. It presents great opportunities for enhanced, efficient and environment-friendly economic growth.

3. L. Alcorta, "Industrialization, employment and the Sustainable Development Agenda", Development, vol. 58, No. 3 (2017).

4. UNIDO, Industrial Development Report 2013 (Vienna, 2013), p. 27.

5. ibid., p. 24.

6. ibid., p. 22.

7. ibid., p. 44.

8. Additive manufacturing comprises several subtypes of industrial procedures, such as 3D printing, rapid prototyping and direct digital manufacturing.

9. $A D B$ staff estimates computed for $A D B$ developing member countries, based on data from the International Road Federation, World Road Statistics (Geneva, 2015) and UNDESA, World Population Prospects: The 2015 Revision Database. Available from www.un.org/en/development/desa/publications/world-population-prospects2015-revision.html (accessed 24 January 2017). 
10. World Bank, World Development Indicators. Available from http://data.worldbank.org/data-catalog/worlddevelopment-indicators (accessed 16 February 2017).

11. Penetration rates reached 94 per 100 inhabitants. See International Telecommunications Union, World Telecommunication/ICT Indicators Database. Available from http://www.itu.int/en/ITU-D/Statistics/Pages/ publications/wtid.aspx (accessed 14 December 2016).

12. ibid.

13. UNIDO, Industrial Development Report 2016 (Vienna, 2016), p. 35.

14. The contribution to world manufacturing production depends to a large extent on volume and such factors as size and population growth. In contrast, the industrialization process centres around a comprehensive structural change.

15. UNIDO, International Yearbook of Industrial Statistics 2016 (Vienna, 2016). pp. 37, 38.

16. United Nations, SDG Indicators Global Database. Available from https://unstats.un.org/sdgs/indicators/ database/ (accessed 16 February 2017).

17. ibid.

18. ADB, Key Indicators Special Chapter on Infrastructure (Manila, 2016). Available from www.adb.org/sites/default/ files/publication/204091/ki2016.pdf.

19. Calculation by the McKinsey Global Institute, Southeast-Asia at the Crossroads (2014), cited in Asia Infrastructure Financing: Getting It Right Would Lift Medium-Term Growth, S. Hansakul, and H. Levinger, (Frankfurt, Deutsche Bank Research, 2016). Available from www.dbresearch.com/PROD/DBR_INTERNET_ENPROD/PROD0000000000380319/Asia_infrastructure_financing\% 3A_Getting_it_right_wo.pdf.

20. $\mathrm{PPP}=$ purchasing power parity. Trends based on calculations provided by ESCAP using International Energy Agency data for $\mathrm{CO}_{2}$ emissions and World Bank data for GDP in 2011 PPP. See ESCAP, Statistical Database. Available from http://data.unescap.org (accessed 15 December 2016).

21. World Bank, World Development Indicators. Available from http://data.worldbank.org/data-catalog/worlddevelopment-indicators (accessed 16 February 2017).

22. Several regional institutions have recognized the need to promote shared infrastructure services and to enhance regional cooperation. See ESCAP, ADB and UNDP, Eradicating Poverty and Promoting Prosperity in a Changing Asia-Pacific (Bangkok, 2017).

23. ESCAP, Statistical Database, based on UNSD National Accounts Main Aggregates Database. Available from http://data.unescap.org (accessed 15 December 2016).

24. ibid.

25. Trends based on calculations by ESCAP from the United Nations Statistics Division National Accounts Main Aggregates Database and population figures from World Population Prospect (New York, 2015). Available from http://data.unescap.org (accessed 15 December 2016).

26. ESCAP calculations based on UNESCO Institute for Statistics Data Centre. See ESCAP, Statistical Database. Available from http://data.unescap.org (accessed 15 December 2016).

27. ibid.

28. As per available data; not all countries in the region have the data. See ESCAP, Statistical Database, based on UNESCO Institute for Statistics Data Centre. Available from http://data.unescap.org (accessed 15 December 2016). 
1. See http://unstats.un.org/sdgs/indicators/database (accessed 15 November 2016). The countries for which data exist are: Armenia, Australia, Bangladesh, Bhutan, China, Georgia, Indonesia, India, Islamic Republic of Iran, Kazakhstan, Kyrgyzstan, Cambodia, the Lao People's Democratic Republic, Sri Lanka, Nepal, Pakistan, the Philippines, Russian Federation, Thailand, Turkey and Viet Nam. The total population with data available is around 3.5 billion, out of 4.3 billion, which leaves about one billion people not measured.

2. DESA, "Inequality and the 2030 Agenda for Sustainable Development", Development Issues, No. 4 (2015). Available from www.un.org/en/development/desa/policy/wess/wess_dev_issues/dsp_policy_04.pdf; See also UNDP, Humanity Divided: Confronting Inequality in Developing Countries (New York, 2013). Available from www. undp.org/content/dam/undp/library/Poverty \% 20Reduction/Inclusive \% 20development/Humanity \% 20Div ided/ HumanityDivided_Full-Report.pdf.

3. See endnote 1.

4. Between 1996 and 2013, although this varies slightly depending on data availability. The countries or areas in which social protection has increased are (in order of lowest to highest change in expenditures): Kyrgyzstan, Malaysia, Fiji, Brunei Darussalam, Bangladesh, Nepal, Timor-Leste, China, India, Samoa, the Philippines, Hong Kong, China, Georgia, Thailand, Cambodia, Mongolia, Singapore, Maldives, Republic of Korea, Tajikistan and Armenia. See ESCAP, Time for Equality: The Role of Social Protection in Reducing Inequalities in Asia and the Pacific (Bangkok, United Nations, 2015).

5. ESCAP, Statistical Database, based on ILOSTAT Global Wage Report. Available from http://data.unescap.org (accessed 15 December 2016).

6. See http://unstats.un.org/sdgs/indicators/database/ (accessed 15 November 2016).

7. ESCAP, Time for Equality: The Role of Social Protection in Reducing Inequalities in Asia and the Pacific (Bangkok, United Nations, 2015); World Bank, Poverty and Shared Prosperity 2016: Taking on Inequality (Washington, D.C., 2016).

8. According to ESCAP calculations of the Palma Index, which measures the ratio of the income share of the top $10 \%$ to the bottom $40 \%$ of a country's population, in 8 countries in the region out of the 12 countries with available data, income inequalities had increased. See ESCAP, Time for Equality: The Role of Social Protection in Reducing Inequalities in Asia and the Pacific (Bangkok, United Nations, 2015) p. 25.

9. ILO, World Employment Social Outlook (Geneva, 2016).

10. ESCAP, Statistical Database, based on OECD, Development Database on Aid from DAC members. Available from http://data.unescap.org (accessed 15 December 2016).

11. ESCAP, Economic and Social Survey of Asia and the Pacific 2016 (Bangkok, United Nations, 2016). 


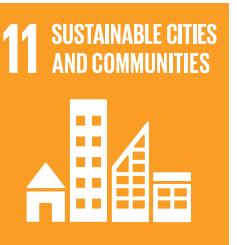

1. This profile draws from the urbanization chapter of ESCAP, ADB and UNDP, Eradicating Poverty and Promoting Prosperity in a Changing Asia-Pacific (Bangkok, 2017).

2. ESCAP and UN-Habitat, The State of Asian and Pacific Cities 2015: Urban Transformations: Shifting from Quantity to Quality (Bangkok, 2015).

3. UNDESA, World Urbanization Prospect 2014 (Geneva, 2014). The rapid urbanization is driven mostly by urban growth in large countries, such as China and India, but also smaller countries, like Cambodia and the Lao People's Democratic Republic, where urbanization rates are among the highest in the world.

4. M. Hildebrand, T. Kanaley, and B. Roberts, Strategy Paper-Sustainable and Inclusive Urbanization (New York, UNDP, 2013).

5. UN-Habitat, World Cities Report 2016. Urbanization and Development: Emerging Futures (Nairobi, 2016).

6. Habitat III and UN Task Team, Issue paper 19: Transport and Mobility (New York, 2015).

7. ESCAP, Valuing Waste, Transforming Cities (Bangkok, 2015). Calculated by ESCAP based on World Bank data from World Bank, What a Waste: A Global Review of Solid Waste Management (Washington D.C, 2012).

8. ESCAP and UN-Habitat, The State of Asian and Pacific Cities 2015: Urban Transformations: Shifting from Quantity to Quality (Bangkok, 2015).

9. J. Vidal, "Air pollution: A dark cloud of filth poisons the world's cities", The Guardian, 16 January (2016). Available from www.theguardian.com/global-development/2016/jan/16/winter-smog-hits-worlds-cities-air-pollution-soars (accessed 13 December 2016).

10. AON, 2015 Nepal Earthquake Event Recap Report (Kathmandu, 2015). Available from http://thoughtleadership. aonbenfield.com/Documents/201509-nepal-earthquake.pdf.

11. ESCAP, Statistical Database, based on United Nations Statistics Division MDG Indicators Database. Available from http://data.unescap.org (accessed 15 December 2016).

12. B. Baber, If Mayors Ruled the World: Dysfunctional Nations, Rising Cities (New Haven, CT, Yale University Press, 2013).

13. ESCAP and UN-Habitat, The State of Asian and Pacific Cities 2015: Urban transformations: Shifting from For institutional clearance (24.02.2017) quantity to quality (Bangkok, 2015).

14. Calculated by ESCAP, based on countries for which data are available. Regional aggregates and world total might differ from related figures calculated by UN-Habitat due to differences in methods applied. ESCAP calculated figures should be considered low-range estimates. See ESCAP, Statistical Database. Available from http://data. unescap.org (accessed 15 December 2016).

15. Calculated by ESCAP based on countries for which data are available. Regional aggregates and world total might differ from related figures calculated by UN-HABITAT due to differences in methods applied. ESCAP calculated figures should be considered low-range estimates. See ESCAP, Statistical Database. Available from http://data. unescap.org (accessed 15 December 2016).

16. UN-Habitat, World Cities Report 2016. Urbanization and Development: Emerging Futures (Nairobi, 2016).

17. ESCAP Statistical Database based on United Nations Statistics Division MDG Indicators Database. Available from http://data.unescap.org (accessed 15 December 2016).

18. The most recent years for which data are available for 19 Asia-Pacific countries are 2010-2012.

19. ESCAP, Statistical Yearbook for Asia and the Pacific 2015 (Bangkok, United Nations, 2015).

20. UN-Habitat, World Cities Report 2016 (Nairobi, 2016).

21. UNDESA, World Urbanization Prospects (Geneva, 2014). 
1. United Nations, and others, System of Environmental Economic Accounting 2012-Central Framework (New York, 2014). Available from www.miljodirektoratet.no/Documents/publikasjoner/M319/M319.pdf.

2. ESCAP, Statistical Database. Calculated by ESCAP using data from UNEP ROAP and CSIRO. The GDP figures are sourced from United Nations Statistics Division, National Accounts Main Aggregates Database. Available from http://data.unescap.org (accessed 27 January 2017).

3. ESCAP, "Asia-Pacific countries adopt region-wide codes to promote sustainable agriculture at UN forum in New Delhi" (2015). Available from www.unescap.org/news/asia-pacific-countries-adopt-region-wide-codes- promotesustainable-agriculture-un-forum-new.

4. ESCAP, Statistical Database. Calculated by ESCAP using data from UNEP ROAP and CSIRO. The GDP figures are sourced from United Nations Statistics Division, National Accounts Main Aggregates Database. Available from http://data.unescap.org (accessed 27 January 2017).

5. ibid. This figure increased to 2.7 kilograms in 2015. Comparable data for world aggregates were not available.

6. ESCAP, Statistical Yearbook for Asia and the Pacific 2015 (Bangkok, United Nations, 2016). Available from www. unescap.org/resources/statistical-yearbook-asia-and-pacific-2015.

7. ESCAP, Statistical Database, Calculated by ESCAP using data from UNEP ROAP and CSIRO. Available from http:// data.unescap.org (accessed 27 January 2017).

8. ibid.

9. ESCAP Statistical Database based on UNEP and Emission Database for Global Atmospheric Research. Available from http://data.unescap.org (accessed 15 December 2016).

10. Calculated by ESCAP, based on data from UNEP ROAP Indicators for a Resource Efficient and Green Asia and the Pacific, using data from Emission Database for Global Atmospheric Research. The GDP figures were sourced from United Nations Statistics Division, National Accounts Main Aggregates Database. See ESCAP, Statistical Database. Available from http://data.unescap.org (accessed December 2016).

11. Calculated by ESCAP, based on World Bank data. See ESCAP, Valuing Waste, Transforming Cities (Bangkok, 2015). Available from www.unescap.org/resources/valuing-waste-transforming-cities.

12. S. Honda, D.S. Khetriwal, and R. Kuehr, Regional E-waste Monitor (Tokyo, UNU and Japan Ministry of Environment, 2016). Available from https://drive.google.com/file/d/OB1bF9zth54L8N01XTW9PU04yS3c/view. The report covers 11 countries and territories comprising nearly 30 per cent of the world's population.

13. United Nations, Responsible Consumption and Production. Why It Matters? (New York, 2015). Available from www.un.org/sustainabledevelopment/sustainable-consumption-production/.

14. Save Food Asia-Pacific. Available from www.savefood.net/what-are-food-loss-and-food-waste/.

15. C.M. Rochman, and others, "Ingested plastic transfers hazardous chemicals to fish and induces hepatic stress", Scientific Reports, vol. 3, No. 3263 (2013).

16. Calculated by ESCAP, based on Global Reporting Initiative Database. Available from www.globalreporting.org/ services/Analysis/Reports_List/Pages/default.aspx (accessed 15 December 2016).

17. ESCAP, Statistical Database, based on International Energy Agency. Available from http://data.unescap.org (accessed 15 December 2016).

18. ESCAP, Case Study—Indonesia's Bantuan Langsung Tunai Cash Transfer Programme. Low Carbon Green Growth Roadmap for Asia and the Pacific (Bangkok, United Nations, 2012). Available from www.unescap.org/sites/ default/files/22. per cent20CS-Indonesia-Bantuan-Langsung-Tunai-Cash-Transfer- Programme.pdf.

19. D. Baker, "Understanding the economic impact of tourism in the Asian Pacific region using the tourism satellite account", International Journal of Business and Social Science, vol. 4, No. 3 (2013), pp. 1-8. Available from http:// ijbssnet.com/journals/Vol_4_No_3_March_2013/2.pdf. 
1. SDG 13 also acknowledges that the UNFCCC is the primary international, intergovernmental forum for negotiating the global response to climate change.

2. Average for 2000-2012 period. See ESCAP, Statistical Database, based on Emission Database for Global Atmospheric Research data. Available from http://data.unescap.org (accessed 15 December 2016).

3. FCCC/CP/2015/10/Add.1 Decision 1/CP.21, Adoption of the Paris Agreement, para 114.

4. United Nations, Framework Convention on Climate Change. Available from http://unfccc.int/paris_agreement/ items/9444.php. See the Nationally Determined Contributions Registry (interim). Available from www.unfccc.int/ ndcregistry/Pages/All.aspx.

5. ESCAP, Statistical Database, based on the National Progress Report of the Sendai Monitor, reported to UNISDR. Available from http://data.unescap.org (accessed 15 December 2016).

6. ESCAP, Disasters without Borders: Regional Resilience for Sustainable Development (Bangkok, United Nations, 2015).

7. UNFCCC, Progress in the Process to Formulate and Implement National Adaptation Plans: Note by the Secretariat (Geneva, 2016). FCCC/SBI/2016/INF.11. Available from http://unfccc.int/resource/docs/2015/sbi/eng/inf11.pdf.

8. UNESCO, Not Just Hot Air: Putting Climate Change Education into Practice (Paris, 2015). Available from http:// unesdoc.unesco.org/images/0023/002330/233083e.pdf.

9. Principle 10 of the Rio Declaration states, "Environmental issues are best handled with participation of all concerned citizens, at the relevant level. At the national level, each individual shall have appropriate access to information concerning the environment that is held by public authorities, including information on hazardous materials and activities in their communities, and the opportunity to participate in decision- making processes. States shall facilitate and encourage public awareness and participation by making information widely available. Effective access to judicial and administrative proceedings, including redress and remedy, shall be provided."

10. Green Climate Fund. Available from www.greenclimate.fund/partners/contributors/resources-mobilized.

11. See http://unfccc.int/files/cooperation_and_support/financial_mechanism/standing_committee/application/ pdf/2016_ba_summary_and_recommendations.pdf.

12. See http://dfat.gov.au/international-relations/themes/climate-change/Documents/climate-finance-roadmap-tous100-billion.pdf.

13. The report defines climate-aligned bonds as "green bonds with use of proceeds defined and labelled as green, as well as a larger universe of bonds financing climate-aligned assets that do not carry a green label".

14. This covers the period January 2005 to May 2016. See Climate Bonds Initiative, Bonds and Climate Change: The State of the Market in 2016 (London, HSBC, 2016). Available from www.climatebonds.net/files/files/CBI per cent20State per cent20of per cent20the per cent20Market per cent202016 per cent20A4.pdf.

15. ESCAP, Statistical Database, based on EM-DAT: CRED/OFDA International Disaster Database. Available from http://data.unescap.org/escap_stat/ (accessed 15 December 2016).

16. ESCAP, Disasters in Asia and the Pacific: 2015 Year in Review (Bangkok, United Nations, 2015).

17. ESCAP, Disasters in Asia-Pacific: 2015 Year in Review (Bangkok, United Nations, 2016). Available from www. unescap.org/sites/default/files/2015_Year per cent20in per cent20Review_final_PDF_1.pdf.

18. R. Few, "Climate change and disaster risk", presentation for training course on climate change and development, 5 July 2016, University of East Anglia.

19. Reuters, "Five Pacific Islands lost to rising seas as climate change hits", The Guardian, 10 May (2016). Available from www.theguardian.com/environment/2016/may/10/five-pacific-islands-lost-rising-seas- climate-change. 
1. FAO, The State of World Fisheries and Aquaculture 2016 (Rome 2016). Available from www.fao.org/3/a- i5555e. pdf.

2. B.S. Halpern, and others "A global map of human impact on marine ecosystems", Science, vol. 319, No. 5865, 15 February (2008), pp. 948-952.

3. See http://palaugov.pw/wp-content/uploads/2015/10/RPPL-No.-9-49-Palau-National-Marine-Sanctuary-Act.pdf.

4. UNEP, Marine Plastic Debris and Microplastics - Global Lessons and Research to Inspire Action and Guide Policy Change (Nairobi, 2016).

5. The Vessel Day Scheme sets overall limits on the number of days that purse seine fishing vessels can be licensed to fish in the waters of the countries that are Parties to the Nauru Agreement.

6. These revenues are shared among the eight countries that are Parties to the Nauru Agreement (Federated States of Micronesia, Kiribati, the Marshall Islands, Nauru, Palau, Papua New Guinea, Solomon Islands and Tuvalu) and control more than $60 \%$ of the tuna resources in the Western and Central Pacific Ocean. See www.pnatuna.com/ node/340.

7. Parties to the Nauru Agreement, "PNA members confirm: Vessel Day Scheme is here to stay", press release, 10 April (2016). Available from www.pnatuna.com/node/340.

8. IPCC, Climate Change 2013: The Physical Science Basis, Contribution of Working Group I to the Fifth Assessment Report of the Intergovernmental Panel on Climate Change (Cambridge, UK, Cambridge University Press, 2013), p. 9.

9. Expressed as the sum of individual country values (in square kilometres) and weighted average using territorial water as weight (percentage of territorial water). See ESCAP, Statistical Database, based on United Nations Statistical Division, MDG Indicators Database. Available from http://data.unescap.org (accessed 15 December 2016).

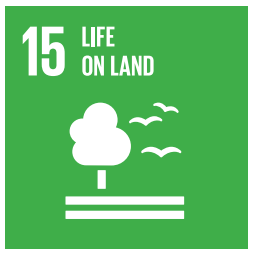

1. Millennium Ecosystem Assessment, Ecosystems and Human Well-being: Synthesis (Washington, D.C., Island Press, 2005).

2. Afghanistan, Bangladesh, Bhutan, Brunei Darussalam, Cambodia, China, Democratic People's Republic of Korea, India, Indonesia, Japan, the Lao People's Democratic Republic, Malaysia, Maldives, Mongolia, Myanmar, Nepal, Pakistan, the Philippines, the Republic of Korea, Singapore, Sri Lanka, Thailand, Timor- Leste and Viet Nam.

3. D. Juffe-Bignoli, and others, Asia Protected Planet 2014 (Cambridge, UK, UNEP-WCMC, 2014).

4. ESCAP, Statistical Database, based on United Nations Statistical Division, MDG Indicators Database. Available from http://data.unescap.org/escap_stat/ (accessed 15 December 2016).

5. ibid. The regional total is less than the loss in South-East Asia because of the gains in North and Central Asia and in South and South-West Asia. These figures were calculated by ESCAP from the FAO data on total forest area minus planted forest. Care should be taken when interpreting the numbers because there is a problem with comparability of forest statistics across countries.

6. World Bank, based on UNEP and the World Conservation Monitoring Centre data, as compiled by the World Resources Institute and based on data from national authorities, national legislation and international agreements. Available from http://data.worldbank.org/indicator/ER.LND.PTLD.ZS (accessed 15 December 2016). 
7. The IUCN classification uses quantitative criteria, based on population size, rate of decline and area of distribution, to assign species to these categories. Listing in a higher extinction risk category implies a higher expectation of extinction; over the specified time frames, more species listed in a higher category are expected to become extinct than those in a lower one (without effective conservation action).

8. See www.globalagriculture.org/report-topics/land-grabbing.html.

9. FAO, Impacts of Foreign Agricultural Investment on Developing Countries: Evidence from Case Studies (Rome, 2014). Available from www.fao.org/3/a-i3900e.pdf.

10. K. Jesper, Challenges and Opportunities of Foreign Investment in Developing Country Agriculture for Sustainable Development (Rome, FAO, 2014). Available from www.fao.org/3/a-i4074e.pdf.

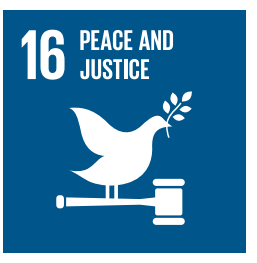

1. ADB, Inequality in Asia-Pacific: Trends, Drivers and Policy Implications (Manila, 2014).

2. For example, women, ethnic and sexual minorities, migrants, people affected by HIV, drug users, persons with disabilities and older persons. See also www.ohchr.org/Documents/Issues/Discrimination/Joint_LGBTI_ Statement_ENG.PDF.

3. S. Jha, and J. Zhuang, "Governance unbundled", Finance and Development, vol. 51, No. 2 (2014). Available from www.imf.org. See also S. Aiyar, and others, "Growth slow down and the middle income trap", IMF Working Paper (Washington, D.C., IMF, 2013) WP/13/71; K. Sen, "Governance and development outcomes in Asia", Economics Working Paper Series No. 384 (Manila, ADB, 2014)

4. There are also shortcomings for other targets under the goal; for the targets where the methodology is clear, the data are not regularly collected in many countries in the region.

5. ADB, Inequality in Asia-Pacific: Trends, Drivers and Policy Implications (Manila, 2014).

6. M. Gulati, and M.Y. Rao, "Corruption in the electricity sector: A pervasive scourge", in The Many Faces of Corruption: Tackling Vulnerabilities at the Sector Level, J. Campos, and S. Pradhan, eds. (Washington, D.C., World Bank, 2007). Available from https://openknowledge.worldbank.org; Water Integrity Network, Fighting Corruption to Reduce Poverty: Linking Global and Local Strategies: Seminar Report 2006-World Water Week (Stockholm, 2006); P. Stålgren, "Corruption in the water sector: Causes, consequences and potential reform", Swedish Water House Policy Brief, No. 4. (2006). Available from www.waterintegritynetwork.net.

7. UNDP and UNODC, Coming to Grips with Illicit Financial Flows in Asia-Pacific 2002-2011: Case studies of Bangladesh, Indonesia, Malaysia, and Nepal (Bangkok, 2015).

8. For example, in East and North-East Asia, the illicit financial flows (at an estimated $\$ 152$ billion) amount to $44 \%$ of the commercial resource inflows. For more details, see UNDP and DFAT, Australian Government, Asia-Pacific Effective Development Cooperation Report 2014 (Bangkok, 2014); UNDP and UNODC, Coming to Grips with Illicit Financial Flows in Asia-Pacific 2002-2011: Case studies of Bangladesh, Indonesia, Malaysia, and Nepal (Bangkok, 2015).

9. See United Nations Statistical Commission, Meta data for Goal 16. Available from http://unstats.un.org/sdgs/ files/metadata-compilation/Metadata-Goal-16.pdf (accessed 15 December 2016).

10. ESCAP, Statistical Database, based on UNODC data. Available from http://data.unescap.org/escap_stat/ (accessed 15 December 2016).

11. ibid.

12. ibid.

13. For additional information, see UN-ACT. Available from http://un-act.org/commit/ (accessed 15 December 2016).

14. ESCAP, Statistical Database, based on UNICEF. Available from http://data.unescap.org/escap_stat/ (accessed 15 December 2016). 
15. See Civil Registration and Vital Statistics in Asia and the Pacific. Available from www.getinthepicture.org/ resource/asian-and-pacific-civil-registration-and-vital-statistics-decade-2015-2024 (accessed 15 December 2016).

16. Average from 2012 to 2014 . ESCAP, Statistical Database, based on UNODC data. Available from http://data. unescap.org. (accessed 15 December 2016).

17. See www.ohchr.org/Documents/Issues/Discrimination/Joint_LGBTI_Statement_ENG.PDF.

18. See J. True, and others, "Women's political participation in Asia and the Pacific", Social Science Research Council Working Paper (New York, 2014). Available from http://webarchive.ssrc.org.

19. Inter-Parliamentary Union, Youth Participation in National Parliaments 2016 (Geneva, 2016).

20. OHCHR, "Human Rights Council adopts text on civil society space and suspends thirty-second regular session", press release, 16 June 2016. Available from www.ohchr.org/EN/NewsEvents/Pages/DisplayNews. aspx?NewsID=20225\&LangID=E\#sthash.mNcBJA77.dpuf. See also http://chinadevelopmentbrief.cn/wp-content/ uploads/2015/11/Mark-Sidel-Discussion-Paper-Civil- Society-Regulation-and-Space-in-Asia2.pdf.

21. UNODC, Global Study on Homicide 2013: Trends, Context, Data (Geneva, 2013, United Nations publication, Sales No. 14.IV.1). Available from www.unodc.org/documents/data-and- analysis/statistics/GSH2013/2014_GLOBAL_ HOMICIDE_BOOK_web.pdf (accessed 11 July 2016).

22. ESCAP, Statistical Year Book for Asia and the Pacific 2015 (Bangkok, United Nations, 2016).

23. ibid.

24. The index is based on 12 indicators covering a wide range of state failure risk elements, such as extensive corruption and criminal behaviour, inability to collect taxes or draw on citizen support, large-scale involuntary dislocation of the population, sharp economic decline, group-based inequality, institutionalized persecution or discrimination, severe demographic pressures, brain drain and environmental decay. See the Fragile States Index 2015. Available from http://fsi.fundforpeace.org/ (accessed 11 July 2016).

25. Asia Pacific RCM Thematic Working Group on International Migration Including Human Trafficking, Asia- Pacific Migration Report 2015: Migrants' Contribution to Development (Bangkok, 2015) p. 9.

1. Asia-Pacific DEF, Achieving the Sustainable Development Goals in the Era of the Addis Ababa Action Agenda: Progress on Establishing Integrated National Financing Frameworks in the Asia-Pacific (Dhaka, 2016). Available from www.asia- pacific.undp.org/content/rbap/en/home/library/democratic_governance/achieving-thesustainable- development-goals.

2. ibid.

3. ADB, Making Money Work-Financing a Sustainable Future in Asia and the Pacific (Manila, 2015).

4. ibid.

5. ESCAP, Statistical Database, based on OECD Development Database on Aid from DAC members. Available from http://data.unescap.org (accessed 15 December 2016).

6. World Bank, National accounts data and OECD National Accounts data files. Available from http://data. worldbank.org (accessed 15 December 2016).

7. ESCAP, Financing for Transformation. From Agenda to Action on Sustainable Development in Asia and the Pacific (Bangkok, 2015). Available from www.unescap.org/sites/default/files/Financing-for-Transformation-Final.pdf.

8. ESCAP, Economic and Social Survey in Asia-Pacific 2014 (Bangkok, 2014). Available from www.unescap.org/ resources/economic-and-social-survey-asia-and-pacific-2014. 
9. With $10 \%$ or lower tax-to-GDP ratios, based on data from ADB, Key Indicators for Asia and the Pacific 2016 (Manila, 2016). Available from www.adb.org/statistics.

10. United Nations, The Sustainable Development Goals Report 2016 (New York, 2016).

11. D. Kar and J. Spanjers, Illicit Financial Flows from Developing Countries: 2004-2013 (Washington, D.C., Global Financial Integrity, 2014). Available from www.gfintegrity.org/report/illicit-financial-flows-from- developingcountries-2004-2013/.

12. ibid.

13. ESCAP, Statistical database, based on World Bank, World Development Indicator. Available from http://data. unescap.org (accessed 15 December 2016).

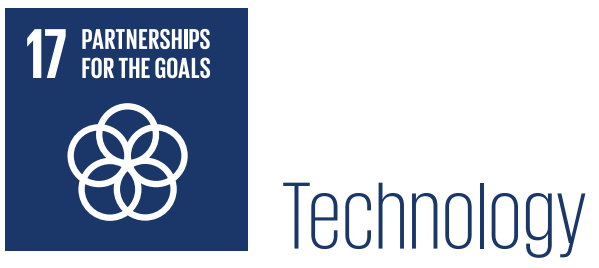

1. Absorptive capacity is defined as "an economy's ability to avail itself of the technologies present in the marketplace given the capacity of the country to utilize the technology for its benefit". See ESCAP, Harnessing Science, Technology and Innovation for Inclusive and Sustainable Development in Asia and the Pacific (Bangkok, United Nations, 2016). Available from www.unescap.org/sites/default/files/STI_Theme_Study.pdf.

2. ESCAP, Harnessing Science, Technology and Innovation for Inclusive and Sustainable Development in Asia and the Pacific (Bangkok, United Nations, 2016). Available from www.unescap.org/sites/default/files/STI_Theme_ Study.pdf.

3. See for example, ESCAP, Harnessing Science, Technology and Innovation for Inclusive and Sustainable Development in Asia and the Pacific (Bangkok, United Nations, 2016). Available from www.unescap.org/sites/ default/files/STI_Theme_Study.pdf.

4. United Nations, The Report of the High-Level Panel of Eminent Persons on the Post-2015 Development AgendaA New Global Partnership: Eradicate Poverty and Transform Economies through Sustainable Development (New York, 2013). Available from www.post2015hlp.org/wp-content/uploads/2013/05/UN- Report.pdf.

5. ESCAP, ADB and UNDP, Making it Happen - Technology, Finance and Statistics for Sustainable Development in Asia and the Pacific: Asia-Pacific Regional MDGs Report 2014/2015 (Bangkok, ESCAP, 2015).

6. Some stakeholders challenge the definition of "stakeholders" in the context of determining who should be represented in these mechanisms. See N. Daño, "Multi-stakeholder STI Mechanisms at the UN: Fad or Trap", in Spotlight on Sustainable Development 2016: Report of the Reflection Group on the 2030 Agenda for Sustainable Development, Social Watch, and others (Beirut, Bonn, Montevideo, New York, Penang and Suva, 2016). Available from www.2030spotlight.org/sites/default/files/contentpix/spotlight/pdfs/Agenda-2030_engl_160713_WEB. pdf.

7. ESCAP calculations, based on data from ESCAP, Statistical Database. Available from http://data.unescap.org (accessed 15 December 2016).

8. UNESCO, Science Report, 2016 (Paris, 2016).

9. World Intellectual Property Organization, World Intellectual Property Report 2015: Breakthrough Innovation and Economic Growth (Geneva, 2015). Available from www.wipo.int/edocs/pubdocs/en/wipo_pub_944_2015.pdf.

10. OECD, Green Growth Indicators Database. Available from http://stats.oecd.org/Index. aspx? DataSetCode=GREEN_GROWTH (accessed 5 January 2016).

11. The source of this figure includes incubators, accelerators, co-working spaces, fab labs, makerspaces, hackerspaces and other innovation spaces in its definition. A tech hub "offers space and services to start-ups but also to create a large community of stakeholders (partners, start-ups, investors etc.)" See V. du Boucher, "A few things we learned about tech hubs in Africa and Asia". Available from www.gsma.com/mobilefordevelopment/ programme/ecosystem-accelerator/things-learned-tech-hubs- africa-asia. 
12. ESCAP, Harnessing Science, Technology and Innovation for Inclusive and Sustainable Development in Asia and the Pacific (Bangkok, United Nations, 2016). Available from www.unescap.org/sites/default/files/STI_Theme_ Study.pdf. The ESCAP Committee on ICT and STI was established in 2016 and met for the first time as an intergovernmental forum that connects these subregional platforms at the regional level.

13. Cornell University, INSEAD and World Intellectual Property Organization, The Global Innovation Index 2015. Available from http://www.wipo.int (accessed 15 December 2016).

14. ESCAP, Harnessing Science, Technology and Innovation for Inclusive and Sustainable Development in Asia and the Pacific (Bangkok, United Nations, 2016). Available from www.unescap.org/sites/default/files/STI_Theme_ Study.pdf.

15. Twenty countries in Asia and the Pacific have less than $2 \%$ fixed-broadband penetration rate. See ESCAP, State of ICT in Asia and the Pacific 2016-Uncovering the Widening Digital Divide (Bangkok, United Nations, 2016). Available from www.unescap.org/sites/default/files/State \% 20 of \% 20ICT \% 20in \% 20Asia \% 20and \% 20the \% 20 Pacific \% 202016.pdf.

16. ESCAP, Harnessing Science, Technology and Innovation for Inclusive and Sustainable Development in Asia and the Pacific (Bangkok, United Nations, 2016). Available from www.unescap.org/sites/default/files/STI_Theme_ Study.pdf.

17. UNESCO, Science Report, 2015 (Paris, 2015).

18. ESCAP, UNEP, UNU and IGES, Transformations for Sustainable Development: Promoting Environmental Sustainability in Asia and the Pacific (Bangkok, United Nations, 2016). Available from www.unescap.org/ resources/transformations-sustainable-development-promoting-environmental-sustainability-asia-and (accessed 5 January 2016).

19. See, for example, an analysis of a successful case of technological cooperation in the waste sector between Surabaya (Indonesia) and Kitakyushu (Japan), which encouraged replication in other cities in Indonesia and in other countries. T.A. Kurniawan, and others, "City-to-city level cooperation for generating urban co- benefits: The case of technological cooperation in the waste sector between Surabaya (Indonesia) and Kitakyushu (Japan), Journal of Cleaner Production, vol. 58, 1 November (2013), pp. 43-50.

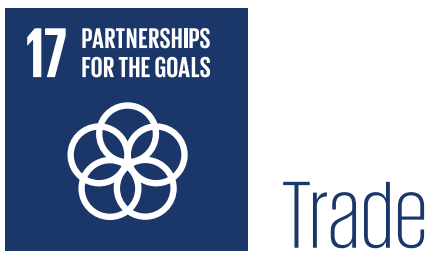

1. ESCAP, Asia-Pacific Trade and Investment Report 2015 (Bangkok, United Nations, 2015). Available from www. unescap.org/sites/default/files/Full \% 20Report \% 20- \% 20APTIR \% 202015.pdf.

2. ESCAP, Asia-Pacific Trade and Investment Report 2015 (Bangkok, United Nations, 2015). Available from www. unescap.org/sites/default/files/Full \% 20Report \% 20- \% 20APTIR \% 202015.pdf.

3. For some least developed countries, however, this can lead to an erosion of preferences unless a universal dutyfree, quota-free scheme for them is fully enforced.

4. Although the indicator guideline prescribes that oil and arms be excluded from the calculation of this indicator, the Harmonized System codes for oil and arms to be excluded were not specified in the guideline. The data used for this analysis thus includes oil and arms.

5. ESCAP, Statistical Database, based on WTO data. Available from http://data.unescap.org/escap_stat/ (accessed 15 December 2016). For details on the metadata, see http://stat.wto.org/StatisticalProgram/ WSDBStatProgramTechNotes.aspx? Language $=\mathrm{E}$.

6. ESCAP calculation using data from ESCAP, Statistical Database. Available from http://data.unescap.org/escap_ stat/ (accessed October 2016).

7. The indicator guideline prescribes that oil and arms need to be excluded from the calculation of this indicator. However, the Harmonized System codes for oil and arms to be excluded were not specified in the guideline. The data used for this analysis includes oil and arms. 
8. ESCAP, "Double trouble? Meeting the export target for Asia-Pacific least developed countries in the 2030 Agenda for Sustainable Development", ESCAP Trade Insights, No. 15, February (2015). Available from www.unescap.org/ sites/default/files/Trade \% 20insights \% 20No \% 2015.pdf.

9. Based on tariff data provided by WTO. Available from http://stat.wto.org/TariffProfile/WSDBTariffPFHome. aspx? Language $=\mathrm{E}$.

10. A. Nicita, and V. Rollo, "Tariff preferences as a determinant for exports from sub-Saharan Africa", Policy Issues in International Trade and Commodities Research Study Series No. 60 (New York and Geneva, UNCTAD, 2013). Available from http://unctad.org/en/PublicationsLibrary/itcdtab61_en.pdf.

11. UNCTAD, Trading into Sustainable Development: Trade, Market Access, and the Sustainable Development Goals. Developing Countries in International Trade Studies (New York and Geneva, 2016). Available from http://unctad. org/en/PublicationsLibrary/ditctab2015d3_en.pdf. 



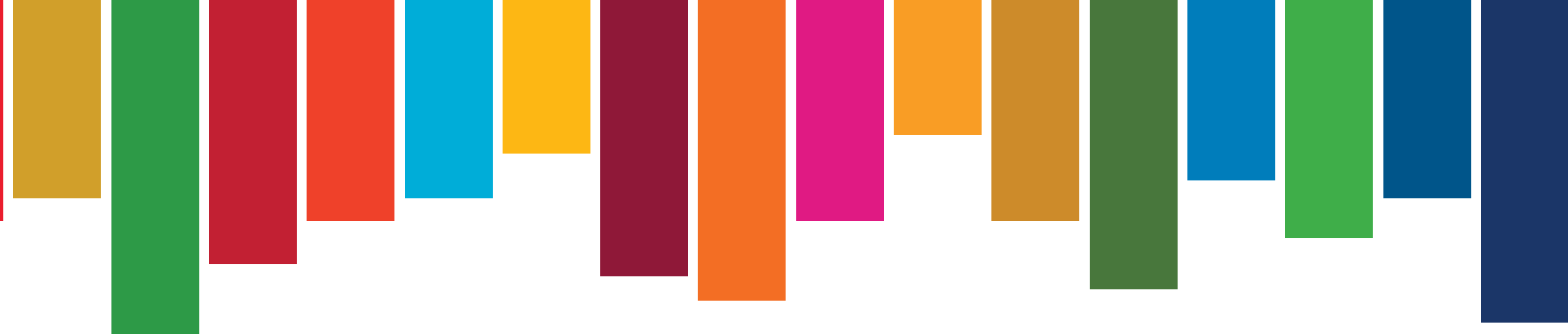

This report examines each of the 17 Sustainable Development Goals (SDGs) and describes the outlook for achieving each one in the Asia-Pacific region. It singles out "bright spots" and "hot spots", provides insights about each goal and points to emerging issues. It reveals many of the common challenges that governments will confront as they work to develop appropriate responses to the 2030 Agenda for Sustainable Development.

The outlook report represents a preliminary but comprehensive stocktaking effort in the region to provide the best available knowledge that can help governments, regional agencies and other development actors as they forge the much-needed social and political consensus on the gaps and priorities for achieving each SDG.

Despite the publishers' confidence in the rigour of this report, the content does not fully match the breadth and complexity of information required by governments and other development actors to fully grasp the nuances of the goals and targets. Indicators are incomplete, and data are limited. But even where hard data exists, the interpretation of progress or lack thereof sometimes varies. With the experiences and lessons learned from the preparation of this report, the Asia-Pacific SDG Partnership (of the United Nations Economic and Social Commission for Asia and the Pacific, the Asian Development Bank and the United Nations Development Programme) is emboldened to continue providing policy-relevant inputs so that the SDGs deliver for all people, especially those who are at risk of being left behind.

This report is a product of the Asia-Pacific SDG Partnership. Aligning with the complexity of the SDGs, its preparation involved a multiple-disciplinary team of more than 100 experts, drawn mainly from the partner agencies, with contributions from various United Nations agencies.

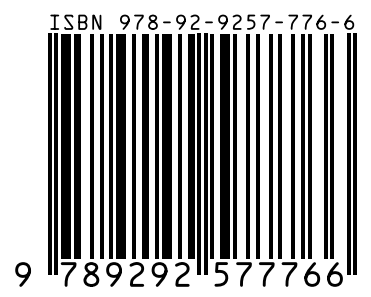

